Celso Yukio Nakashima

\title{
MODELO DE COMPORTAMENTO TERMODINÂMICO DE UMA BOMBA MULTIFÁSICA DO TIPO DUPLO PARAFUSO
}

Dissertação apresentada à Escola Politécnica da Universidade de São Paulo para a obtenção do título de Mestre em Engenharia.

São Paulo 
Celso Yukio Nakashima

\title{
MODELO DE COMPORTAMENTO TERMODINÂMICO DE UMA BOMBA MULTIFÁSICA DO TIPO DUPLO PARAFUSO
}

\author{
Dissertação apresentada à Escola \\ Politécnica da Universidade de São Paulo \\ para a obtenção do título de Mestre em \\ Engenharia. \\ Área de Concentração: \\ Energia e Fluidos \\ Orientador: \\ Sílvio de Oliveira Jr.
}

São Paulo

2000 
Aos que sonham equel utam ... 


\section{Agradecimentos}

Um trabalho, por mais simples que seja, nunca é fruto de uma única pessoa e não seria este uma exceção. Durante todo o desenvolvimento da pesquisa agora apresentada nesta dissertação, recebi ajuda diversa e valiosa sem a qual dificilmente este trabalho seria o mesmo. A todos os que, direta ou indiretamente, contribuíram para que este projeto chegasse ao fim, meus sinceros agradecimentos.

Ao Prof. Sílvio de Oliveira Júnior, pela orientação tranqüila e segura que sempre mostrou os rumos a serem seguidos;

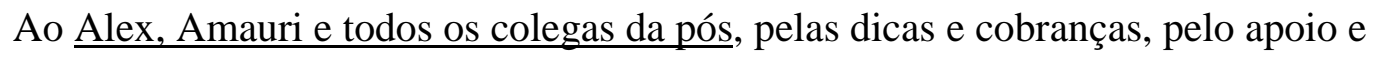
amizade que sempre me empurraram adiante;

À Petrobras, por todas as preciosas informações sem as quais este trabalho nunca seria completo;

Ao Departamento de Engenharia Química da USP, por permitir a utilização da infraestrutura do Laboratório de Simulações e do programa Hysys.Process v 2.1;

Ao Eng. Marcos Pereda e à Soteica do Brasil, pelo suporte fornecido na utilização do programa Hysys.Process v 2.1;

À $\underline{\text { CAPES}}$, pelo apoio financeiro. 


\section{Sumário}

$\begin{array}{lr}\text { Lista de figuras } & \text { VI } \\ \text { Lista de tabelas } & \text { IX } \\ \text { Nomenclatura } & \text { X } \\ \text { Resumo } & \text { XII } \\ \text { Abstract } & \text { XIII }\end{array}$

1 INTRODUÇÃ 0 ................................................................................................................1

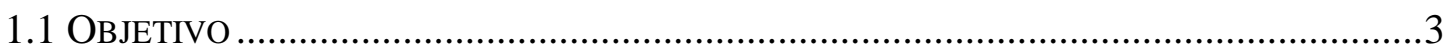

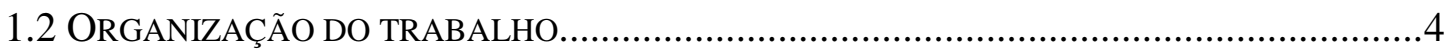

2 REVISÃO BIBLIOGRÁFICA ..................................................................................5

2.1 A MÉTODOS DE PROCESSAMENTO PRIMÁRIO DE PETRÓLEO EM ÁGUAS PROFUNDAS..5

2.2 BOMBAS MULTIFÁSICAS TIPO DUPLO PARAFUSO ...................................................

3 FUNDAMENTOS DA ANÁLISE EXERGÉTICA .................................................20

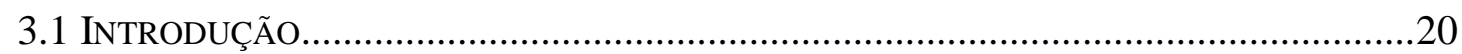

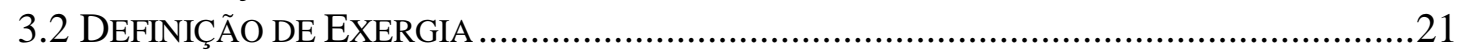

3.3 MEIO AMBIENTE, ESTADO DE REFERÊNCIA RESTRITO E ESTADO MORTO...................22

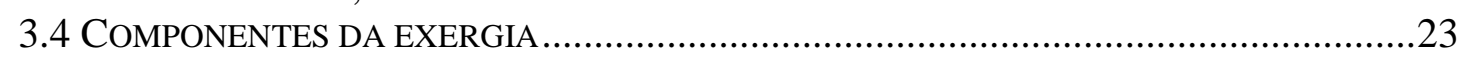

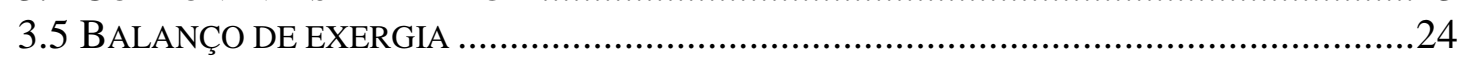

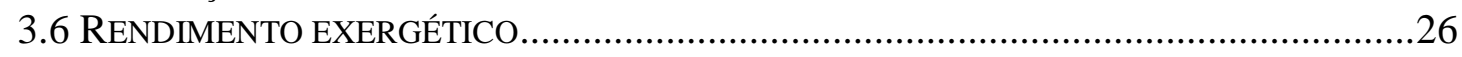

4 MODELO DE COMPORTAMENTO TERMODINÂMICO....................................28

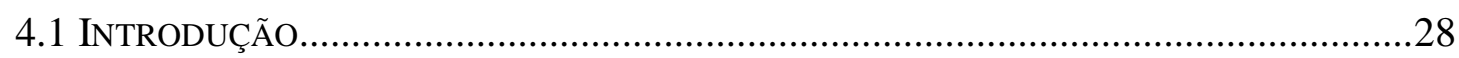

4.2 AVALIAÇÃO DO COMPORTAMENTO DO MODELO PROPOSTO........................................

4.2.1 Efeito do FVG e do número de estágios ............................................................36

4.2.2 Efeito da eficiência das bombas e compressores do modelo.............................43

4.2.3 Efeito do perfil de pressão ao longo dos estágios ...........................................45

4.3 MODELAGEM DAS PERDAS DE UMA BOMBA MULTIFÁSICA REAL............................48

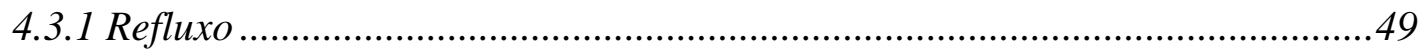

4.3.2 Eficiência das bombas e compressores ...........................................................57

4.4 CONSIDERAÇÕES SOBRE O NÚMERO DE ESTÁGIOS DO MODELO..................................63

4.5 COMPARAÇÃ̃ E DISCUSSÃO DOS RESULTADOS .....................................................67

4.5.1 Refluxo e perfil de pressão...............................................................................6 67

4.5.2 Potência e temperatura de descarga ............................................................81 


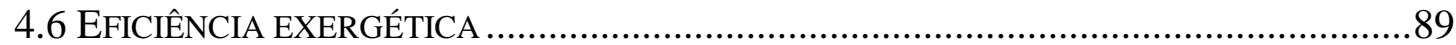

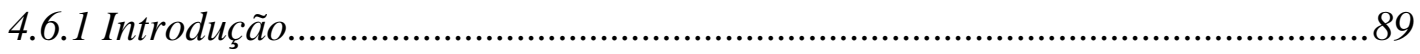

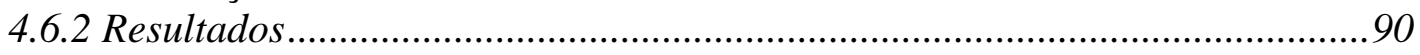

5 CONCLUSÕES .............................................................................................................................99

6 REFERÊNCIAS BIBLIOGRÁFICAS .......................................................104

Apêndice:

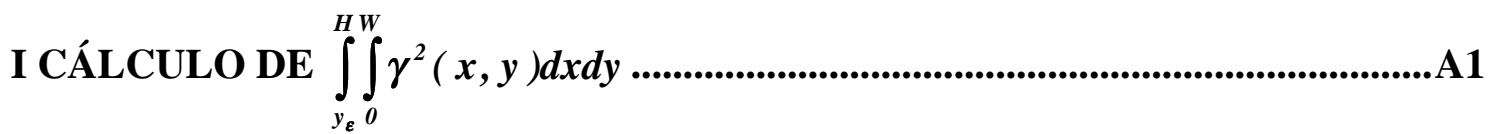

II EXPLICAÇÕES SOBRE O MODELO DESENVOLVIDO NO

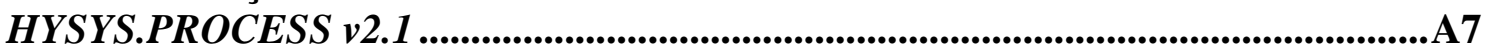

III EFICIÊNCIA EXERGÉTICA DE UMA BOMBA MULTIFÁSICA DE DUPLO PARAFUSO: DEFINIÇÕES ALTERNATIVAS ................................A10 


\section{Lista de figuras}

Fig. 2.1: Princípio de funcionamento da bomba de duplo parafuso................................

Fig. 2.2: Tipos de fendas nas bombas tipo duplo parafuso. ............................................11

Fig. 2.3: Modelo de para uma bomba multifásica parafuso (WINCEK (1992))..............12

Fig. 2.4: Perfil de pressão ao longo do parafuso (COOPER (1996))...............................13

Fig. 2.5: Modelo de bomba de três câmaras (adaptado de WINCEK (1992)) .................16

Fig. 2.6: Rotação mínima de bombeamento multifásico (COOPER et al. (1996)).........18

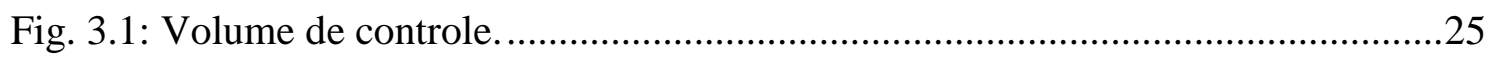

Fig. 4.1: Modelo para a simulação do comportamento termodinâmico de uma bomba

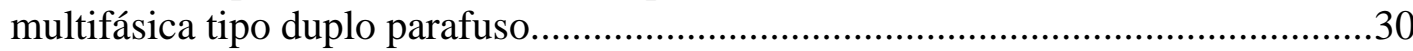

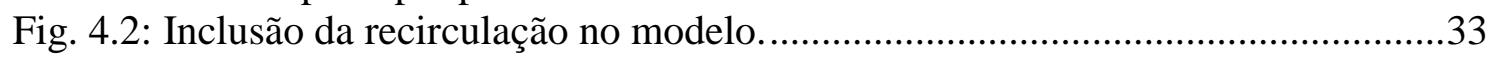

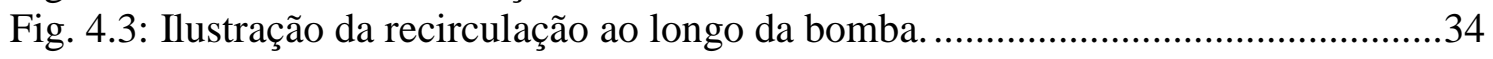

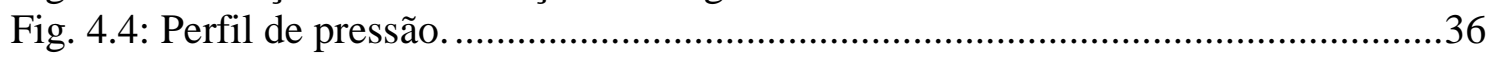

Fig. 4.5: Variação da pressão e dos volumes de gás e óleo na bomba multifásica. .........38

Fig. 4.6: Gráfico $\dot{\mathbf{V}} \mathbf{x} \mathbf{p}$ para o processo de bombeamento multifásico. ............................38

Fig. 4.7: Diferença entre o processo de bombeamento multifásico e sua representação

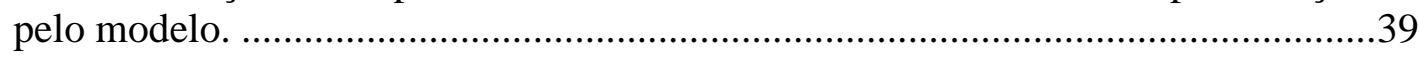

Fig. 4.8: Ilustração da diferença entre as potências de bombeamento e compressão da bomba real e as potências calculadas pelo modelo.

Fig. 4.9: Diagrama Pressão x Vazão Volumétrica obtido com dados do modelo para $\mathrm{FVG}=95 \%$

Fig. 4.10: Diagrama Pressão x Vazão Volumétrica obtido com dados do modelo para $\mathrm{FVG}=30 \%$.

Fig. 4.11: Processos de compressão e bombeamento para um número de estágios maior.

Fig 4.12: Perfis de pressão utilizados nas simulações

Fig. 4.13: Significado da distribuição linear de pressão no modelo..................................47

Fig. 4.14: Significado da distribuição de pressão com gradiente crescente. ....................47

Fig. 4.15: Parâmetros geométricos para o calculo do refluxo através da fenda periférica.

Fig. 4.16: Parâmetros geométricos para o cálculo do refluxo através da fenda radial (WINCEK (1992)).

Fig. 4.17: Parâmetros geométricos para o cálculo do refluxo através da fenda de flanco (WINCEK (1992)). 
Fig. 4.18: Potência de atrito nas diversas regiões da bomba multifásica. .57

Fig. 4.19: Balanço de forças na região periférica............................................................58

Fig. 4.20: (a) Seção transversal do canal (MICHAELI e GREFENSTEIN (1995)). (b)

Adaptação do grau de preenchimento para a bomba multifásica parafuso...............60

Fig. 4.21: Canal do parafuso (adaptado de CAMPBELL et al. (1998)) ..........................61

Fig. 4.22: Divisão do parafuso em duas regiões distintas para análise do escoamento (adaptado de HONG e WHITE (1998))....

Fig. 4.23: Acúmulo de líqüido devido à recirculação. ..................................................63

Fig. 4.24: Modelo com número de estágios igual ao dobro do número de câmaras da bomba.

Fig. 4.25: Desenho esquemático da bomba multifásica.

Fig. 4.26: Relação experimental entre refluxo e diferença de pressão (adaptado de EGASHIRA (1996)) para água e resultados da simulação utilizando equações para escoamento turbulento liso (em azul) e turbulento rugoso (em vermelho). ..............70

Fig. 4.27: Diagrama de coeficiente de atrito para tubos circulares com rugosidade

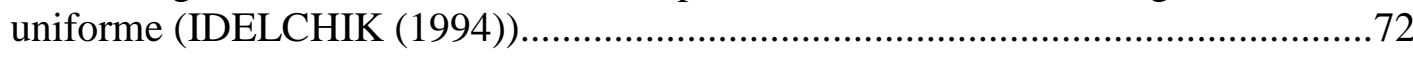

Fig. 4.28: Perfil de pressão - comparação com dados experimentais $\left(1200 \mathrm{rpm}, \mathrm{p}_{\mathrm{S}}=150\right.$ $\mathrm{kPa}, \mathrm{FVG}=60 \%, \Delta \mathrm{p}=2940 \mathrm{kPa})$.

Fig. 4.29: Perfil de pressão - comparação com dados experimentais (1200 rpm, $\mathrm{p}_{\mathrm{S}}=150$ $\mathrm{kPa}, \mathrm{FVG}=90 \%, \Delta \mathrm{p}=2940 \mathrm{kPa}$ ).

Fig. 4.30: Perfil de pressão - comparação com dados experimentais $\left(1200 \mathrm{rpm}, \mathrm{p}_{\mathrm{S}}=440\right.$

$\mathrm{kPa}, \mathrm{FVG}=60 \%, \Delta \mathrm{p}=2940 \mathrm{kPa})$...

Fig. 4.31: Perfil de pressão - comparação com dados experimentais $\left(1200 \mathrm{rpm}, \mathrm{p}_{\mathrm{S}}=440\right.$ $\mathrm{kPa}, \mathrm{FVG}=90 \%, \Delta \mathrm{p}=2940 \mathrm{kPa}$ ).

Fig. 4.32: Perfil de pressão - comparação com dados experimentais $\left(1800 \mathrm{rpm}, \mathrm{p}_{\mathrm{S}}=150\right.$ $\mathrm{kPa}, \mathrm{FVG}=60 \%, \Delta \mathrm{p}=2940 \mathrm{kPa}$ ).

Fig. 4.33: Perfil de pressão - comparação com dados experimentais $\left(1800 \mathrm{rpm}, \mathrm{p}_{\mathrm{s}}=147\right.$

$\mathrm{kPa}, \mathrm{FVG}=90 \%, \Delta \mathrm{p}=2940 \mathrm{kPa})$.

Fig. 4.34: Perfil de pressão - comparação com dados experimentais $\left(1200 \mathrm{rpm}, \mathrm{p}_{\mathrm{S}}=290\right.$ $\mathrm{kPa}, \mathrm{FVG}=60 \%, \Delta \mathrm{p}=980 \mathrm{kPa})$.

Fig. 4.35: Perfil de pressão - comparação com dados experimentais $\left(1200 \mathrm{rpm}, \mathrm{p}_{\mathrm{S}}=290\right.$ $\mathrm{kPa}, \mathrm{FVG}=90 \%, \Delta \mathrm{p}=980 \mathrm{kPa})$.

Fig. 4.36: Influência do FVG no perfil de pressão (1200 rpm, $\mathrm{p}_{\mathrm{S}}=150 \mathrm{kPa}, \Delta \mathrm{p}=2940$ $\mathrm{kPa})$.

Fig. 4.37: Influência da pressão de sucção no perfil de pressão (1200 rpm, FVG=90\%, $\Delta \mathrm{p}=2940 \mathrm{kPa})$.

Fig. 4.38: Influência da rotação do parafuso no perfil de pressão $\left(\mathrm{p}_{\mathrm{S}}=150 \mathrm{kPa}, \Delta \mathrm{p}=2940\right.$ $\mathrm{kPa}, \mathrm{FVG}=60 \%$ ).

Fig. 4.39: Influência da diferença de pressão no perfil de pressão (1200 rpm, $\mathrm{FVG}=60 \%, \mathrm{p}_{\mathrm{S}}=150($ ) e $290(\quad) \mathrm{kPa}) .$.

Fig. 4.40: Influência da viscosidade do líqüido no perfil de pressão ( $\mathrm{p}_{\mathrm{s}}=650 \mathrm{kPa}$, $\Delta \mathrm{p}=2500 \mathrm{kPa})$.

Fig. 4.41: Comparação entre potências calculada e experimental (ensaio 311031)........85

Fig. 4.42: Comparação entre potências calculada e experimental (ensaio 311032)........85

Fig. 4.43: Comparação entre potências calculada e experimental (ensaio 311030)........86

Fig. 4.44: Comparação entre potências calculada e experimental (ensaio 312030)........86

Fig. 4.45: Comparação entre potências calculada e experimental (ensaio 308030)........87

Fig. 4.46: Comparação entre potências calculada e experimental (ensaio 309533)........87 
Fig. 4.47: Potência de atrito em função da diferença de pressão e FVG. 88

Fig. 4.48: Comportamento da eficiência de uma bomba multifásica de duplo parafuso.91

Fig. 4.49: Variação da eficiência exergética com o FVG e $\Delta$ p para $2000 \mathrm{rpm}$...............93

Fig. 4.50: Variação da eficiência exergética com o FVG e $\Delta$ p para $3000 \mathrm{rpm}$...............93

Fig. 4.51: Eficiência exergética versus $\Delta$ p para água e óleo: a) 8 estágios e b) 3 estágios.

Fig. 4.52: Eficiência exergética versus $\Delta$ p para 3 e 8 estágios: a) água e b) óleo..............97

Fig. II.1: Modelo de comportamento termodinâmico - Tela do programa...................A7

Fig. II.2: Definição da condição do fluido na sucção do modelo..................................A8

Fig. II.3: Cálculo da vazão de recirculação no modelo. .............................................A9 


\section{Lista de tabelas}

Tabela 2.1: Algumas características de bombas multifásicas.

Tabela 4.1: Frações molares (\%) dos componentes dos fluxos de alimentação do modelo.

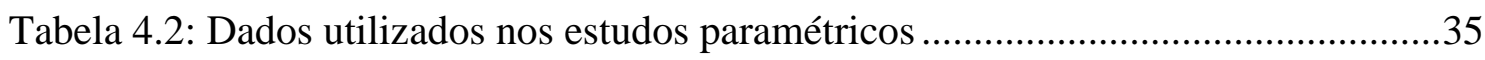

Tabela 4.3: Consumo de potência do modelo: a) $\mathrm{p}_{\mathrm{D}}=2600 \mathrm{kPa}$; b) $\mathrm{p}_{\mathrm{D}}=4528 \mathrm{kPa}$..........36

Tabela 4.4: Relação $\dot{\mathbf{W}} / \dot{\mathbf{W}}_{\text {teor }}$ para cada estágio do modelo em função do FVG ( $\mathrm{p}_{\mathrm{D}}=$

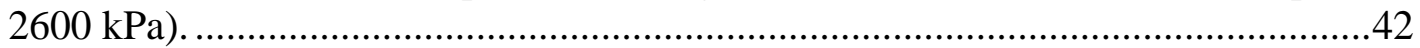

Tabela 4.5: Relação $\dot{\mathbf{W}} / \dot{\mathbf{W}}_{\text {teor }}$ para cada estágio do modelo em função do FVG ( $\mathrm{p}_{\mathrm{D}}=$ $4528 \mathrm{kPa})$.

Tabela 4.6: Comparação entre as potências consumidas pelo modelo com 8 e 16 estágios: a) $\mathrm{FVG}=30 \%$; b) $\mathrm{FVG}=95 \%$

Tabela 4.7: Influência do rendimento das bombas e compressores no modelo $\left(\mathrm{P}_{\mathrm{D}}=2600\right.$ $\mathrm{kPa})$.

Tabela 4.8: Efeito do perfil de pressão nas simulações do modelo: a) $\eta=100 \%$; b) $\eta=50 \%$

Tabela 4.9: Parâmetros geométricos da bomba multifásica estudada por EGASHIRA $(2000)^{7}$.

Tabela 4.10: Dados experimentais utilizados para a comparação com o modelo (EGASHIRA et al. (1996)).

Tabela 4.11: Vazão volumétrica de refluxo: Modelo x Experimental. .............................77

Tabela 4.12: Parâmetros geométricos da bomba L4HK 200-54 da Leistritz..................81

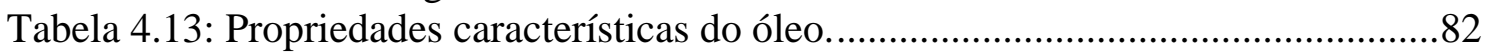

Tabela 4.14: Viscosidade dinâmica em função da pressão e temperatura. .......................82

Tabela 4.15: Dados experimentais utilizados para a comparação com o modelo

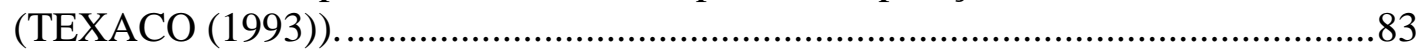

Tabela 4.16: Comparação entre os dados do modelo e dados experimentais. .................84

Tabela 4.17: Comparação entre eficiência exergética e isotérmica. ..............................91

Tabela 4.18: Parâmetros utilizados na comparação da eficiência exergética entre bombas de geometrias diferentes.......................................................................94

Tabela 4.19: Comparação das eficiências exergéticas de bombas de diâmetros diferentes.

Tabela III.1: Comparação entre as diferentes definições de eficiência exergética. 


\section{Nomenclatura}

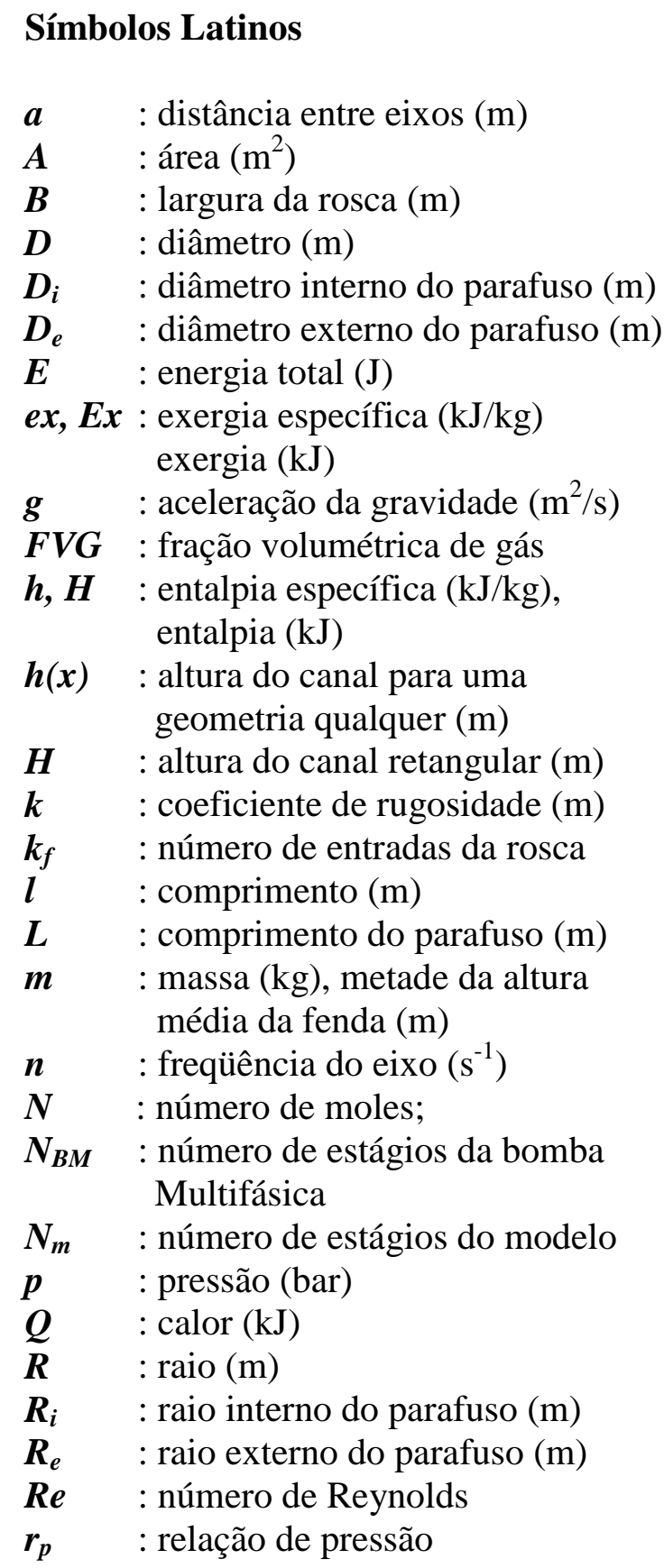

$\boldsymbol{s} \quad$ : entropia específica $(\mathrm{kJ} / \mathrm{kgK})$, altura da fenda (m)

$s_{0} \quad$ : fenda radial - altura mínima (m)

$\boldsymbol{S} \quad$ : entropia $(\mathrm{kJ} / \mathrm{K})$

st : passo do parafuso (m)

$\boldsymbol{t} \quad$ : tempo (s)

$\boldsymbol{T} \quad$ : temperatura (K)

$\boldsymbol{u}, \boldsymbol{v}, \boldsymbol{w}$ : componentes da velocidade $(\mathrm{m} / \mathrm{s})$

$\boldsymbol{U}$ : energia interna total $(\mathrm{kJ})$

$\boldsymbol{v}, \boldsymbol{V}:$ volume específico $\left(\mathrm{m}^{3} / \mathrm{kg}\right)$, volume $\left(\mathrm{m}^{3}\right)$

VC : Volume de controle

$\boldsymbol{W}$ : trabalho $(\mathrm{kJ})$, largura do canal (m)

$\boldsymbol{x} \quad$ : fração molar

$\boldsymbol{x}_{\boldsymbol{\varepsilon}}, \boldsymbol{y}_{\boldsymbol{\varepsilon}}$ : grau de preenchimento do canal

$\boldsymbol{x}, \boldsymbol{y}, \boldsymbol{z}$ : coordenadas ortogonais

$z \quad$ : elevação (m)

\section{Símbolos Gregos}

$\alpha \quad$ : ângulo da rosca

$\boldsymbol{\beta} \quad$ : ângulo de intersecção

$\boldsymbol{\Delta} \quad$ : variação finita em uma quantidade

$\gamma$ : parâmetro de distribuição de pressão no parafuso,

$\mathcal{X}(\boldsymbol{x}, \boldsymbol{y})$ : taxa de cisalhamento $\left(\mathrm{s}^{-1}\right)$

$\eta \quad$ : rendimento

$\eta_{e x}$ : rendimento exergético

$\eta_{\text {isot }}$ : eficiência isotérmica

$\eta_{\text {mec }} \quad$ : eficiência mecânica 


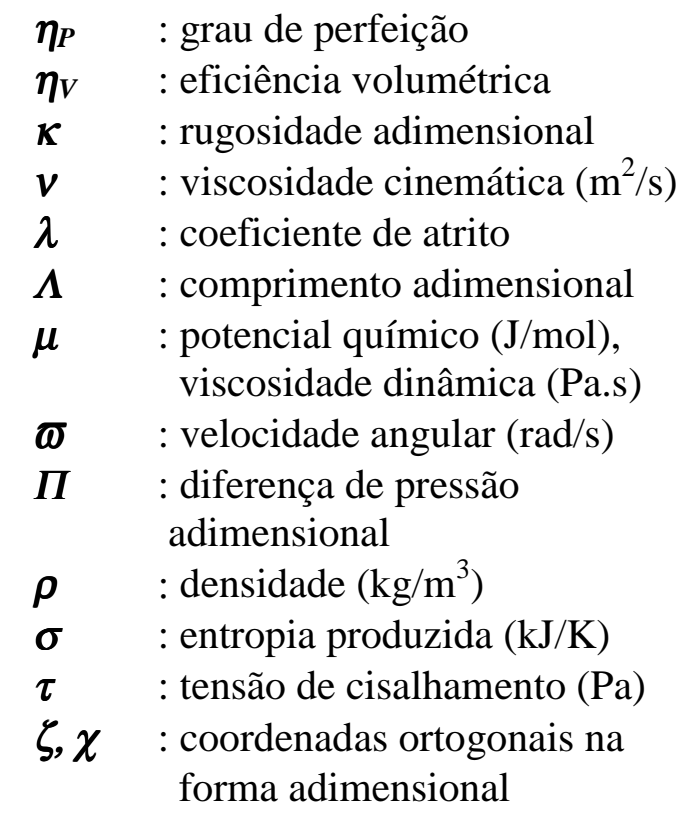

\section{Subscritos}
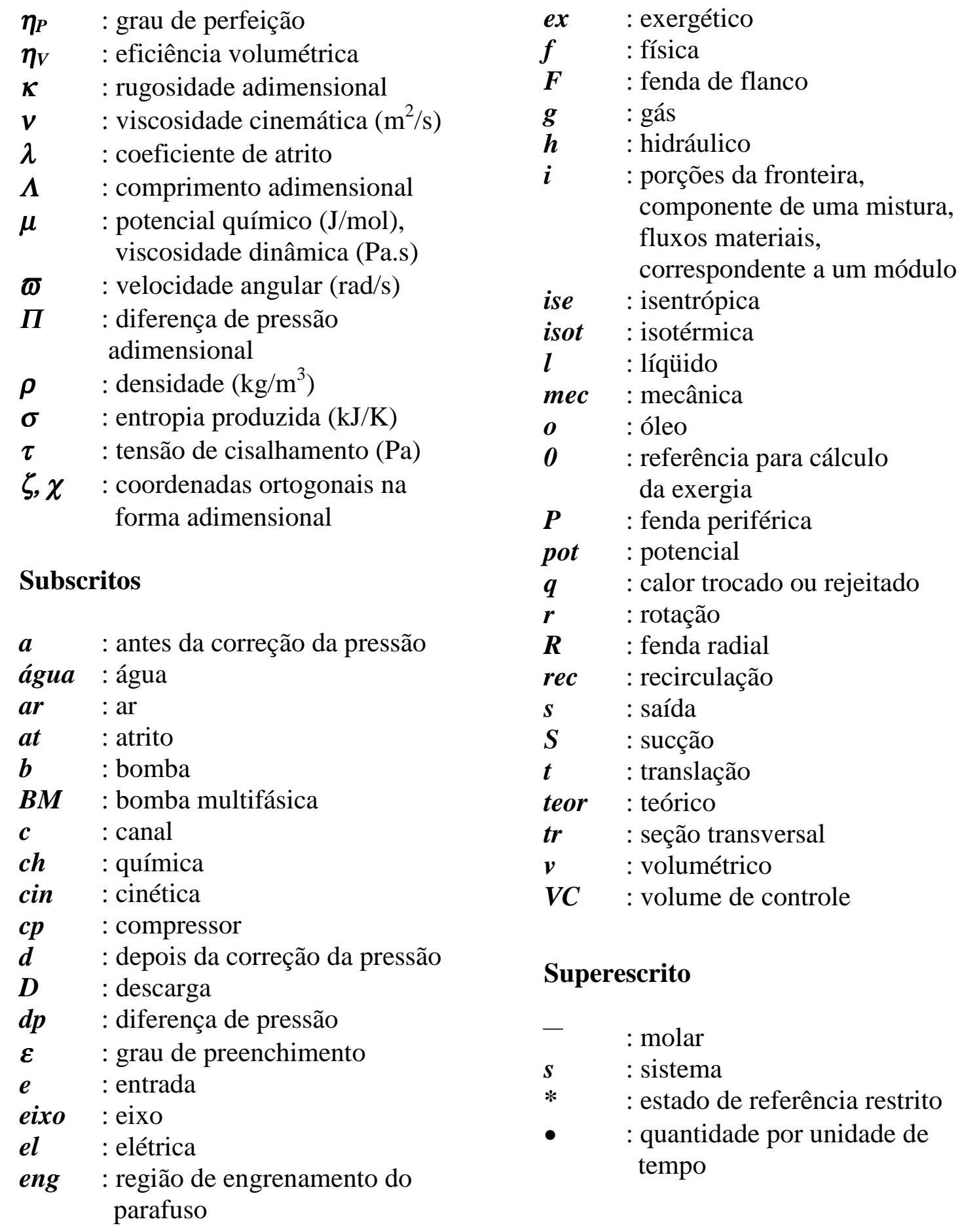

\section{Superescrito}

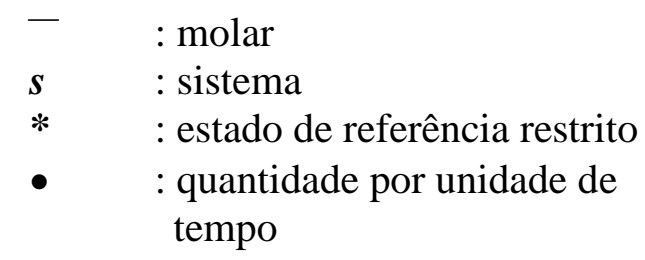




\section{Resumo}

Esse trabalho apresenta um modelo termodinâmico de uma bomba multifásica do tipo duplo parafuso. Para uma dada condição de operação, o modelo calcula a potência consumida, as condições do fluido na descarga e o perfil de pressão ao longo da bomba. Ao invés de simular diretamente o escoamento dentro da bomba, simulou-se os processos que ocorrem dentro das suas câmaras. Para tanto, dividiu-se o processo de bombeamento multifásico em uma sequiência de processos simples, facilitando-se a construção do modelo no simulador de processos Hysys.Process v2.1.

Os resultados de potência e temperatura de descarga obtidos com a simulação mostram uma boa concordância com valores experimentais, principalmente para FVG's baixos. Para FVG's elevados, o modelo passa a superestimar a potência consumida indicando que as fendas, nesses casos, já não se encontram totalmente preenchidas com líqüido.

Dos resultados obtidos para o refluxo, conclui-se que, das equações sugeridas na literatura, aquelas para escoamento turbulento liso são mais adequadas para os números de Reynolds envolvidos. O perfil de pressão e a vazão de refluxo quando o escoamento é multifásico aproxima-se qualitativamente das medições experimentais.

Estudou-se a influência de diversos parâmetros na eficiência exergética da bomba. Os resultados mostram que a otimização da eficiência depende das condições de operação da bomba: FVG, tipo de líqüido, diferença de pressão, entre outros. 


\section{Abstract}

The goal of this project was to develop a thermodynamic model of a twin-screw multiphase pump. With given operation conditions the model can determine the absorbed power, discharge conditions and the pressure profile along the screw. An alternative approach was suggested to overcome the complex flow problem and the processes inside the pump were simulated instead of direct simulation of the flow. For this purpose, the multiphase pumping process was divided in a sequence of simple processes so the model could be developed in an easier way.

The power and temperature values calculated by the model are in good agreement with experimental data, mainly when the gas fraction is low. With higher gas fractions, the model overestimates the absorbed power indicating that screw gaps are not completely filled with liquid anymore.

Concerning about the backflow rate, the results show that the equations for turbulent flow in smooth ducts fits better the Reynolds number range in the gaps. The pressure profile and backflow rate for multiphase flow agree qualitatively with experimental results.

The influence of several parameters in the exergetic eficiency of the pump were analysed and results show that the efficiency optimization depends on pump operation conditions: gas fraction, liquid type, pressure difference and others. 


\section{Capítulo 1}

\section{Introdução}

Atualmente, cerca de um quinto da produção mundial de petróleo e gás provém da exploração de reservas localizadas no fundo do $\operatorname{mar}^{1}$. No Brasil, onde a produção em alto mar é ainda mais importante, aproximadamente $80 \%$ do petróleo vem de plataformas marítimas ${ }^{2}$. A tendência para o futuro é que essa participação aumente, tendo em vista a descoberta de novos campos em profundidades maiores que 200 metros. Dessa forma, a atividade em águas profundas continuará a participar de forma crescente na exploração de petróleo. No entanto, para que seja economicamente viável, a expansão da produção para águas profundas depende de avanços tecnológicos que reduzam os custos de instalação e de operação.

As duas formas mais comuns de escoar os fluidos (óleo e gás) são utilizar a própria energia (pressão) do reservatório ou separar o líquiido do gás e transportá-los independentemente através de bombas e compressores. A partir dos primeiros anos da década de 70, segundo CAETANO et al. (1997), a indústria de petróleo começa a concentrar pesquisas no desenvolvimento de uma máquina de fluxo capaz de adicionar, diretamente, energia para o fluido multifásico proveniente de poços de petróleo - as

\footnotetext{
${ }^{1}$ Estimado a partir de dados da International Petroleum Encyclopedia 1996.

${ }^{2}$ Fonte: PETROBRAS, dados de 1998.
} 
bombas multifásicas. Existem basicamente dois tipos de bombas multifásicas: as helicoaxiais e as parafuso. As bombas helico-axiais têm diversos estágios que comprimem a mistura dinamicamente, ou seja, a velocidade da bomba gera a pressão necessária. Já as bombas parafuso são máquinas de deslocamento positivo. Embora os dois tipos de bomba estejam sendo avaliados, as bombas helico-axiais apresentam algumas limitações como blocagem da bomba ao atingir certas quantidades críticas de gás, necessidade de maior velocidade do eixo para bombear porcentagens maiores de gás para a mesma pressão, mudanças no torque com as variações na quantidade de gás e a necessidade de desenvolvimento de geometrias especiais para o bombeamento multifásico. Assim, para aplicação na extração do petróleo, onde as pressões de sucção são altas (100 a 200 bar, usualmente) e o volume de gás varia muito, a bomba de duplo parafuso surge como uma atraente alternativa para esse tipo de escoamento e, segundo CAETANO et al.(1997), é a que tem, até o momento, maior número de unidades fabricadas.

A utilização das bombas multifásicas no lugar de equipamentos convencionais, segundo CAETANO et al. (1997), apresenta vantagens como economia no equipamento e instrumentos, redução do espaço ocupado e do peso do equipamento, além de proporcionar menores custos de operação devido à redução do equipamento a ser mantido e do pessoal necessário para a operação. Segundo GONZALES e GUEVARA (1996), o custo de um equipamento multifásico atinge cerca de $70 \%$ do custo de um equipamento convencional. No entanto, a eficiência das bombas multifásicas é pequena (30 a 50\%) comparada à eficiência das bombas (60 a 70\%) e compressores (70 a 90\%) convencionais. Ou seja, investe-se menos capital no equipamento e na sua operação, mas a energia consumida é maior. Assim sendo, é muito importante que sejam feitos estudos que comprovem a viabilidade econômica das bombas multifásicas. Apenas um estudo dessa natureza foi feito por DARRIGAN (1995) para bombas helico-axiais, 
comprovando o potencial de aplicação desse tipo de bomba. Para as bombas parafuso, também apenas um trabalho publicado por GONZÁLES e GUEVARA (1995) mostra o potencial de aplicação deste equipamento.

Motivada por essa escassez de informação, a PETROBRAS mostrou interesse no desenvolvimento de um modelo, atualmente inexistente, que permita prever o comportamento termodinâmico da bomba. Todos os modelos para bombas de duplo parafuso até agora publicados preocupam-se apenas com o comportamento hidráulico a fim de prever a capacidade volumétrica da bomba, adotando hipóteses simplificadoras que inviabilizam a sua utilização em análises comparativas, por exemplo. Portanto, é importante estabelecer um modelo que permita prever o comportamento termodinâmico da bomba e que possa ser utilizado tanto no seu desenvolvimento como em análises comparativas frente a outros métodos de processamento primário de petróleo.

\subsection{Objetivo}

O objetivo desse trabalho é desenvolver um modelo que seja capaz de simular o comportamento termodinâmico de uma bomba multifásica com duplo parafuso. Para uma dada condição de operação, o modelo será capaz de calcular: potência consumida, condições do fluido na descarga da bomba, perfil de pressão ao longo do eixo da bomba e vazão de refluxo.

O modelo será construído com o auxilio do simulador de processos Hysys.Process v2.1 e os resultados obtidos serão comparados com os resultados experimentais (potência, refluxo, temperatura de descarga e perfil de pressão) encontrados na literatura.

Uma vez construído o modelo, este será utilizado como ferramenta para a realização de uma análise exergética de uma bomba multifásica. O objetivo da análise é 
identificar a influência de diversos parâmetros na eficiência da bomba. O modelo é necessário para a determinação das propriedades termodinâmicas dos fluidos envolvidos antes e depois do processamento.

\subsection{Organização do trabalho}

O capítulo 2 apresenta uma revisão dos trabalhos relacionados à bomba multifásica parafuso. A intenção deste capítulo é explicar o funcionamento da bomba e os processos que ocorrem dentro dela, importantes para a construção e compreensão do modelo. Também nesse capítulo estão resumidas as pesquisas que já foram feitas tendo a bomba como tema.

No capítulo 3 estão apresentados alguns conceitos básicos da análise exergética, fundamentais para a compreensão dos estudos realizados no capítulo 4.6.

O capítulo 4 mostra a construção do modelo com as hipóteses adotadas e os métodos empregados. Ele tem quatro partes principais: uma avaliação inicial do comportamento do modelo, onde se definiu a configuração mais adequada para representar a bomba multifásica e estudou-se a influência de alguns parâmetros no modelo; a modelagem e inclusão no modelo dos processos que afastam a bomba do ideal; uma comparação dos resultados do modelo com dados experimentais encontrados na literatura para a sua validação e, finalmente, a análise exergética realizada, que mostra a influência de diversos parâmetros na eficiência da bomba.

No capítulo 5 estão as principais conclusões obtidas durante todo o trabalho bem como algumas sugestões para trabalhos futuros. 


\section{Capítulo 2}

\section{Revisão Bibliográfica}

\subsection{A Métodos de processamento primário de petróleo em águas profundas}

A exploração de petróleo em águas profundas depende do desenvolvimento de novas alternativas que tornem o processamento primário do petróleo mais econômico. $\mathrm{O}$ trabalho de CAMARGO et al. (1997) descreve quais os sistemas que vêm sendo pesquisados para aplicação em águas profundas:

a) "Gas lift": neste método, aumenta-se a vazão de um poço através da redução do peso específico dos produtos, conseguida com a contínua injeção de gás em um determinado ponto da tubulação. As vantagens desse método são a excelente faixa de vazão e flexibilidade operacional. Além disso, pode operar com alto FVG (fração volumétrica de gás ${ }^{3}$ ), alta viscosidade e alguma areia. No entanto, o método tem baixa eficiência e exige uma maior quantidade de equipamentos para manipular o gás que recircula. Outro problema é que o método perde eficiência em poços longe da plataforma pois a injeção de gás aumenta a perda de carga e, também, contribui para o resfriamento dos produtos e agravando problemas de formação de cera e hidratos.

\footnotetext{
${ }^{3}$ A fração volumétrica de gás, neste trabalho, será definida como a razão entre o volume ou a vazão volumétrica do gás e o volume ou vazão volumétrica total.
} 
b) Bomba elétrica submarina: trata-se de uma bomba centrífuga multi-estágios, acoplada a um motor elétrico, instalada na base da tubulação. Esse método apresenta uma excelente faixa de vazão mas tem pouca flexibilidade operacional e só pode operar com baixo FVG.

c) Bomba hidráulica a jato: este equipamento utiliza a quantidade de movimento de um fluido para mover outro. Ele é instalado na tubulação e alimentado por um fluido proveniente da plataforma. Esse fluido, de alta pressão e baixa velocidade, passa por um bocal aumentando sua velocidade e diminuindo a pressão. A redução na pressão aumenta a vazão do petróleo. O fluido se mistura com os produtos e essa mistura tem a pressão aumentada ao passar por um difusor, sendo impulsionada à plataforma. $\mathrm{O}$ método apresenta uma excelente faixa de vazão e flexibilidade operacional e pode trabalhar com alto FVG, embora a presença de gás reduza a eficiência. Além disso, pode-se usar o fluido de alimentação para diminuir a viscosidade dos produtos ou controlar a formação de cera e hidratos. Uma desvantagem é a impossibilidade de recircular o fluido de alimentação, sendo necessário seu contínuo suprimento.

d) Bomba de cavidades progressivas: é uma bomba de deslocamento positivo com rotor helicoidal. De acordo com CZARNECKI (1976), essa bomba seria classificada como uma bomba de parafuso único. É um equipamento indicado para trabalhar com fluidos viscosos e abrasivos, também pode trabalhar com alto FVG. No entanto, apresenta baixa vazão e pouca flexibilidade operacional.

e) Bomba multifásica: A bomba multifásica é um equipamento projetado para bombear fluidos multifásicos. Existem basicamente dois tipos: bombas de deslocamento positivo (tipo duplo parafuso) e rotodinâmicas (tipo helico-axiais). Embora cada tipo tenha suas características específicas, pode-se dizer que ambas trabalham com grandes vazões e possuem boa flexibilidade operacional. Podem trabalhar com alto FVG e sua 
utilização dispensa a separação da mistura gás-líquiido. Além disso, são compactas e têm configuração mecânica relativamente simples. As características individuais dos dois tipos, incluindo desvantagens, estão na tabela 2.1.

Tabela 2.1: Algumas características de bombas multifásicas.

\begin{tabular}{l|l}
\hline \multicolumn{1}{c|}{ Bomba Helico-axial } & \multicolumn{1}{c}{ Bomba de duplo parafuso } \\
\hline Eficiência dependente do FVG & Eficiência dependente do FVG \\
Projeto do rotor depende das condições & $\begin{array}{l}\text { Potência consumida praticamente } \\
\text { independente do FVG } \\
\text { de sucção } \\
\text { Torque varia com o FVG }\end{array}$ \\
Vazão elevada & $\begin{array}{l}\text { Compressão do gás pode levar a um } \\
\text { super-aquecimento para alto FVG } \\
\text { Requer lubrificação das engrenagens de } \\
\text { sincronização }\end{array}$ \\
\hline
\end{tabular}

f) Separação submarina: nos sistemas de separação submarina, o líqüido e o gás são separados por um separador localizado no leito submarino. Em seguida, o gás e o líqüido são transportados em tubulações distintas até a plataforma. A forma como isso ocorre varia, podendo-se, por exemplo, bombear o óleo e utilizar a pressão de separação para transportar o gás ou, então, injetar gás a alta pressão. Os sistemas de separação apresentam boa faixa de vazão e flexibilidade operacional e podem trabalhar com alto FVG. Além disso, pode-se utilizar um único sistema para coletar o produto de diversos poços. O principal problema desse sistema é a dificuldade de separação de gás e líquiido quando a viscosidade é alta.

No mesmo trabalho, CAMARGO et al. (1997) faz uma comparação técnica entre quatro dessas alternativas: "Gas lift", bomba elétrica submarina ("ESP”), bomba multifásica parafuso e separação submarina. O sistema de separação em questão é o Vasps, que utiliza uma bomba elétrica submersível para bombear o óleo separado, e a própria pressão de separação para transportar o gás. A bomba elétrica submarina foi a 
opção que apresentou melhores resultados, porém o FVG na sucção está limitado a 15\%. A bomba multifásica parafuso mostrou-se tecnicamente viável em todos os cenários estudados e o sistema de separação, segundo os autores, parece ser aplicável apenas em poços de baixa produtividade ou, então, em poços localizados em águas rasas.

DARRIGAN (1995) também comparou as quatro alternativas, com a diferença que a bomba multifásica é do tipo helico-axial. O seu estudo mostrou que a bomba multifásica, seguida pela separação submarina, seria responsável por um significativo benefício econômico. Segundo os dados do trabalho, os benefícios tendem a ser maiores quanto maiores forem a profundidade do poço e a sua distância à plataforma.

\subsection{Bombas multifásicas tipo duplo parafuso}

As bombas parafuso são um tipo especial de bomba rotativa de deslocamento positivo na qual o fluxo através do eixo de bombeamento é axial. Nesse tipo de bomba, um ou mais rotores com a forma de um parafuso giram impulsionados por um motor. A rotação dos parafusos faz com que os seus filetes se engrenem formando câmaras fechadas como mostra a figura 2.1. Essas câmaras aprisionam o fluido na entrada e o transportam ao longo do eixo até a descarga, onde os filetes desengrenam e liberam o fluido. Sendo uma bomba de deslocamento positivo, ela teoricamente consegue transportar para a descarga qualquer substância - sólida, líqüida ou gasosa - que possa ser introduzida nas passagens de sucção. Isto permite que a bomba de duplo parafuso trabalhe com frações volumétricas de gás (FVG) variando de zero a 95\% (100\% caso garanta-se cerca de 5\% de recirculação de líqüido utilizando-se um tanque de acumulação) e que sua performance, com a adequada especificação dos materiais de contato, não se deteriore com a presença de areia na mistura. 


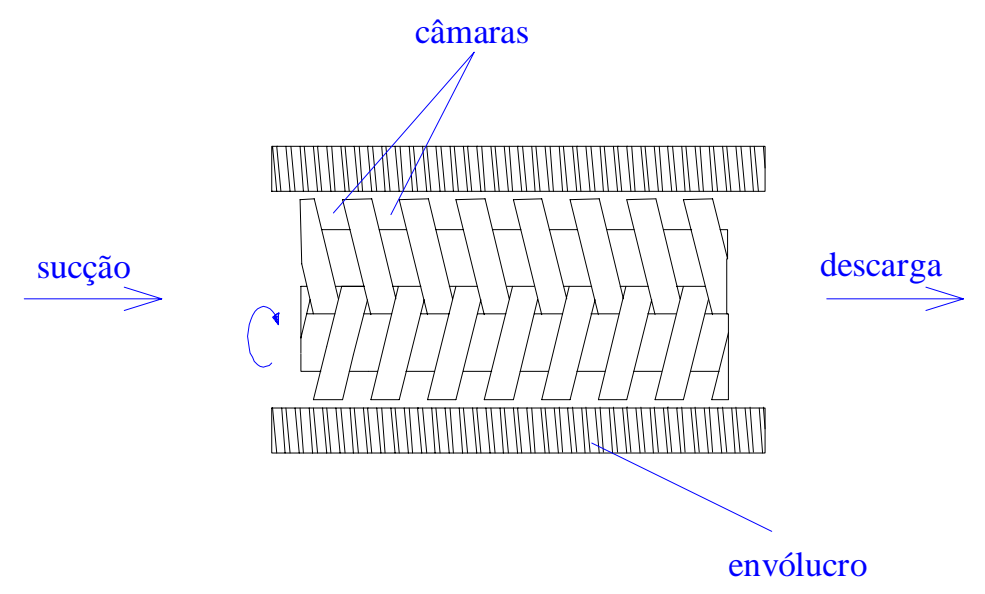

Fig. 2.1: Princípio de funcionamento da bomba de duplo parafuso.

Uma visão geral do bombeamento multifásico pode ser encontrada no trabalho de COOPER et al.(1996). Nesse trabalho são expostos os fundamentos do bombeamento multifásico, além de uma detalhada descrição de bombas helico-axiais e parafuso, bem como procedimentos de operação e teste. $\mathrm{O}$ artigo apresenta, também, um critério de seleção para a escolha do tipo de bomba adequado para determinadas condições de operação. Tal critério utiliza a pressão de sucção e o FVG do escoamento para a criação de três categorias:

a) Baixo FVG (10 a 20\%) e pressão de sucção baixa ou média (1,0 a 15,0 bar);

b) Alto FVG (20 a 60\%) e pressão de sucção baixa (1,0 a 5,0 bar) e

c) Alto FVG (20 a 90\% ou mais) e pressão de sucção alta (acima de 15,0 bar).

Sendo que, para a terceira categoria, os autores sugerem a utilização de bombas helicoaxiais modificadas e bombas parafuso.

Segundo CZARNECKI (1976), as bombas parafuso podem ser classificadas em três tipos básicos: parafuso único, múltiplos parafusos sincronizados e múltiplos parafusos não sincronizados. Nas bombas de parafuso único, a carcaça que envolve o parafuso constitui um estator que se engrena com o mesmo para a formação das 
câmaras. As mais utilizadas, no entanto, são as bombas de parafusos múltiplos. Nesse tipo de bomba, dois ou mais parafusos engrenam-se para a formação das câmaras. Se os parafusos forem acionados simultaneamente através de engrenagens que mantêm a rotação dos parafusos em fase, diz-se que eles são sincronizados. A vantagem, nesse caso, é que os filetes dos parafusos teoricamente não entram em contato entre si, evitando o desgaste e diminuindo a sensibilidade da bomba à presença de partículas sólidas. Se, entretanto, não houver engrenagens de acoplamento, não há sincronia, e o movimento é transmitido de um parafuso para o outro diretamente, num processo semelhante ao funcionamento de engrenagens helicoidais. Essa configuração, embora mais simples, exige uma maior precisão de usinagem e acabamento. Uma configuração bastante comum é a que utiliza parafusos gêmeos, ou seja, dois conjuntos de parafusos contrapostos que operam no mesmo eixo. Nesse caso, além de se conseguir duplicar a vazão sem um acréscimo significativo na complexidade do equipamento, as forças axiais dos parafuso são opostas e se anulam. No caso do bombeamento multifásico com bomba parafuso, a configuração mais utilizada é a bomba de parafusos duplos, sincronizados e gêmeos.

A vazão teórica de uma bomba de duplo parafuso pode ser obtida através dos parâmetros geométricos do parafuso. A vazão real, entretanto, é sempre menor pois, nesse tipo de bomba, existe um refluxo. Esse refluxo ocorre devido à presença necessária de espaços entre os componentes fixos e rotativos da bomba, que formam fendas por onde passa o fluido. WINCEK (1992) define as seguintes fendas (figura 2.2):

a) Fenda periférica: localizada entre os filetes do parafuso e o seu envólucro;

b) Fenda radial: localizada entre os filetes de um parafuso e a raiz dos filetes do outro parafuso;

c) Fenda de flanco: localizada entre os filetes dos dois parafusos. 


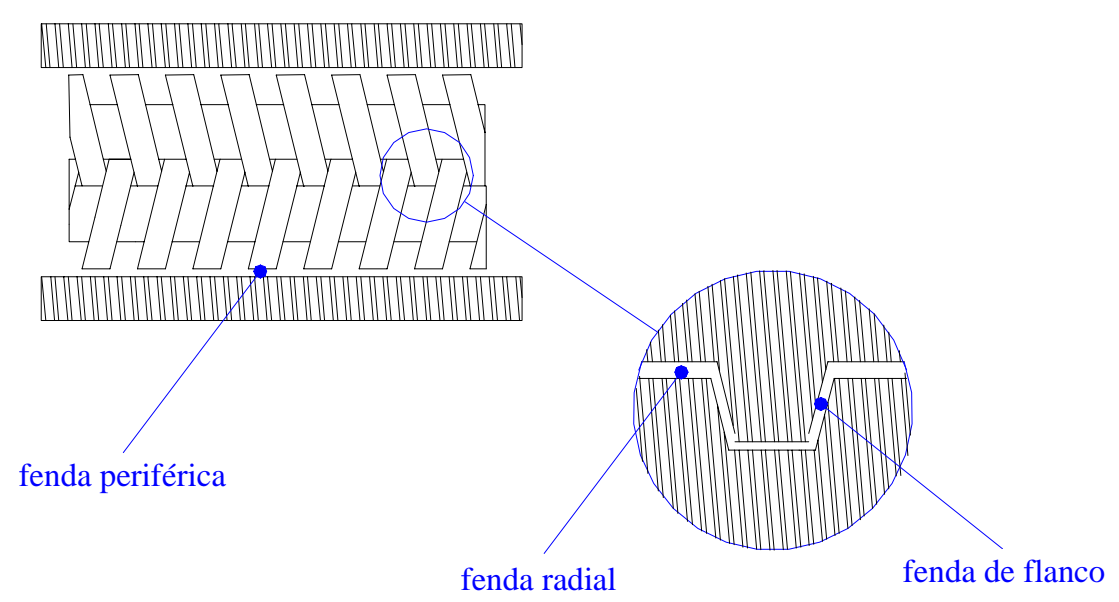

Fig. 2.2: Tipos de fendas nas bombas tipo duplo parafuso.

Essas fendas, aliadas ao gradiente de pressão entre as câmaras e ao movimento de rotação da bomba que arrasta o fluido, faz com que uma pequena parte desse fluido retorne. Deve-se observar que, apesar do refluxo ocorrer de todas as câmaras posteriores para as imediatamente anteriores, o que define o refluxo total da bomba é o refluxo que ocorre entre a primeira câmara e a região de sucção. Ou seja, o refluxo total depende, além do movimento de rotação, do gradiente de pressão entre a primeira câmara e a região de sucção. No caso de escoamentos multifásicos, a presença dessas passagens obriga que sempre haja um pouco de líquiido disponível para selar as câmaras sob o risco de se reduzir a capacidade da bomba. Segundo DAL PORTO e LARSON (1997) isso torna necessária a recirculação de parte do líqüido da região de descarga para a sucção para os casos em que o FVG é muito alto (acima de 95\%).

Um modelo da bomba multifásica parafuso foi proposto por CHRISTIANSEN apud WINCEK (1992). Segundo ele, durante o transporte multifásico a bomba de duplo parafuso atua como uma mistura de bomba e compressor. O parafuso pode ser subdividido em uma série de câmaras, com fendas, que se deslocam axialmente da sucção para a descarga (ver figura 2.3). Devido ao movimento de rotação do parafuso, 
existe uma força centrífuga que faz com que o líqüido permaneça na periferia, preenchendo as fendas, e que o gás fique no centro das câmaras. Dessa forma, supõe-se que o refluxo seja apenas de líqüido. O refluxo do líqüido comprime o gás, o que provoca uma diminuição do seu volume conforme as câmaras se aproximam da região de descarga. Com isso, o refluxo que chega a uma câmara, proveniente de uma câmara posterior, mais próxima da descarga, deve ser maior que o refluxo que deixa essa câmara para a anterior. Assim, os gradientes de pressão entre as câmaras não são iguais, mas progressivamente crescentes. Pode-se perceber que, segundo este modelo, a potência teórica de bombeamento multifásico, para uma bomba tipo duplo parafuso, é dada pelo produto da vazão volumétrica teórica do fluido multifásico pela diferença de pressão entre a sucção e a descarga. Os dados sobre potência obtidos por COOPER et al. (1996) e, também, por MEZZEDIMI et al. (1999) ajudam a confirmar isso. COOPER et al. (1996) registraram uma variação linear da potência com a diferença de pressão e, além disso, a potência altera-se muito pouco com o FVG, diminuindo um pouco quando o FVG aumenta. No trabalho de MEZZEDIMI et al. (1999), pode-se observar que, para uma mesma condição de operação (vazão volumétrica e $\Delta$ p) a potência diminui, de forma aproximadamente linear, com o aumento do FVG. Essa diminuição pode ser atribuída à redução da viscosidade, devido ao maior aumento de temperatura.

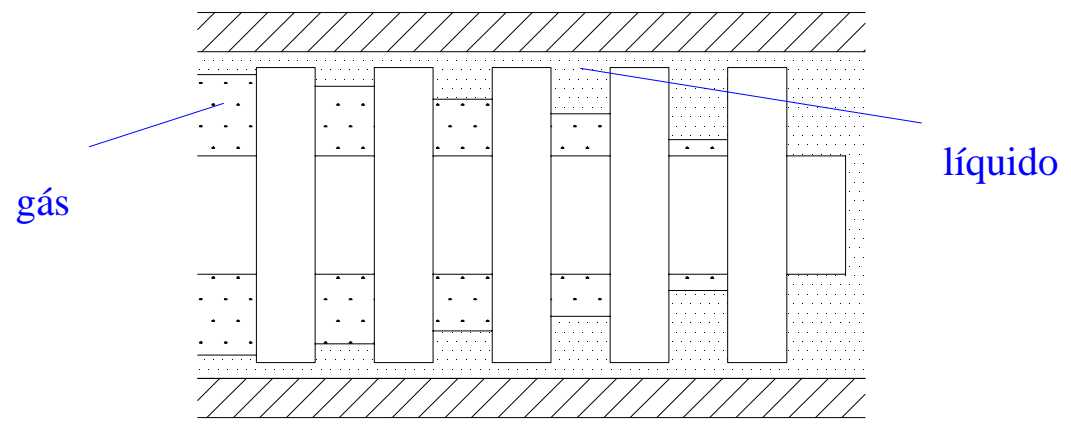

Fig. 2.3: Modelo de para uma bomba multifásica parafuso (WINCEK (1992)). 
O desenvolvimento da pressão entre a sucção e a descarga depende da quantidade de gás no fluido bombeado. Para FVG=0, o fluido é incompressível e esse desenvolvimento dá-se de forma gradual e uniforme conforme o fluido se mova ao longo do eixo. Já para fluidos compressíveis, como os multifásicos, o gradiente de pressão é maior próximo da área de descarga, como visto no parágrafo anterior (figura 2.4, COOPER (1996)). Uma característica das bombas parafuso é que elas não geram pressão como as helico-axiais, mas o fluido é comprimido pelo fluido que reflui através das passagens. BRANDT e WIETSTOCK (1992) realizaram testes que confirmam esse comportamento da bomba multifásica. Para uma mistura água-nitrogênio, mediram um perfil praticamente linear para $0 \%$ de gás e, para $90 \%$ de gás, verificaram um aumento abrupto da pressão a partir da metade do comprimento do parafuso. EGASHIRA et al. (1996) mediram o perfil de pressão para diversas condições de operação. Entre os fatores que afastam o perfil da linearidade estão: aumento do FVG, diminuição da pressão de sucção e aumento da rotação.

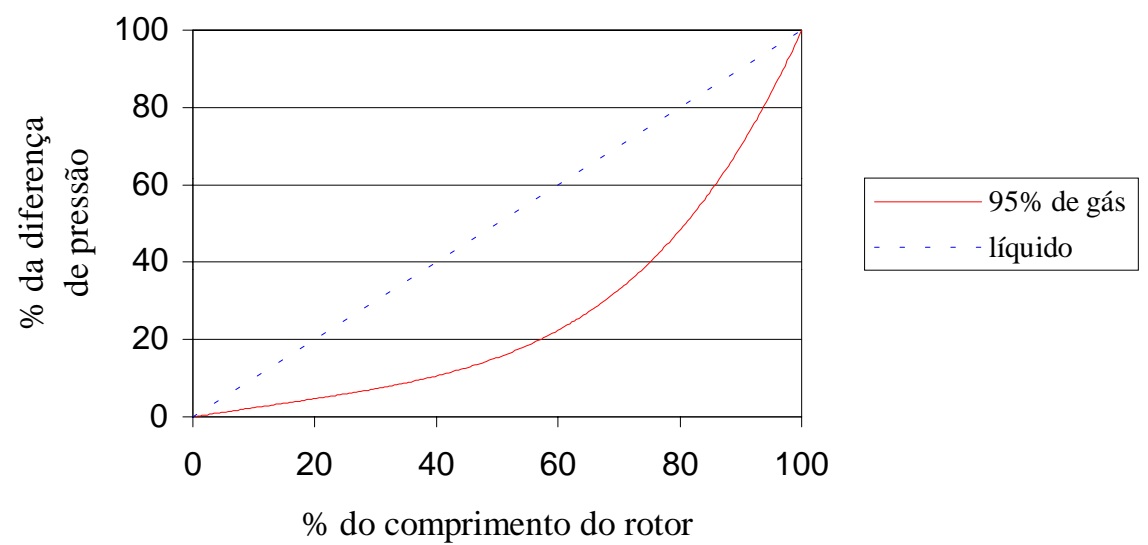

Fig. 2.4: Perfil de pressão ao longo do parafuso (COOPER (1996)).

A eficiência volumétrica da bomba, razão entre a vazão real e a teórica, depende diretamente da magnitude do refluxo: quanto maior o refluxo, menor a eficiência 
volumétrica. Observando-se a figura 2.4, pode-se ver que o gradiente de pressão na região de sucção diminui com o aumento da fração volumétrica de gás, reduzindo o refluxo devido ao gradiente de pressão e, conseqüentemente, aumentando a eficiência volumétrica. Diversos trabalhos confirmam essa relação entre eficiência volumétrica e FVG. Os testes de BRANDT e WIETSTOCK (1992), que realizaram ensaios com três FVG's diferentes (0, 50 e 90\%), mostram um grande aumento da eficiência volumétrica conforme o FVG aumenta. A diferença entre a eficiência volumétrica obtida para 0 e 90\% de gás aumenta bastante para diferenças de pressão maiores. COOPER et al. (1996) e MEZZEDIMI et al. (1999) obtiveram resultados semelhantes. No entanto, como os ensaios foram realizados com FVG de até 100\%, é possível observar uma degradação da eficiência volumétrica para altas porcentagens de gás. A partir de $80 \%$ (MEZZEDIMI et al. (1999)) ou 90\% (COOPER et al. (1996)) de gás há uma queda na eficiência volumétrica causada, provavelmente, pela insuficiência de líquiido disponível para a selagem das fendas do parafuso. Além da fração volumétrica de gás, outro fator que influencia a eficiência volumétrica é o passo do parafuso. Segundo COOPER (1996), para dois parafusos de mesmo comprimento, aquele que tiver menor passo apresentará menor refluxo e provocará menos pulsação do escoamento. Isso pois passos menores implicam câmaras menores e mais numerosas.

A eficiência volumétrica, no entanto, não é a mais adequada para avaliar o desempenho já que não leva em conta a potência consumida pela bomba. No trabalho de WINCEK (1992), encontram-se duas fórmulas para a avaliação de desempenho da bomba: a eficiência isotérmica e a eficiência adiabática. A primeira, proposta por KARGE apud WINCEK (1992), é dada por:

$$
\eta_{B M}=\frac{\dot{W}_{i s o t, g}+\dot{W}_{i s e, l}}{\dot{W}_{\text {eixo }}}
$$


onde: $\dot{W}_{i s o t, g}=F V G \cdot \dot{V}_{B M, S} \cdot p_{S} \cdot \ln \left(p_{D} / p_{S}\right)$, é a potência isotérmica de compressão;

$\dot{W}_{i s e, l}=(1-F V G) \cdot \dot{V}_{B M, S} .\left(p_{D}-p_{S}\right)$, é a potência isentrópica de bombeamento;

$\dot{W}_{\text {eixo }}$ é a potência no eixo da bomba de duplo parafuso.

A segunda, proposta por CHRISTIANSEN apud WINCEK (1992), é semelhante, bastando substituir a potência de compressão isotérmica pela adiabática. O problema desses métodos é que eles aproximam o processo de compressão como sendo um processo ideal: isotérmico ou adiabático. Se existe líqüido suficiente para absorver todo o calor liberado pelo processo de compressão ou se a quantidade de líqüido é tão pequena que praticamente nenhum calor é absorvido, poderia se idealizar os processos como isotérmico ou adiabático, respectivamente. No entanto, existe pouca informação a respeito das porcentagens de líqüido que permitiriam a utilização de uma ou outra eficiência, ou em que faixa nenhuma delas se aplicaria, supondo que haja uma região de transição em que o processo não possa ser idealizado. WINCEK (1992), diz que o processo de compressão aproxima-se do isotérmico para escoamentos água-ar com FVG de até $90 \%$. Para petróleo, COOPER et al (1998) afirma que o processo tende a ser isotérmico para quantidades típicas de líqüido, embora não defina valores em que se poderia aplicar a eficiência isotérmica. Para escoamentos só de gás, sugere a utilização da eficiência adiabática.

O dimensionamento de uma bomba de duplo parafuso depende de diversos fatores tais como, segundo DAL PORTO e LARSON (1997): fluxos de óleo, gás e água, pressões de sucção e descarga, temperatura de sucção, regime de escoamento, quantidade de areia no escoamento e variação das condições de escoamento com o tempo. No entanto, embora os parâmetros de projeto sejam bastante estudados e 
conheça-se, qualitativamente, o comportamento da bomba multifásica parafuso, é muito difícil encontrar, na literatura, métodos de cálculo e dimensionamento.

Apenas dois modelos de cálculo para o transporte de misturas multifásicas para bombas multifásicas parafuso foram encontrados. No modelo formulado por WINCEK (1992) para misturas ar-água, o movimento contínuo das câmaras é "discretizado". Ou seja, considera-se que as câmaras, ao invés de aprisionarem o fluido na entrada e moverem-se continuamente até a descarga, onde liberam o fluido, caminham em passos. Assim, uma bomba com 3 câmaras poderia ser representada como na figura 2.5: quando a última câmara se abre para a descarga, o resto das câmaras desloca-se uma posição para a frente. Admitindo-se que o perfil de velocidades nas fendas é uma superposição dos escoamentos de Couette, devido à rotação do parafuso, e Pouiseuille, devido ao gradiente de pressão, e que todas as fendas estão preenchidas com líqüido, pode-se calcular as vazões volumétricas de refluxo em todas as câmaras. Adotando-se a hipótese de escoamento isotérmico, encontra-se também as pressões em cada câmara. A principal limitação desse modelo é que a descrição do comportamento hidráulico é feita desacoplando-se os processos termodinâmicos dos hidráulicos, uma vez que a temperatura do gás é admitida constante. Outro modelo, formulado por EGASHIRA et
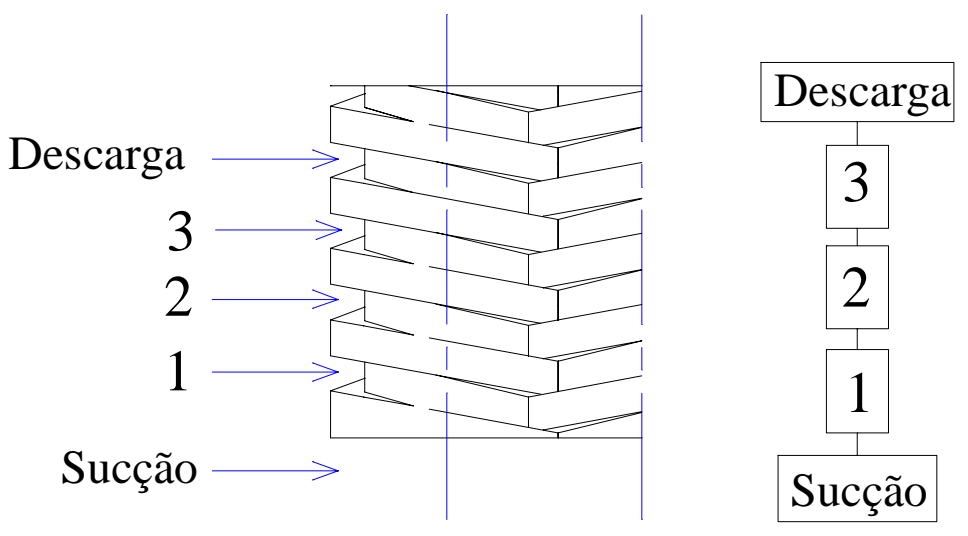

Fig. 2.5: Modelo de bomba de três câmaras (adaptado de WINCEK (1992)) 
al. (1996), calcula os valores de refluxo e condições na saída da bomba a partir do perfil de pressão obtido experimentalmente. Admite-se que a pressão varia exponencialmente com o comprimento do fuso e adapta-se um expoente para que a curva se encaixe da melhor forma possível aos dados experimentais. Essa curva é utilizada nos cálculos do modelo.

Os testes realizados com bombas multifásicas parafuso são apresentados em diversos artigos. BRANDT e WIETSTOCK (1992) mostram os resultados de testes de duas bombas parafuso. Esses testes, feitos com uma mistura de água e nitrogênio, além de confirmar o comportamento da eficiência volumétrica e do perfil de pressão, mostram que a deflexão do eixo é influenciada, principalmente, pela diferença de pressão entre a sucção e a descarga: quanto maior essa diferença, maior a deflexão. Os efeitos do escoamento pistonado ("slug flow") também foram avaliados. Esse regime de escoamento é caracterizado por uma série de bolhas de gás, grandes e individuais, que ocupam a quase totalidade da seção transversal de escoamento, o que faz com que o escoamento fique intermitente, alternando períodos em que há apenas líqüido e períodos em que só escoa gás. Segundo os testes, a passagem das bolhas pela bomba provoca a diminuição do torque e da temperatura de descarga, e o aumento da deflexão do eixo, do esforço dos mancais e da pressão de descarga.

DAL PORTO e LARSON (1997) conduziram testes de longa duração de duas bombas multifásicas parafuso: uma localizada em terra e outra em uma plataforma "offshore". Os resultados comprovaram a confiabilidade das bombas e serviram para a identificação de diversos problemas operacionais como: erosão causada pela presença de areia no escoamento, escoamento pistonado, refluxo e "flashing" (evaporação causada por atrito). 
COOPER et al. (1996) realizaram ensaios de uma bomba de duplo parafuso utilizando uma mistura água-ar. Além de comprovarem o comportamento da eficiência volumétrica, os resultados mostram que existe uma rotação mínima acima da qual a bomba de duplo parafuso é capaz de bombear escoamentos $100 \%$ gasosos até uma determinada pressão de descarga, como mostra a figura 2.6. Para rotações abaixo da mínima, ocorre, ultrapassando-se uma determinada fração de gás, uma súbita perda de pressão na descarga. Alternando a injeção de ar e água na linha de sucção, simulou-se um escoamento pistonado. Nessas condições, o comportamento foi considerado normal, sem mudanças significativas na potência e sem problemas mecânicos ou hidráulicos.

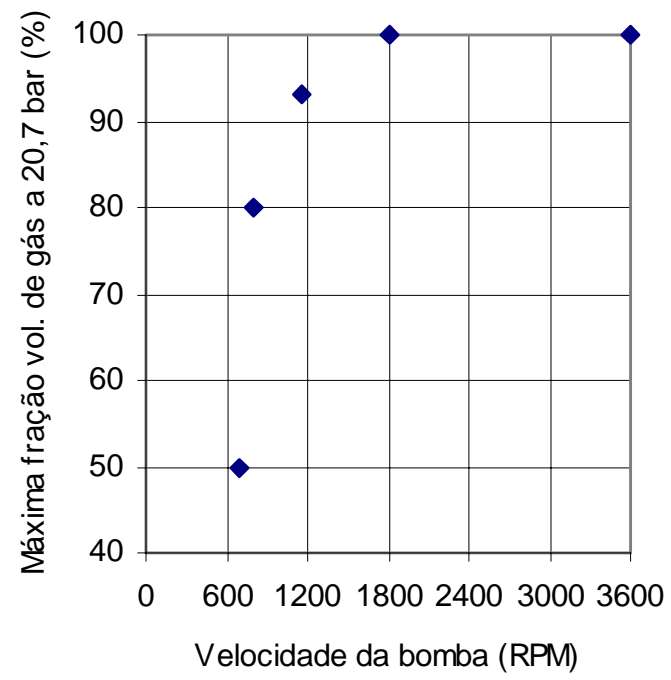

Fig. 2.6: Rotação mínima de bombeamento multifásico (COOPER et al. (1996)).

MEZZEDIMI et al. (1999) realizaram ensaios de longa duração com uma bomba multifásica. No teste da bomba submarina, que operou durante 7500 horas, verificou-se que não houve degradação na performance devido à erosão, corrosão ou desgaste. Uma inspeção realizada após o teste confirmou que não havia mudanças significativas 
(condições das fendas e da superfície do parafuso) em comparação com as condições iniciais.

Estudos sobre a viabilidade da utilização de bombas multifásicas são escassos, apenas dois artigos, sendo um deles para bombas helico-axiais, foram encontrados. DARRIGAN (1995) comparou diferentes formas de extrair petróleo: extração natural, air lift, bomba multifásica helico-axial, bomba elétrica submersível e separação submarina, para dois diferentes cenários: equipamento localizado em águas rasas (150 metros) ou profundas (1000 metros), a uma distância de 20 ou $50 \mathrm{~km}$ de uma plataforma. Os resultados mostram que o bombeamento multifásico e, depois, a separação submarina são os dois métodos mais econômicos.

GONZÁLEZ e GUEVARA (1995) realizaram um teste de campo de uma bomba multifásica do tipo duplo parafuso. Após cinco meses de operação, as principais vantagens e desvantagens observadas foram:

a) Vantagens:

1. o investimento inicial é $30 \%$ menor do que o equipamento convencional;

2. as linhas de escoamento têm menor diâmetro;

3. a área ocupada é $50 \%$ menor;

4. a produção estimada aumentou $15 \%$;

b) Desvantagens:

1. o consumo de energia é três vezes maior.

Baseados nesses resultados, eles estimaram um tempo de retorno do investimento um pouco menor quando se utiliza uma bomba multifásica: 7,6 meses contra 8,6 do equipamento convencional de separação em plataformas. 


\section{Capítulo 3}

\section{Fundamentos da Análise Exergética}

\subsection{Introdução}

A análise energética, baseada na $1^{\mathrm{a}}$ lei da termodinâmica, é uma das ferramentas mais utilizadas na avaliação da eficiência de processos e sistemas térmicos. O problema, no entanto, é que o balanço de energia não diferencia a qualidade, ou seja, a capacidade de realizar mudança, das diversas formas de energia. $\mathrm{Na}$ análise energética, por exemplo, $1 \mathrm{~kJ}$ de calor e $1 \mathrm{~kJ}$ de trabalho são tratados da mesma forma, no entanto, sabese que a qualidade da energia na forma de trabalho é maior que a do calor. Ou seja, os balanços de energia não fornecem informações sobre os processos de degradação da qualidade da energia. Dessa forma, a análise energética apresenta algumas falhas que impedem uma avaliação efetiva dos processos e sistemas. Alguns exemplos dessas falhas, segundo TSATSARONIS (1993), são:

a) a $1^{\text {a }}$ lei não reconhece qualquer perda num reator químico adiabático ou num processo de estrangulamento adiabático;

b) a $1^{\mathrm{a}}$ lei não mostra que uma parte da entalpia de uma corrente ou uma parcela da taxa de transferência de calor é inútil termodinamicamente; 
c) a $1^{\mathrm{a}}$ lei não detecta qualquer degradação de energia num trocador de calor adiabático;

d) a $1^{\text {a }}$ lei identifica o condensador de uma instalação de potência como o responsável pela eficiência relativamente baixa da instalação inteira, sendo que, na verdade, a caldeira é a responsável.

Assim, fica claro que a análise através da primeira lei, apesar de simples e útil, não permite avaliar racionalmente o uso da energia. Segundo BEJAN et al. (1996), na análise de sistemas térmicos seria interessante a utilização de um método que utilizasse a idéia de algo que possa ser destruído, ao contrário da energia que sempre se conserva. A exergia, sendo uma grandeza baseada no conceito da segunda lei da termodinâmica, serve perfeitamente como base para determinar a eficiência de sistemas. Com o método exergético apresentado no texto a seguir, baseado em OLIVEIRA Jr. (1996), tem-se como avaliar a perda real de energia em relação à energia fornecida ou transformada no sistema e nos seus componentes assim como pode-se definir a eficiência dos sistemas de forma racional. Além disso a exergia serve como uma medida da qualidade da energia do ponto de vista termodinâmico.

\subsection{Definição de Exergia}

A possibilidade de realização de trabalho útil existe sempre que dois sistemas que não estejam em equilíbrio são colocados em contato. Se um desses sistemas for o meio ambiente e o outro um sistema de interesse qualquer, pode-se definir a exergia como sendo o trabalho que pode ser realizado quando um sistema evolui do estado em que se encontra até um estado de equilíbrio termodinâmico com os componentes comuns do meio ambiente (equilíbrio mecânico, térmico e químico), através de processos reversíveis, interagindo apenas com os componentes do meio ambiente. 


\subsection{Meio ambiente, estado de referência restrito e estado morto}

Para possibilitar o cálculo da exergia de um sistema ou fluxo, é necessário definir uma referência para que se possa avaliar o máximo trabalho possível de ser realizado por um sistema. Essa referência, por definição, é o meio ambiente. Considerase meio ambiente a porção da vizinhança do sistema estudado cujas propriedades (pressão, temperatura e potencial químico) não se alterem significativamente ao interagir com o sistema. O conceito de meio ambiente usado na análise exergética exige que ele esteja em estado de perfeito equilíbrio termodinâmico, ou seja, o meio deve ser homogêneo, não podendo possuir qualquer gradiente ou diferença de pressão, temperatura, potencial químico, energias cinética e potencial. Assim não existe a possibilidade de realização de trabalho através de interações entre porções do meio. Embora o meio ambiente real seja complexo, procura-se, em geral modelá-lo como uma composição de substâncias existentes em abundância na atmosfera, oceanos ou crosta terrestre.

Quando um sistema qualquer tiver suas substâncias em equilíbrio térmico e mecânico com o meio, ele terá atingido o estado de referência restrito. Nesse estado considera-se que exista uma barreira física impedindo a transferência de massa entre sistema e meio. Dessa maneira o sistema teria a mesma pressão e temperatura do meio mas, em geral, não terá atingido o equilíbrio químico. Se a barreira for removida, permitindo-se que o sistema atinja também o equilíbrio químico, então considera-se que o sistema alcançou o estado morto. Ao atingir esse estado, é impossível a realização de trabalho pelo sistema através de interações com o meio. 


\subsection{Componentes da exergia}

Desconsiderando-se efeitos pouco comuns na análise de sistemas térmicos como: efeitos nucleares, magnéticos, elétricos e de tensão superficial, pode-se dividir a exergia em quatro componentes: exergia cinética, potencial, física e química.

$$
E x=E x_{c i n}+E x_{p o t}+E x_{f}+E x_{c h}
$$

Ou em base mássica:

$$
e x=e x_{c i n}+e x_{p o t}+e x_{f}+e x_{c h}
$$

As exergias cinética e potencial equivalem às energias cinética e potencial pois, a princípio, podem ser totalmente convertidas em trabalho, ou seja:

$$
E x_{\text {cin }}=m \frac{u^{2}}{2} \text { e } E x_{p o t}=m g z
$$

$\mathrm{Na}$ análise de sistemas térmicos, no entanto, essas componentes geralmente têm valor zero pois, na maioria dos casos, o sistema em estudo está em repouso relativo ao meio e as diferenças de altura são desprezíveis.

A exergia física equivale à máxima quantidade de trabalho possível de se obter quando um sistema ou fluxo de uma substância passa de um estado inicial ao estado de referência restrito. Para um sistema a exergia física é dada por:

$$
\begin{gathered}
E x^{s}=E x-E x^{*}+p_{0}\left(V-V^{*}\right)-T_{0}\left(S-S^{*}\right) \\
e x^{s}=e x-e x^{*}+p_{0}\left(v-v^{*}\right)-T_{0}\left(s-s^{*}\right)
\end{gathered}
$$

e para um fluxo:

$$
\begin{gathered}
\dot{E x}=\dot{m}\left(h-h^{*}-T_{0}\left(s-s^{*}\right)\right) \\
e x=h-h^{*}-T_{0}\left(s-s^{*}\right)
\end{gathered}
$$

No cálculo da exergia física basta que o meio esteja caracterizado por uma pressão e temperatura de referência $\left(\mathrm{p}_{0} \mathrm{e} \mathrm{T}_{0}\right)$. 
A exergia química é o máximo trabalho possível de se obter quando um sistema ou fluxo é levado do estado de referência restrito ao estado morto. Para um sistema pode-se escrever:

$$
E x_{c h}^{s}=U^{*}+p_{0} V^{*}-T_{0} S *-\sum_{i=1}^{n} \mu_{0, i} N_{i}=\sum_{i=1}^{n}\left(\mu_{i}^{*}-\mu_{0, i}\right) N_{i}
$$

e para um fluxo em base molar:

$$
\overline{e x}_{c h}=\bar{h} *-T_{0} \bar{s}^{*}-\sum_{i=1}^{n} \mu_{0, i} x_{i}
$$

Assim, a exergia total para um sistema será dada por:

$$
E x^{s}=U+p_{0} V-T_{0} S-\sum_{i=1}^{n} \mu_{0, i} N_{i}
$$

e para um fluxo, tem-se:

$$
\overline{e x}=\bar{h}-T_{0} \bar{s}-\sum_{i=1}^{n} \mu_{0, i} x_{i}
$$

\subsection{Balanço de exergia}

A análise exergética consiste no emprego simultâneo da Primeira e Segunda leis da Termodinâmica na avaliação de desempenho de processos de conversão de energia, permitindo a efetiva avaliação termodinâmica dos processos, uma vez que quantifica as irreversibilidades que ocorrem durante o desenvolvimento destes processos.

O emprego combinado da Primeira e Segunda leis da Termodinâmica permite que se estabeleça o balanço de exergia. Considerando-se o volume de controle mostrado na figura 3.2, pode-se escrever os balanços de energia e entropia, para condições de regime permanente:

- Balanço de Energia:

$$
\dot{Q}-\dot{W}=\dot{H}_{s}-\dot{H}_{e}
$$




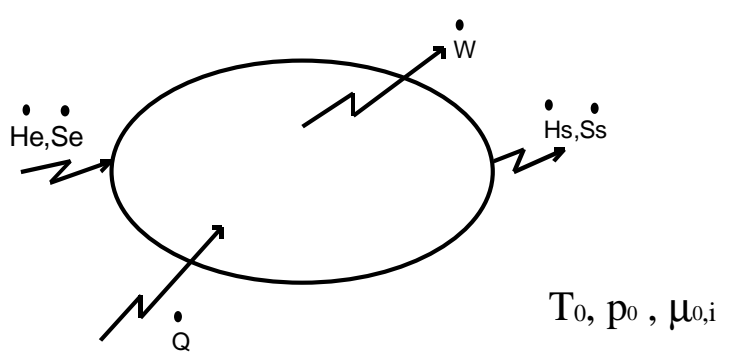

Fig. 3.1: Volume de controle.

- Balanço de Entropia:

$$
\frac{\dot{Q}}{T}+\dot{\sigma}=\dot{S}_{s}-\dot{S}_{e}
$$

Multiplicando-se a equação 3.13 por (- $\mathrm{T}_{\mathrm{o}}$ ) e somando-a à equação 3.12 tem-se:

$$
\dot{H}_{s}-\dot{H}_{e}-T_{o}\left(\dot{S}_{s}-\dot{S}_{e}\right)=\dot{Q}\left(1-\frac{T_{o}}{T}\right)-\dot{W}-T_{o} \dot{\sigma}
$$

A equação 3.14 é o balanço de exergia válido para o volume de controle considerado. Ele é formado pelos seguintes termos:

(variação de exergia entre os fluxos de entrada e saída $)=($ exergia associada ao calor trocado $)+($ exergia pura $=$ trabalho realizado $)-($ exergia destruída $)$

A variação de exergia entre os fluxos de entrada e saída do volume de controle caracteriza o máximo trabalho que poderia ser obtido entre os estados de entrada e saída (trabalho reversível). Esta capacidade de realizar trabalho é igual à somatória composta pelas seguintes parcelas:

- trabalho que seria obtido de um motor térmico reversível operando entre os níveis de temperatura $\mathrm{T}$ e $\mathrm{T}_{0}$, consumindo $\dot{\mathrm{Q}}$ e rejeitando calor para o meio ambiente a $\mathrm{T}_{0}$ (este trabalho é a exergia associada ao calor trocado);

- trabalho efetivamente realizado (exergia pura); 
- trabalho disponível destruído devido à existência de processos irreversíveis (exergia destruída $\left.=\mathrm{T}_{0} \dot{\sigma}\right)$.

A equação 3.14, o balanço de exergia, pode ser considerada como a lei da degradação da energia, uma vez que permite a quantificação da redução da capacidade de realização de trabalho, devido à ocorrência de processos irreversíveis durante o desenvolvimento de processos de conversão de energia.

Constata-se assim que a capacidade de realização de trabalho (exergia) não se conserva, sendo sempre reduzida toda vez que houver algum processo irreversível (expansão não resistida, perda de carga, mistura, troca de calor com $\Delta T$ finito, reação química) ocorrendo no volume de controle analisado.

\subsection{Rendimento exergético}

O rendimento exergético é um parâmetro que permite avaliar o rendimento de um sistema ou equipamento do ponto de vista termodinâmico. Existem diversas formas de se definir a eficiência exergética, algumas delas são:

- Grau de Perfeição:

$$
\eta_{P}=\frac{\text { exergia dos produtos úteis }}{\text { exergia de alimentação }}
$$

- Rendimento exergético:

$$
\begin{gathered}
\eta_{\text {exl }}=\frac{\text { exergia útil produzida }}{\text { consumo de exergia }} \\
\eta_{e x 2}=\frac{\sum(\text { exergia de saída })}{\sum(\text { exergia de entrada })}
\end{gathered}
$$

Devido às várias formas de equacionar o rendimento, alguns pesquisadores procuraram definir um método geral para calcular o rendimento exergético. BEJAN et 
al. (1996), por exemplo, utilizaram os termos produto e combustível para identificar, respectivamente, o resultado desejado produzido por um sistema e os recursos gastos para gerar o produto. $\mathrm{O}$ rendimento exergético é dado pela razão entre a exergia do produto e a do combustível. KOTAS (1985), de maneira semelhante, agrupou as transferências de exergia em dois grupos: produção desejada e alimentação necessária. A razão entre a exergia dos dois grupos fornece o rendimento exergético. Nos dois casos, considerações sobre o objetivo do equipamento ou sistema e a exergia consumida para alcançá-lo levam, em geral, às definições particulares das equações 3.15, 3.16 e 3.17. Deve-se, portanto, ter muito cuidado no equacionamento do rendimento exergético pois, caso ele seja definido erradamente, as conclusões baseadas nele serão inconsistentes. 


\section{Capítulo 4}

\section{Modelo de Comportamento Termodinâmico}

\subsection{Introdução}

O escoamento do petróleo não processado ao longo da bomba multifásica parafuso é muito complexo por diversos motivos. Primeiro, o fluido que escoa, o petróleo, é composto por diversos elementos químicos e apresenta muitas fases (óleo, água, gás e também, ocasionalmente, areia, hidratos de gás natural e depósitos orgânicos), e toda essa complexa mistura escoa em câmaras que possuem movimento de translação e rotação. Além disso, existem processos de transferência de calor e massa entre as fases, devido a processos de mistura, evaporação e condensação, e entre as câmaras, devido aos fluxos que escoam entre as câmaras através das fendas. Para contornar esse problema e viabilizar a construção do modelo, decidiu-se adotar a mesma formulação "discretizada" adotada por WINCEK (1992), em que a bomba foi representada por um determinado número de câmaras e admitiu-se que o fluido deslocase em passos da câmara de sucção até a de descarga. No entanto, como o modelo de WINCEK (1992) foi feito para misturas água-ar e não leva em conta os processos termodinâmicos, importantes na análise exergética, será adotado um método de solução 
diferente que permita a construção de um modelo que possa prever o comportamento termodinâmico da bomba.

Neste trabalho, a bomba multifásica será considerada uma sequiência de separadores, bombas, compressores e misturadores que formarão diversos estágios de compressão, como mostra a figura 4.1. Assim, admite-se que o fluido da região de sucção será separado em gás e líquiido, o líquiido será bombeado, o gás será comprimido, eles serão misturados para homogeneizar a temperatura e então seguirão ao próximo estágio. Isso será feito sucessivamente até que o fluido atinja a descarga. Representando-se o processo de bombeamento multifásico como uma seqüência de processos simples, além de se facilitar a simulação dos balanços de energia e massa necessários ao modelo, permite que este seja construído e simulado com o auxílio de um simulador de processos. As hipóteses utilizadas para a construção do modelo são:

a) Regime permanente;

b) Escoamento adiabático: não há troca de calor com o meio ambiente, apenas entre as fases do fluido multifásico;

c) Equilíbrio térmico entre as fases: as diversas fases do fluido, em uma determinada câmara, encontram-se à mesma temperatura;

d) Recirculação apenas de líqüido: supõe-se que as fendas estejam sempre preenchidas com líqüido, de forma que apenas líqüido retorna através das fendas;

e) Não há evaporação por atrito ("flashing”): considera-se que esse fenômeno, que pode alterar a vazão através das fendas, não ocorre e

f) Fenda periférica concêntrica: a fenda anular na região periférica do parafuso é considerada concêntrica, não se levando em conta os desvios provocados pela flexão do eixo. 


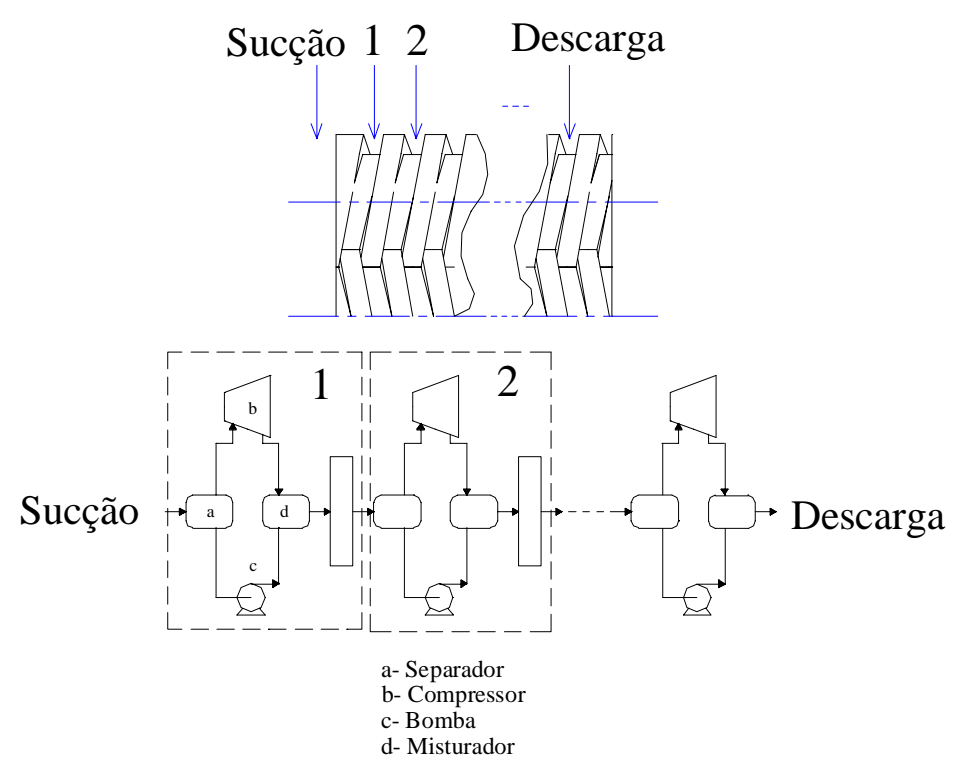

Fig. 4.1: Modelo para a simulação do comportamento termodinâmico de uma bomba multifásica tipo duplo parafuso.

Segundo o manual da HYPROTECH (1996) o simulador escolhido, Hysys.Process v2.1, permite a completa caracterização dos fluidos com os quais pretende-se trabalhar. Fornecendo-se a composição química, temperatura, pressão e vazão, um fluxo já está completamente definido. As propriedades físicas e de transporte, calculadas automaticamente para cada fase, são: viscosidade, densidade, condutividade térmica e tensão superficial, determinadas a partir de modelos previamente selecionados para serem utilizados no simulador. Para escoamentos trifásicos (duas fases líqüidas), o programa usa regras empíricas para determinar a propriedade aparente da combinação das fases líqüidas. Diversos métodos de calcular propriedades termodinâmicas estão disponíveis. No entanto, para aplicações com óleo, gás e petroquímicos, o manual da HYPROTECH (1996) recomenda a utilização das equações de estado de PengRobinson. Segundo o manual, essas equações permitem uma resolução rigorosa de sistemas monofásicos, bifásicos ou trifásicos com um alto grau de eficiência e confiabilidade. Além disso, as equações são úteis para uma larga faixa de condições, 
servindo para temperaturas maiores que $-271{ }^{\circ} \mathrm{C}$ e pressões de até $100 \mathrm{MPa}$. Outra vantagem do programa é a sua grande quantidade de unidades de operação pré definidas: separadores, misturadores, trocadores de calor, bombas, compressores, dutos, reatores, entre outras. Assim, basta conectar apropriadamente fluxos e unidades de operação para poder modelar uma grande variedade de processos e obter balanços de energia e massa de misturas complexas.

A construção do modelo foi dividida, basicamente, em três partes: avaliação do comportamento, modelagem dos processos de atrito e vazão nas fendas e comparação com resultados experimentais. Na primeira parte, procurou-se avaliar se o modelo era capaz de representar o comportamento de uma bomba multifásica ideal pois, caso contrário, qualquer resultado obtido posteriormente não seria válido. Também nesta parte, foram realizados estudos para verificar o efeito de fatores como: rendimento das bombas e compressores do modelo, perfil de pressão ao longo dos estágios, fração volumétrica de gás $(\mathrm{FVG})$ na sucção e número de estágios, no comportamento do modelo e na sua eficiência exergética. Uma vez tendo identificado a configuração correta, que pudesse representar uma bomba ideal, foram analisados e modelados os processos de atrito viscoso e refluxo que permitem que o modelo represente uma bomba real. Finalmente comparou-se os resultados do modelo com dados experimentais.

\subsection{Avaliação do comportamento do modelo proposto}

A composição do óleo e do gás utilizadas nestes estudos iniciais encontram-se na tabela 4.1. Já o número de estágios escolhidos foi, a princípio, oito, uma vez que esse é um número de câmaras bastante utilizado em bombas multifásicas e, dessa forma, poderia se estabelecer uma relação direta entre os estágios do modelo e os estágios/câmaras da bomba multifásica. 
Logo no início dos estudos, verificou-se que a configuração inicialmente proposta para o modelo (figura 4.1) não representava adequadamente a bomba multifásica por dois motivos:

a) A vazão volumétrica diminuía ao longo dos estágios devido à compressão do gás: esse comportamento é incompatível com a bomba multifásica real uma vez que, mesmo o fluido sendo compressível, a bomba possui as câmaras com volume constante, ou seja, a vazão volumétrica deve manter-se constante ao longo do parafuso, entre a primeira e a última câmara, ainda que a pressão aumente.

b) A potência calculada pelo modelo é dependente do FVG na sucção: para uma mesma vazão na entrada, pode-se reconhecer que a potência total consumida (=Potência de compressão + Potência de bombeamento) tende a diminuir com o aumento do FVG. No caso da bomba real, uma máquina de deslocamento volumétrico, a potência consumida $(\dot{V} \Delta p)$ deve ser independente do FVG.

Tabela 4.1: Frações molares (\%) dos componentes dos fluxos de alimentação do modelo.

\begin{tabular}{cccc}
\hline \multirow{2}{*}{ Componente } & Descrição & \multicolumn{2}{c}{ Fração Molar } \\
\cline { 3 - 4 } & & Gás & Óleo \\
\hline $\mathrm{C} 1$ & Metano & 91,19 & - \\
\hline $\mathrm{C} 2$ & Etano & 0,34 & 0,39 \\
\hline $\mathrm{C} 3$ & Propano & 0,15 & 1,36 \\
\hline $\mathrm{iC} 4$ & i-Butano & 0,24 & 1,09 \\
\hline $\mathrm{nC} 4$ & n-Butano & 0,07 & 2,65 \\
\hline $\mathrm{iC5}$ & i-Pentano & 0,04 & 3,22 \\
\hline $\mathrm{nC5}$ & n-Pentano & - & 3,53 \\
\hline $\mathrm{nC6}$ & n-Hexano & - & 8,64 \\
\hline $\mathrm{nC7}$ & n-Heptano & - & 11,48 \\
\hline $\mathrm{nC} 8$ & n-Octano & - & 13,59 \\
\hline $\mathrm{nC} 9$ & n-Nonano & - & 8,81 \\
\hline $\mathrm{nC} 10$ & n-Decano & - & 7,66 \\
\hline $\mathrm{nC} 11$ & n-C11 & - & 4,54 \\
\hline $\mathrm{C} 12+$ & C12+ & - & 33,40 \\
\hline $\mathrm{N}_{2}$ & Nitrogênio & 6,93 & - \\
\hline $\mathrm{CO} 2$ & Dióxido de Carbono & 0,53 & - \\
\hline
\end{tabular}


Observando-se os modelos propostos para explicar o funcionamento da bomba multifásica, notou-se que o modelo deveria incluir a recirculação do líqüido através das fendas da bomba. Esse fenômeno ocorre pois parte do líqüido escoa das câmaras posteriores para as anteriores, comprimindo o gás e ocupando o volume da câmara que anteriormente era ocupado por este. Dessa maneira, modificou-se o modelo como mostra a figura 4.2. A vazão de recirculação é calculada de modo que a vazão volumétrica após cada estágio de compressão seja a mesma da entrada. Deve-se notar que, embora sejam tecnicamente a mesma coisa, nesta parte do trabalho utilizar-se-á nomes diferentes para distinguir o refluxo que ocorre em todas as câmaras do refluxo total da bomba (entre a primeira câmara e a sucção), facilitando a descrição do trabalho. O primeiro será denominado vazão de recirculação e o segundo de vazão de refluxo.

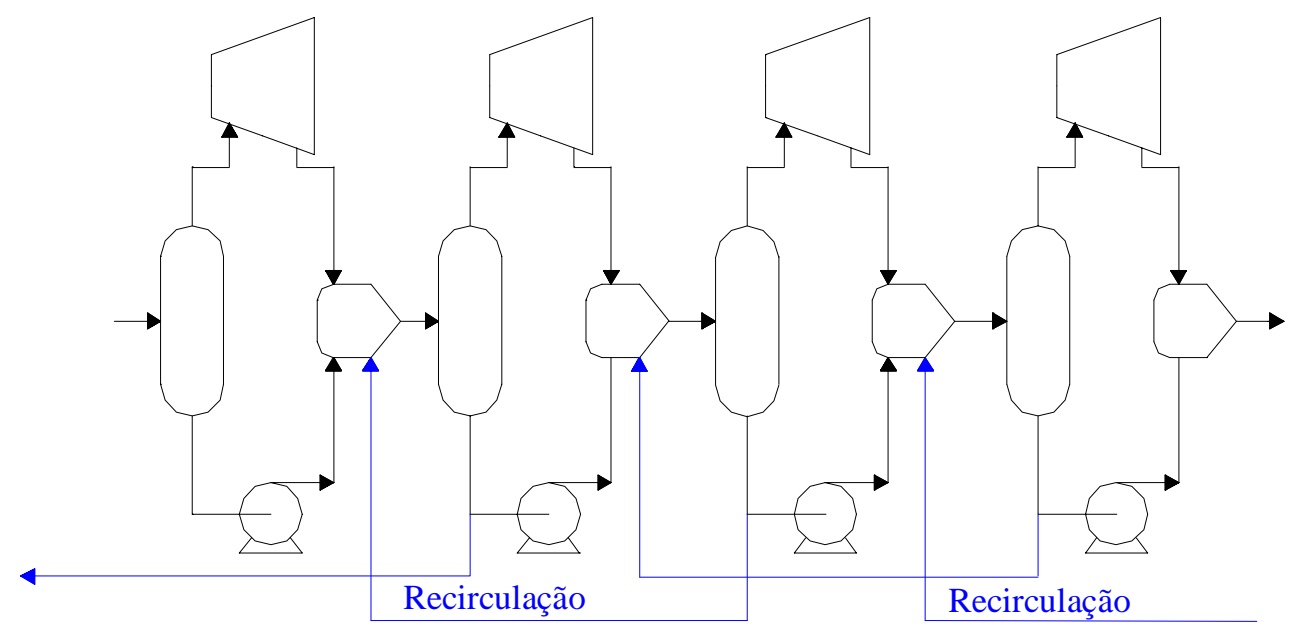

Fig. 4.2: Inclusão da recirculação no modelo.

Pode-se observar que, com a inclusão da recirculação, a vazão mássica $(\dot{\boldsymbol{m}})$ aparentemente aumenta ao longo dos estágios como mostra a figura 4.3, isso, no entanto, não viola a lei de conservação de massa. Isso pode ser explicado com o auxílio 
dessa mesma figura. Se as câmaras da bomba forem representadas como nesta figura, então pode-se perceber que entre a primeira e a última câmara o volume total deve-se manter constante às custas do líqüido que retorna das câmaras posteriores, já que o volume das câmaras da bomba é constante. Ou seja, a diminuição do volume do gás é compensado pelo aumento do volume do líqüido, havendo, como conseqüência, um progressivo aumento da vazão mássica do líqüido. Quando o líqüido atinge a descarga, então há apenas uma redução no volume do gás, uma vez que não existe mais a condição de volume constante devido à ausência dos limites da câmara. Então, todo o líquiido acumulado ao longo da bomba retorna para as câmaras anteriores e a vazão mássica na descarga é a mesma da sucção. Isso significa que parte da potência no eixo é desperdiçada na recirculação do líquiido. A única forma de evitar ou, ao menos, reduzir esse desperdício seria construir a bomba multifásica com parafusos que tivessem uma relação de compressão (câmaras com tamanho decrescente), o que evitaria ou, pelo menos, diminuiria a recirculação do líqüido. No entanto, não é possível aplicar essa solução pois a bomba multifásica deve prever a possibilidade de trabalhar com $100 \%$ de líqüido. Nesse caso, uma bomba com relação de compressão seria danificada.

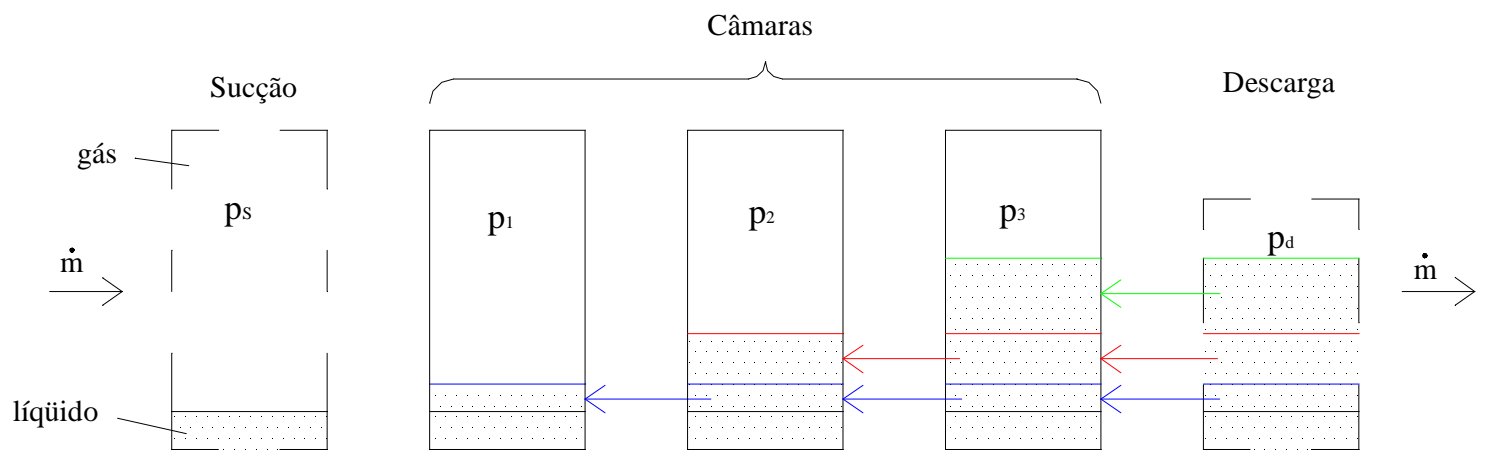

Fig. 4.3: Ilustração da recirculação ao longo da bomba. 
Comparando-se os dois modelos, pode-se dizer que o primeiro representaria uma bomba multifásica hipotética que possuísse uma relação de compressão; enquanto que o segundo, incluindo a recirculação, representa a bomba multifásica parafuso real, sem relação de compressão, que é o objeto de estudo.

Uma vez tendo identificado o modelo que melhor representa a bomba, conduziuse alguns estudos paramétricos que fornecessem informações para o seu aperfeiçoamento. As condições padrão de sucção e descarga utilizadas na maioria das simulações estão na tabela 4.2. A composição dos fluxos de gás e óleo são as mesmas da tabela 4.1. A figura 4.4 mostra o perfil de pressão adotado nesta parte do trabalho, semelhante ao encontrado nas bombas multifásicas reais. Os resultados apresentados a seguir (itens 4.2.1 a 4.2.3) procuram principalmente avaliar se o modelo representa adequadamente uma bomba multifásica ideal: sem perdas por atrito e sem vazão de refluxo. Ou seja, verificam se o modelo trabalhando com eficiência 100\% para bombas e compressores e sem corrente de refluxo, para uma dada condição de operação, consome a mesma potência teórica $(=\dot{V} . \Delta p)$ que a bomba multifásica consumiria operando idealmente.

Tabela 4.2: Dados utilizados nos estudos paramétricos

\begin{tabular}{lc}
\hline \multicolumn{1}{c}{ Variável } & Valor \\
\hline Temperatura de sucção $-\mathrm{T}_{\mathrm{S}}\left({ }^{\circ} \mathrm{C}\right)$ & 30,8 \\
\hline Pressão de sucção - $\mathrm{p}_{\mathrm{S}}(\mathrm{kPa})$ & 672,0 \\
\hline & 2600,0 \\
Pressão de descarga - $\mathrm{p}_{\mathrm{D}}(\mathrm{kPa})$ & 4528,0 \\
\hline Vazão Volumétrica Total na sucção $-\dot{V}\left(\mathrm{~m}^{3} / \mathrm{h}\right)$ & 264,3 \\
\hline Vazão Volumétrica de Óleo na sucção $\left(\mathrm{m}^{3} / \mathrm{h}\right)$ & 251,3 \\
\hline Vazão Volumétrica de Gás na sucção $\left(\mathrm{m}^{3} / \mathrm{h}\right)$ & 13,0 \\
\hline FVG $(\%)$ & 95 \\
\hline Número de estágios $-\mathrm{N}_{\mathrm{BM}}$ & 8 \\
\hline
\end{tabular}




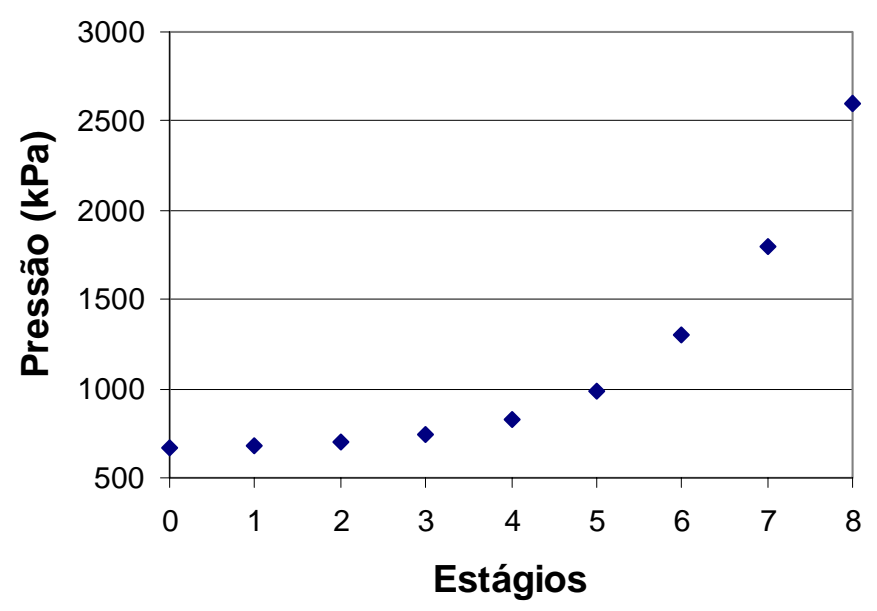

Fig. 4.4: Perfil de pressão.

\subsubsection{Efeito do FVG e do número de estágios}

As tabelas $4.3 \mathrm{a}$ e $4.3 \mathrm{~b}$ mostram os resultados de consumo de potência do modelo e a comparação com a potência teórica, em função do FVG, para pressões de descarga de 2600 e $4528 \mathrm{kPa}$, respectivamente. O rendimento das bombas e compressores adotado foi de $100 \%$.

Tabela 4.3: Consumo de potência do modelo: a) $p_{D}=2600 \mathrm{kPa}$; b) $p_{D}=4528 \mathrm{kPa}$

a)

\begin{tabular}{ccc}
\hline $\begin{array}{c}\text { FVG } \\
(\%)\end{array}$ & $\begin{array}{c}\dot{\mathbf{W}} \\
(\mathrm{kW})\end{array}$ & $\dot{\mathbf{W}} / \dot{\mathbf{W}}_{\text {teor }}$ \\
\hline 0 & 141,5 & 0,9993 \\
30 & 140,7 & 0,9933 \\
60 & 137,2 & 0,9692 \\
95 & 132,7 & 0,9371 \\
\hline
\end{tabular}

b)

\begin{tabular}{ccc}
\hline $\begin{array}{c}\text { FVG } \\
(\%)\end{array}$ & $\begin{array}{c}\dot{\mathbf{W}} \\
(\mathrm{kW})\end{array}$ & $\dot{\mathbf{W}} / \dot{\mathbf{W}}_{\text {teor }}$ \\
\hline 0 & 283,1 & 1,0000 \\
30 & 282,1 & 0,9964 \\
60 & 275,9 & 0,9746 \\
95 & 264,2 & 0,9332 \\
\hline
\end{tabular}

Como pode ser visto na coluna $\dot{\mathbf{W}} / \dot{\mathbf{W}}_{\text {teor }}$, nos dois casos a potência calculada aproxima-se bastante da teórica, havendo, para FVG's crescentes, uma pequena tendência de afastamento do valor teórico. Esse comportamento pode ser observado 
para as duas pressões de descarga testadas. Quando o FVG é nulo, ou seja, somente líquiido está sendo bombeado, a potência calculada é praticamente igual à potência teórica. Com o aumento do FVG, o modelo começa a se afastar do comportamento teórico da bomba multifásica, alcançando até $93 \%$ do valor teórico. Uma vez que a eficiência das bombas e compressores é de 100\%, o consumo menor que o teórico pode ser atribuído à discretização utilizada no método de solução do problema, como será mostrado a seguir.

A figura 4.5 ilustra o deslocamento de uma câmara na bomba multifásica. Quando uma câmara desloca-se da sucção à descarga, o volume do gás diminui continuamente devido ao aumento da pressão, como mostra a curva a-d vermelha. $\mathrm{O}$ espaço anteriormente ocupado pelo gás é preenchido pelo líqüido proveniente da recirculação e, portanto, para uma dada redução do volume do gás, há um aumento de mesma magnitude no volume de líqüido. A curva b-c azul representa o aumento do volume do líqüido e mostra que ela possui um formato idêntico à curva de compressão sendo que a única diferença é que elas são opostas. A soma dos volumes do gás e do líquiido (linha A-B) é constante uma vez que o volume da câmara deve ser sempre o mesmo. A vazão volumétrica ao longo da bomba segue o mesmo comportamento da variação de volume para uma câmara, já que, com a bomba em funcionamento, a formação das câmaras é periódica. A figura 4.6 mostra que a potência total de bombeamento multifásico (área $\mathrm{ABCD}$ ), dada pela soma das potências de compressão do gás (área $\mathrm{AbdD}$ ) e de bombeamento do líqüido (área AacD), depende apenas da vazão volumétrica total e da diferença de pressão. A redução na potência de compressão é compensada com o aumento na potência de bombeamento de forma que, não importa qual seja a quantidade de gás, a potência total será sempre dada pelo produto da vazão volumétrica teórica pela diferença de pressão. 


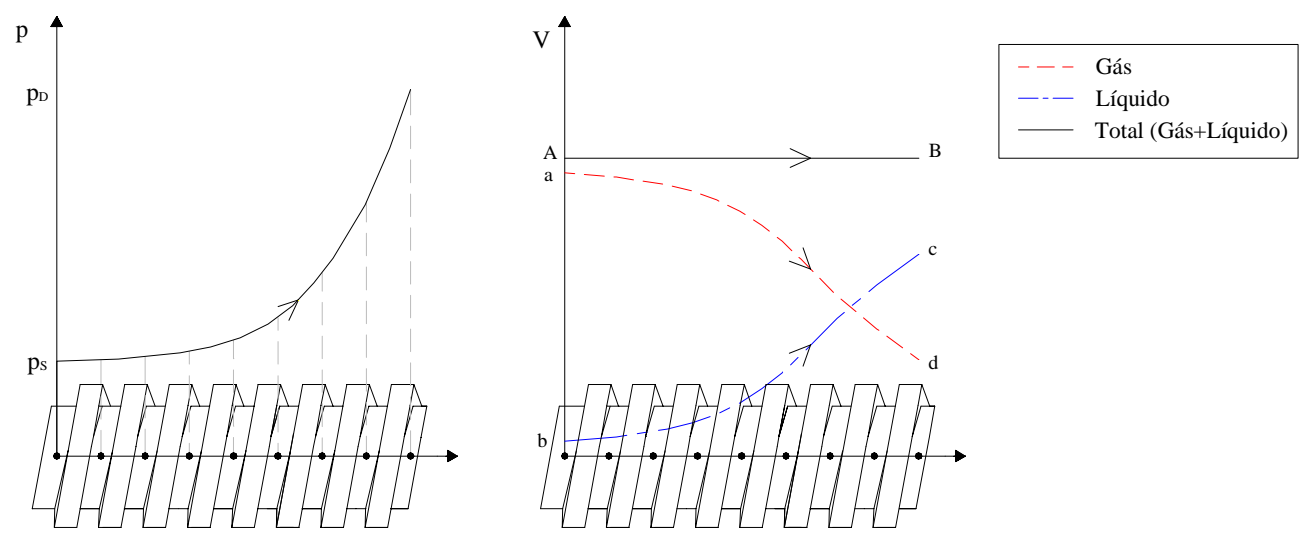

Fig. 4.5: Variação da pressão e dos volumes de gás e óleo na bomba multifásica.

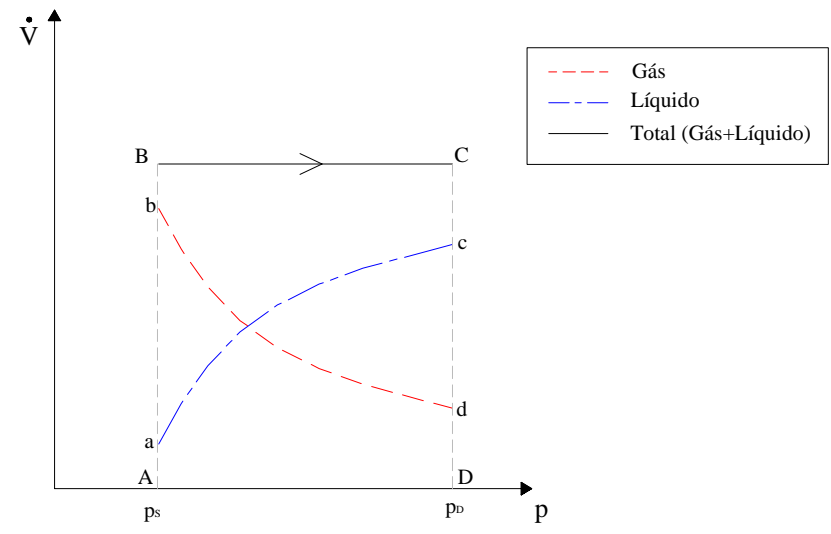

Fig. 4.6: Gráfico $\dot{\mathrm{V}} \mathrm{x}$ p para o processo de bombeamento multifásico.

No entanto, ao discretizar o processo contínuo, considerando-o como uma seqüência de processos simples, introduz-se um erro no cálculo da potência total consumida. A figura 4.7 mostra a diferença entre o processo real (dado pela linha pontilhada cinza) e a forma como ele é representado pelo modelo. O processo contínuo de aumento de pressão, redução do volume do gás, aumento do volume do líquiido e troca de calor entre as fases é representado da seguinte forma: o gás é comprimido, o líqüido é bombeado a volume constante, adiciona-se uma corrente de recirculação para aumentar o volume de líqüido e compensar a redução na vazão de gás e mistura-se o gás e o líquiido para que troquem calor. Isso significa que a modificação nos volumes e a 
troca de calor entre as fases ocorrem apenas em um número limitado de pontos, e não continuamente como no processo real. A figura 4.8 mostra como essa forma de representar o processo introduz um erro no cálculo da potência pelo modelo. O processo teórico (1-3) de aumento de pressão e vazão volumétrica do líqüido entre dois pontos é representado, no modelo, por um processo de bombeamento simples (1-2) seguido de uma correção do volume do líqüido (2-3) através de uma corrente de recirculação. A área 1-2-3 representa a potência que as bombas do modelo deixam de calcular, resultando numa potência de bombeamento menor que a teórica. No caso da compressão (processo 4-6), ela é representada por um processo de compressão (4-5) e resfriamento (5-6) devido à mistura com o líqüido. Dessa forma a potência de compressão calculada pelo modelo é maior que a teórica, e a diferença é representada pela área 4-5-6. Ainda observando-se a figura 4.8, é possível perceber que a área da região 1-2-3 é maior que a da região 4-5-6, ou seja, a potência de compressão que o modelo calcula a mais compensa apenas em parte a menor potência de bombeamento calculada. Dessa forma, a potência de bombeamento multifásico calculada pelo modelo é menor que a teórica.
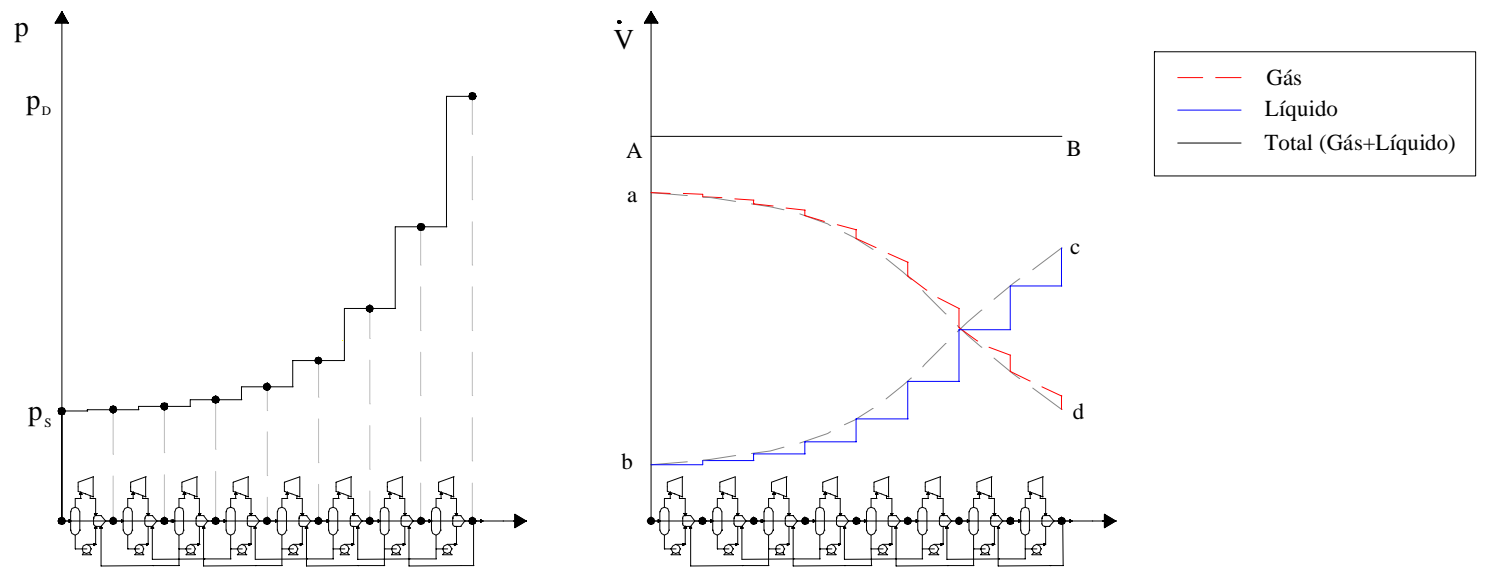

Fig. 4.7: Diferença entre o processo de bombeamento multifásico e sua representação pelo modelo. 


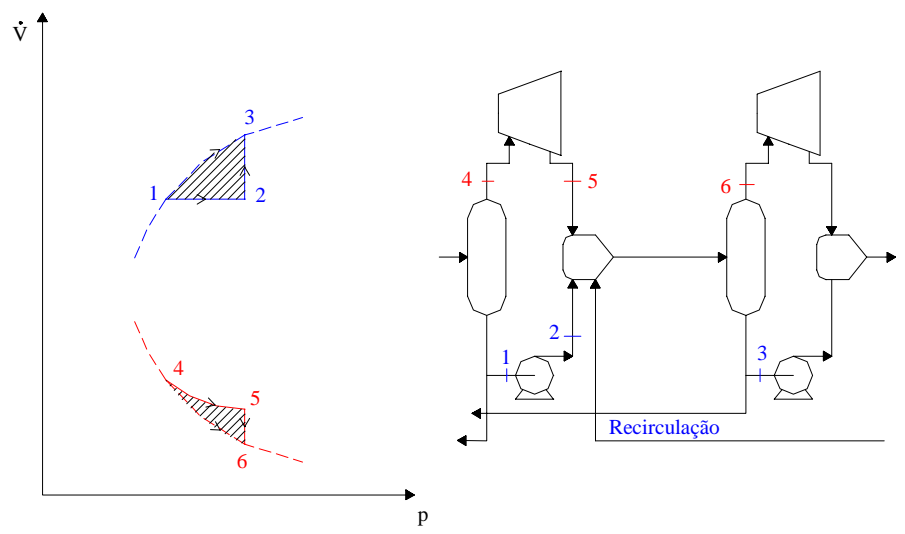

Fig. 4.8: Ilustração da diferença entre as potências de bombeamento e compressão da bomba real e as potências calculadas pelo modelo.

As figuras 4.9 e 4.10 mostram dados obtidos em duas simulações $(\mathrm{FVG}=30 \mathrm{e}$ 95\%). Quando o volume de gás é elevado (alto FVG), a sua temperatura pouco se altera ao ser misturado com o líqüido. Neste caso, o processo de compressão do modelo aproxima-se do teórico (como mostra a figura 4.9) e a potência calculada afasta-se mais da teórica. Para baixo FVG isso não ocorre e a potência de compressão começa a

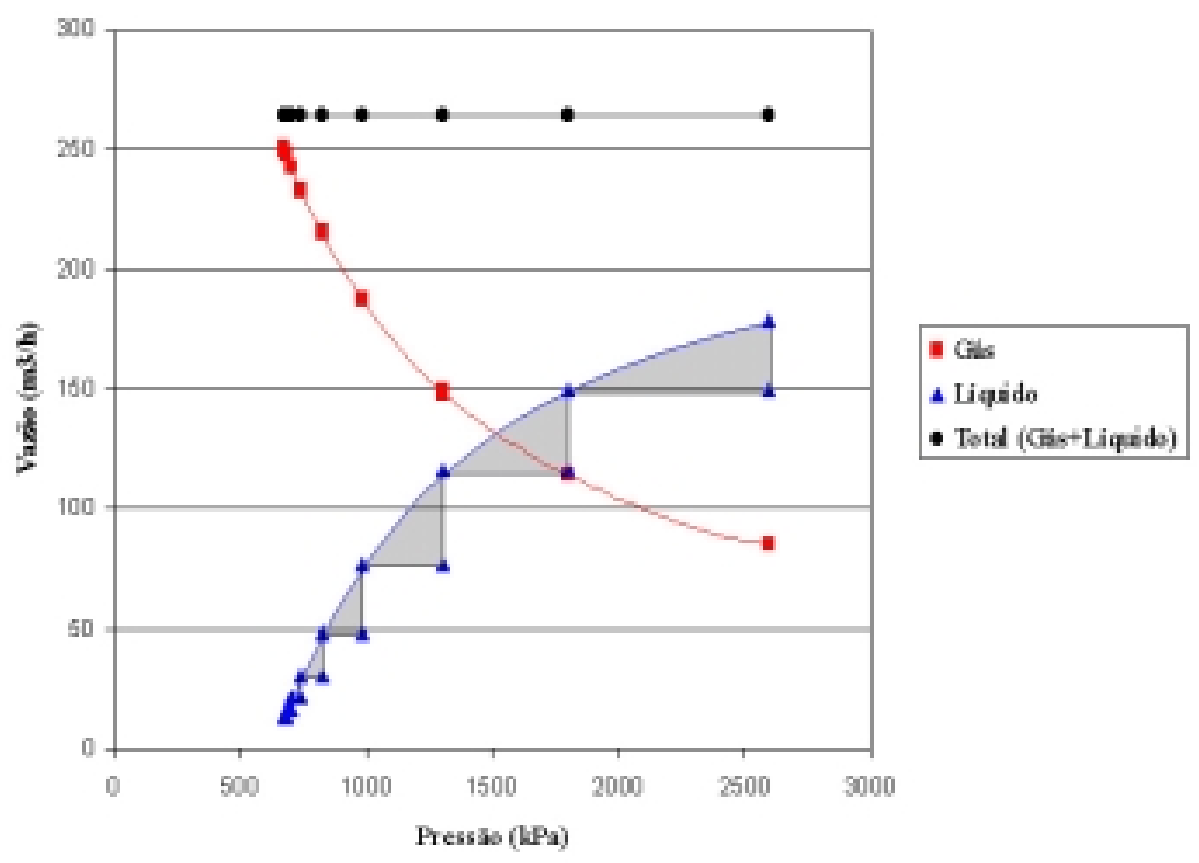

Fig. 4.9: Diagrama Pressão x Vazão Volumétrica obtido com dados do modelo para FVG=95\%. 


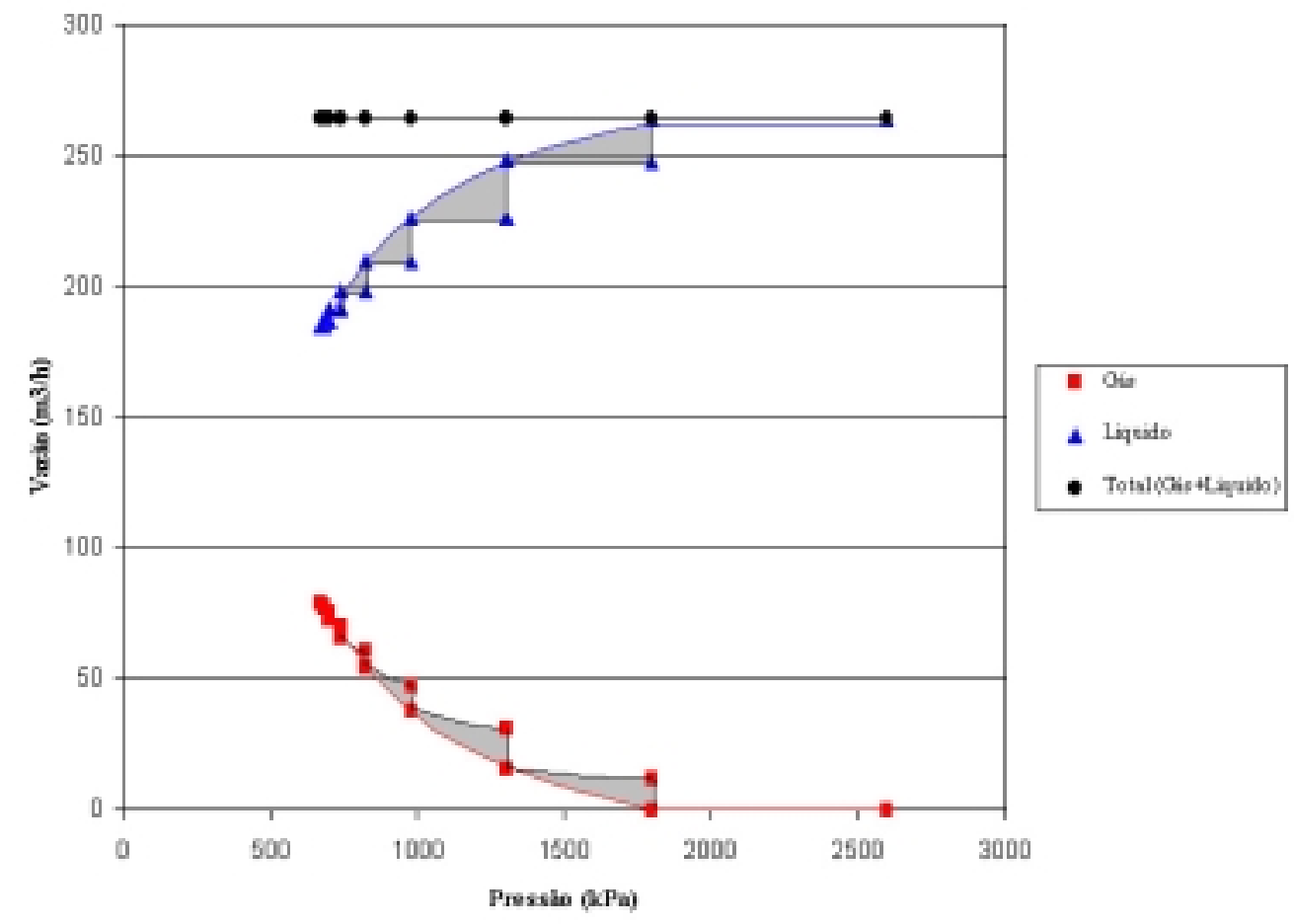

Fig. 4.10: Diagrama Pressão x Vazão Volumétrica obtido com dados do modelo para FVG=30\%.

compensar parte da potência de bombeamento, como pode ser visto na figura 4.10. Dessa forma a diferença para a potência teórica diminui para menores porcentagens de gás. Outro fator que contribui para a aproximação do valor teórico é que, quando o FVG é baixo, a variação do volume do gás com a pressão é menor, o que implica curvas mais próximas da horizontal no diagrama Pressão x Vazão. Comparando-se as figuras 4.9 e 4.10, pode-se perceber que, quanto mais horizontal for a curva, menor será o desvio (representado pelas áreas cinzas). No limite em que $\mathrm{FVG}=0$, não haveria diferença entre o processo real e a representação do modelo.

As tabelas 4.4 e 4.5 mostram a comparação entre a potência calculada e a teórica para cada um dos estágios do modelo. Nos dois casos o comportamento do modelo é semelhante. Nos primeiros estágios o desvio em relação à potência teórica é pequeno uma vez que os gradientes de pressão e, portanto, de volume, são pequenos. Nos 
estágios seguintes, onde há gradientes de pressão e volume crescentes, esse desvio aumenta progressivamente até que, nos últimos estágios, ele volta a diminuir já que nessa região a variação do volume com a pressão (ou seja, a compressibilidade do gás) é menor.

Tabela 4.4: Relação $\dot{W} / \dot{W}_{\text {teor }}$ para cada estágio do modelo em função do FVG ( $\left.p_{D}=2600 \mathrm{kPa}\right)$.

\begin{tabular}{cccccc}
\hline \multirow{2}{*}{ Estágio } & \multirow{2}{*}{$\Delta \mathrm{p}(\mathrm{kPa})$} & \multicolumn{4}{c}{$\mathrm{FVG}(\%)$} \\
\cline { 3 - 6 } & 10 & 1,0000 & 0,9983 & 0,9966 & 0,9938 \\
\hline $\mathbf{1}$ & 20 & 0,9998 & 0,9969 & 0,9932 & 0,9898 \\
\hline $\mathbf{2}$ & 40 & 1,0001 & 0,9939 & 0,9875 & 0,9802 \\
\hline $\mathbf{3}$ & 80 & 0,9999 & 0,9901 & 0,9790 & 0,9648 \\
\hline $\mathbf{4}$ & 160 & 1,0003 & 0,9858 & 0,9676 & 0,9432 \\
\hline $\mathbf{5}$ & 318 & 1,0001 & 0,9843 & 0,9589 & 0,9234 \\
\hline $\mathbf{6}$ & 500 & 1,0000 & 0,9925 & 0,9659 & 0,9303 \\
\hline $\mathbf{7}$ & 800 & 0,9999 & 1,0005 & 0,9738 & 0,9395 \\
\hline $\mathbf{8}$ & & & & & \\
\hline
\end{tabular}

Tabela 4.5: Relação $\dot{W} / \dot{W}_{\text {teor }}$ para cada estágio do modelo em função do FVG $\left(p_{D}=4528 \mathrm{kPa}\right)$.

\begin{tabular}{cccccc}
\hline \multirow{2}{*}{ Estágio } & \multirow{2}{*}{$\Delta \mathrm{p}(\mathrm{kPa})$} & \multicolumn{5}{c}{$\mathrm{FVG}$} \\
\cline { 3 - 6 } & & $\mathbf{0}$ & $\mathbf{3 0}$ & $\mathbf{6 0}$ & $\mathbf{9 5}$ \\
\hline $\mathbf{1}$ & 20 & 0,9998 & 0,9966 & 0,9930 & 0,9891 \\
\hline $\mathbf{2}$ & 40 & 1,0001 & 0,9937 & 0,9872 & 0,9798 \\
\hline $\mathbf{3}$ & 80 & 0,9999 & 0,9896 & 0,9783 & 0,9634 \\
\hline $\mathbf{4}$ & 160 & 1,0003 & 0,9852 & 0,9668 & 0,9405 \\
\hline $\mathbf{5}$ & 320 & 1,0003 & 0,9841 & 0,9575 & 0,9170 \\
\hline $\mathbf{6}$ & 636 & 0,9997 & 0,9907 & 0,9562 & 0,9070 \\
\hline $\mathbf{7}$ & 1000 & 0,9999 & 1,0002 & 0,9717 & 0,9295 \\
\hline $\mathbf{8}$ & 1600 & 1,0003 & 1,0003 & 0,9873 & 0,9458 \\
\hline
\end{tabular}

Os resultados até agora analisados indicam que a utilização de um número maior de estágios poderia diminuir a diferença existente entre a potência calculada pelo modelo e a potência teórica. $\mathrm{Na}$ figura 4.11, as áreas hachuradas mostram aproximadamente a diferença, para menos, que um número maior de estágios causaria, aproximando mais o modelo do comportamento teórico. De fato, os resultados obtidos 
com a utilização de 16 estágios aproximam-se mais da potência teórica como mostram as tabelas $4.6 \mathrm{a}$ e $4.6 \mathrm{~b}$.

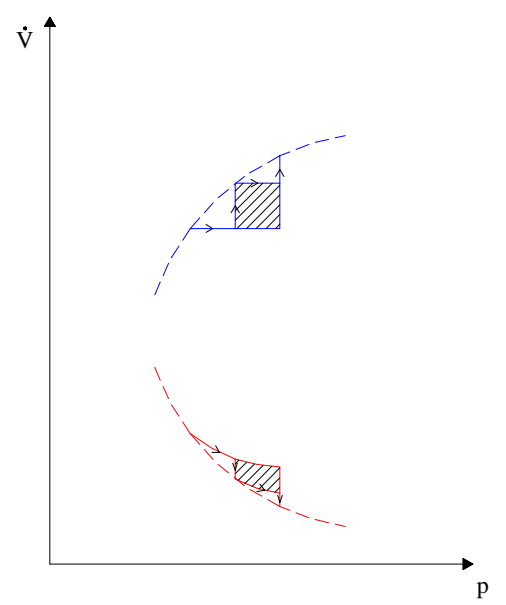

Fig. 4.11: Processos de compressão e bombeamento para um número de estágios maior.

Tabela 4.6: Comparação entre as potências consumidas pelo modelo com 8 e 16 estágios: a) FVG $=30 \%$; b) $\mathbf{F V G}=\mathbf{9 5 \%}$

a)

\begin{tabular}{ccc}
\hline No de estagios & $\dot{\mathbf{W}}$ & $\dot{\mathbf{W}} / \dot{\mathbf{W}}_{\text {teor }}$ \\
\hline 8 & 140,7 & 0,9936 \\
16 & 141,2 & 0,9972 \\
\hline
\end{tabular}

b)

\begin{tabular}{ccc}
\hline No de estagios & $\dot{\mathbf{W}}$ & $\dot{\mathbf{W}} / \dot{\mathbf{W}}_{\text {teor }}$ \\
& $(\mathrm{kW})$ & \\
\hline 8 & 132,7 & 0,9371 \\
16 & 138,4 & 0,9775 \\
\hline
\end{tabular}

\subsubsection{Efeito da eficiência das bombas e compressores do modelo}

No modelo construído no simulador, é necessário fornecer ao programa a eficiência isentrópica das bombas e compressores. Foi feito um estudo variando-se esses parâmetros para verificar sua influência no cálculo da potência e temperatura de descarga pelo modelo e, também, na eficiência exergética. Os resultados estão apresentados na tabela 4.7 . 
Tabela 4.7: Influência do rendimento das bombas e compressores no modelo $\left(P_{D}=2600 \mathrm{kPa}\right)$.

\begin{tabular}{c|c|c|c|c|c|c}
\hline \multicolumn{2}{c|}{ Eficiências Isoentrópicas } & $\dot{\mathbf{W}}_{\mathbf{b}}$ & $\dot{\mathbf{W}}_{\mathbf{c p}}$ & $\dot{\mathbf{W}}$ & $\boldsymbol{\eta}_{\mathbf{e x}}$ & $\mathbf{T}_{\mathbf{D}}$ \\
\hline $\begin{array}{c}\text { Bomba } \\
\%\end{array}$ & $\begin{array}{c}\text { Compressor } \\
\%\end{array}$ & \multicolumn{3}{|c}{$\mathrm{kW}$} & & ${ }^{\circ} \mathrm{C}$ \\
\hline \multirow{3}{*}{$\mathbf{1 0 0}$} & $\mathbf{1 0 0}$ & 59,5 & 73,2 & 132,7 & 0,54 & 52,6 \\
& $\mathbf{7 5}$ & 58,8 & 98,4 & 157,2 & 0,47 & 56,0 \\
& $\mathbf{5 0}$ & 57,4 & 150,0 & 207,4 & 0,38 & 63,1 \\
& $\mathbf{3 0}$ & 54,4 & 258,2 & 312,7 & 0,30 & 77,7 \\
\hline \multirow{3}{*}{$\mathbf{5 0}$} & $\mathbf{1 0 0}$ & 116,0 & 74,5 & 190,5 & 0,41 & 60,8 \\
& $\mathbf{7 5}$ & 114,6 & 100,0 & 214,6 & 0,38 & 64,2 \\
& $\mathbf{5 0}$ & 111,8 & 152,5 & 264,2 & 0,33 & 71,2 \\
& $\mathbf{3 0}$ & 106,2 & 262,0 & 368,2 & 0,28 & 85,1 \\
\hline \multirow{3}{*}{$\mathbf{3 0}$} & $\mathbf{1 0 0}$ & 187,3 & 76,0 & 263,3 & 0,33 & 70,9 \\
& $\mathbf{7 5}$ & 185,1 & 102,1 & 287,1 & 0,31 & 74,2 \\
& $\mathbf{5 0}$ & 180,5 & 155,4 & 335,9 & 0,29 & 80,8 \\
& $\mathbf{3 0}$ & 171,4 & 266,7 & 438,1 & 0,26 & 94,2 \\
\hline
\end{tabular}

Como esperado, o rendimento das bombas e compressores modificam bastante a potência calculada, a eficiência exergética e a temperatura de descarga. O rendimento menor que $100 \%$ representaria as perdas ocorridas no processo real, principalmente devido ao atrito viscoso, que aumentam o consumo de potência, reduzem a eficiência exergética e aumentam a temperatura do fluido.

A potência de compressão obtida pelo modelo com 100\% de eficiência, poderia ser utilizada no lugar das potências de compressão isotérmica e/ou adiabática utilizadas nos métodos de KARGE e de CHRISTIANSEN (apud WINCEK (1992)) para se avaliar o desempenho da bomba multifásica. A vantagem é que o processo de compressão, embora seja representado por uma seqüência de processos adiabáticos, não despreza a interação entre gás e líquiido e não considera o gás como ideal. A potência de compressão do modelo, portanto, não é a isotérmica nem a adiabática, mas transita entre elas conforme o FVG varia. Ela leva em conta o resfriamento provocado pelo líqüido sem, no entanto, idealizar esse processo e admitir que todo ou nenhum calor é 
absorvido. Para pequenas quantidades de líquiido, a potência de compressão se aproximaria da potência adiabática pois somente uma pequena parte do calor liberado seria absorvido pelo líqüido. Já para grandes quantidades de líqüido, a potência seria bem próxima da isotérmica devido à grande absorção de calor. Assim, aplicando-se a potência de compressão do modelo aos métodos de KARGE ou CHRISTIANSEN, chegar-se-á a resultados mais próximos da realidade.

\subsubsection{Efeito do perfil de pressão ao longo dos estágios}

Tendo em vista a falta de informações a respeito do desenvolvimento da pressão ao longo do parafuso da bomba multifásica, decidiu-se verificar o impacto que eventuais falhas na escolha do perfil de pressão para o modelo causariam nos cálculos feitos por ele. Foram realizados estudos para três perfis de pressão diferentes: o primeiro com gradiente crescente de pressão, o segundo com perfil de pressão linear e o terceiro com gradiente decrescente de pressão, como mostra a figura 4.12. Cada perfil foi utilizado na simulação de dois casos: para eficiência de bombas e compressores de $50 \%$ e de $100 \%$.

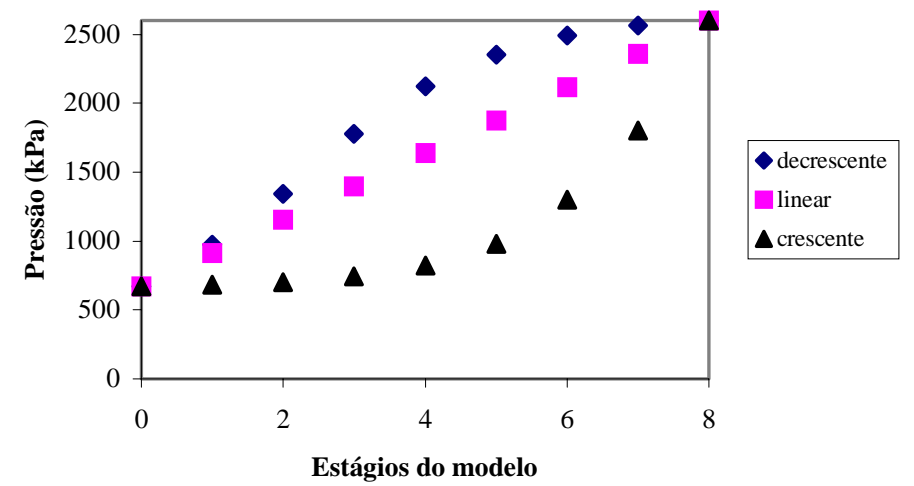

Fig. 4.12: Perfis de pressão utilizados nas simulações. 
Os resultados obtidos, exibidos nas tabelas $4.8 \mathrm{a}$ e $4.8 \mathrm{~b}$, mostram que mesmo grandes variações no perfil de pressão influenciam pouco os dados necessários para a análise exergética e termoeconômica do equipamento. As maiores oscilações encontradas foram de cerca de $3 \%$ para a potência calculada e a eficiência exergética, e de $1 \%$ para a temperatura de descarga. Assim, não é necessário que o modelo tenha o mesmo perfil de pressão da bomba multifásica real para que a represente adequadamente. Isso faz com que informações exatas da pressão ao longo da bomba sejam desnecessárias para a construção do modelo.

Tabela 4.8: Efeito do perfil de pressão nas simulações do modelo: a) $\eta=100 \%$; b) $\eta=50 \%$

a)

\begin{tabular}{lccc}
\hline Perfil de pressão & $\begin{array}{c}\dot{\mathbf{W}} \\
(\mathrm{kW})\end{array}$ & $\boldsymbol{\eta}_{\mathbf{e x}}$ & $\begin{array}{c}\mathbf{T}_{\mathbf{D}} \\
\left({ }^{\circ} \mathrm{C}\right)\end{array}$ \\
\hline Crescente & 132,7 & 0,54 & 52,6 \\
Linear & 135,9 & 0,53 & 52,7 \\
Decrescente & 133,4 & 0,54 & 52,4 \\
\hline
\end{tabular}

b)

\begin{tabular}{lccc}
\hline Perfil de pressão & $\begin{array}{c}\dot{\mathbf{W}} \\
(\mathrm{kW})\end{array}$ & $\eta_{\mathbf{e x}}$ & $\begin{array}{c}\mathbf{T}_{\mathbf{D}} \\
\left({ }^{\circ} \mathrm{C}\right)\end{array}$ \\
\hline Crescente & 264,2 & 0,33 & 71,2 \\
Linear & 271,3 & 0,32 & 71,9 \\
Decrescente & 265,9 & 0,32 & 71,1 \\
\hline
\end{tabular}

O fato do perfil de pressão praticamente não influir no comportamento do modelo (para o cálculo da potência e eficiência exergética) ocorre pois, seja qual for a distribuição de pressão utilizada no modelo, ela estará representando o mesmo processo, embora pontos diferentes dele. As figuras 4.13 e 4.14 ajudam a esclarecer isso. As duas figuras mostram o desenvolvimento da pressão ao longo da bomba multifásica e do modelo. Na figura 4.13, entretanto, o modelo tem uma distribuição linear de pressão e, 
na figura 4.14, uma distribuição com gradientes crescentes. Pode-se ver que, embora os dois casos estejam representando o mesmo processo, os pontos geométricos correspondentes na bomba multifásica são diferentes. Um modelo com uma distribuição com gradientes crescentes representaria pontos do parafuso que são eqüidistantes (figura 4.14), enquanto que uma distribuição linear representaria os pontos do parafuso mostrados na figura 4.13. Em outras palavras, não existe problema em se escolher uma distribuição linear no modelo, ainda que este esteja representando uma condição na qual

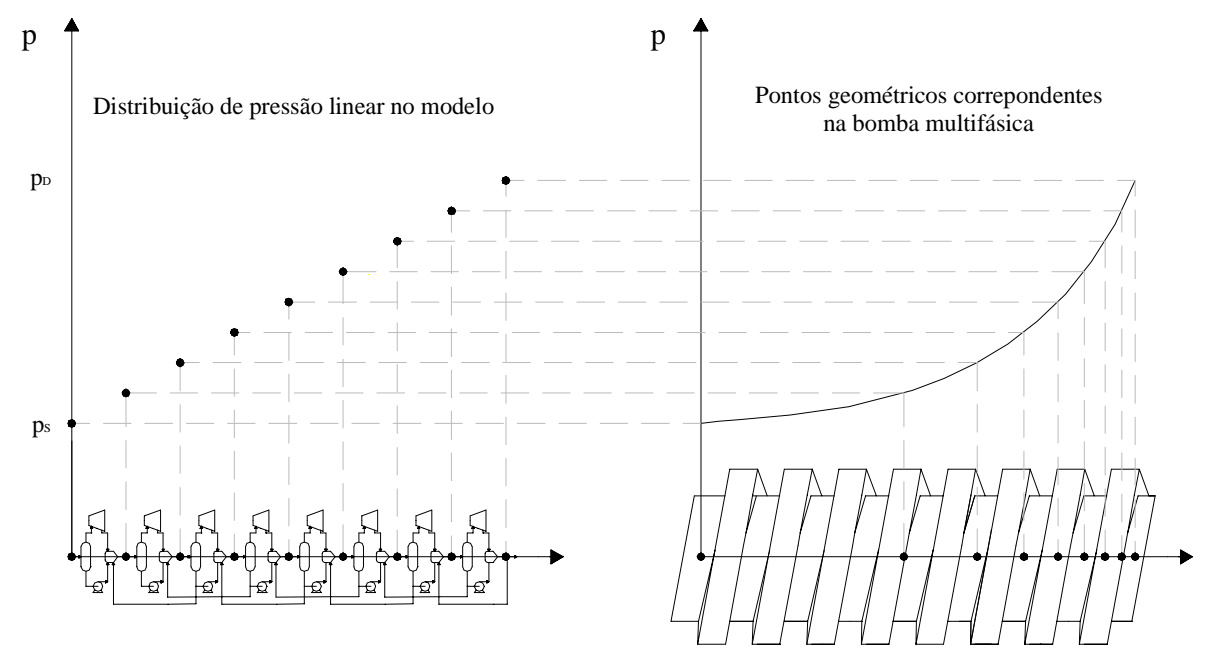

Fig. 4.13: Significado da distribuição linear de pressão no modelo.

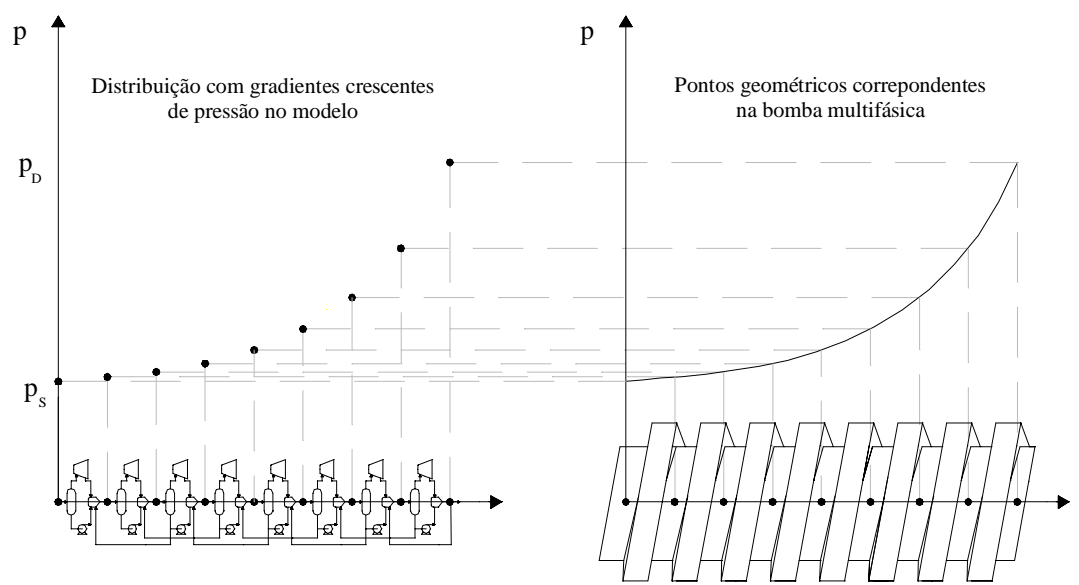

Fig. 4.14: Significado da distribuição de pressão com gradiente crescente. 
a bomba multifásica tem um perfil de pressão com gradientes crescentes. A distribuição linear do modelo não significa que ele esteja representando uma bomba multifásica com perfil linear de pressão, mas, sim, que ele está simulando os pontos da bomba em que o processo atingiu aquela pressão, como mostra a figura 4.13 .

No início dos estudos, foi dito que se desejava obter uma correspondência entre as câmaras da bomba multifásica e os estágios do modelo, daí a escolha da distribuição crescente para o modelo (figura 4.14). No entanto, com os resultados agora obtidos, essa correspondência revela-se pouco importante para a análise exergética. Como será visto a seguir, apenas para o cálculo das vazões de recirculação é que o perfil é relevante.

\subsection{Modelagem das perdas de uma bomba multifásica real}

De acordo com os resultados obtidos no item 4.2, o modelo é capaz de representar, com alguns pequenos desvios, o comportamento ideal da bomba multifásica. Ou seja, o modelo, quando trabalha com eficiência de bombas e compressores de $100 \%$, está simulando uma bomba de duplo parafuso na qual não há nem atrito viscoso, nem a vazão de refluxo. Isso, no entanto, não é suficiente para a avaliação da bomba real. O modelo, para representar a bomba multifásica, deve levar em conta as perdas por atrito viscoso e o refluxo que faz com que a vazão seja menor que a teórica. Somente assim a potência calculada pelo modelo e a temperatura de descarga do fluxo, para uma dada condição de operação, seriam representativas da realidade. Portanto, para que o modelo simule o comportamento real da bomba multifásica, é necessário ajustar a eficiência das bombas e compressores e, também, a vazão de refluxo (recirculação entre a primeira câmara e a sucção) que não havia sido considerada até o momento. 


\subsubsection{Refluxo}

O refluxo da bomba multifásica é dado pelo vazamento que ocorre, através das fendas, entre a primeira câmara e a região de sucção. Na literatura foram encontrados dois métodos que podem ser utilizados no cálculo do refluxo. No método de EGASHIRA et al. (1996), propõe-se que a relação entre a diferença de pressão das câmaras e a velocidade média do escoamento através das fendas seja dada por uma equação ${ }^{4}$ utilizada em cálculos de escoamentos através de fendas:

$$
\Delta p=\frac{\rho v^{2}}{2}\left(\frac{\lambda l}{2 s}+1,5\right)
$$

O termo da direita corresponde à soma dos valores 1,0 e 0,5 relacionados, respectivamente, à perda de carga localizada na entrada e na saída da fenda devido à presença de cantos vivos. Essa equação seria utilizada para as três fendas já definidas para bombas parafuso, embora as equações específicas para cada fenda não tenham sido descritas no artigo. No trabalho, é sugerida a utilização, para o cálculo do fator de atrito no regime laminar, da fórmula para fendas planas $(\lambda=64 / \mathrm{Re})$ ao invés da equação para fendas anulares. Para o regime turbulento, sugere-se a utilização da equação de Blasius para tubos lisos $\left(\lambda=0,316 / \operatorname{Re}^{0,25}\right)$.

A diferença de pressão adimensional seria dada em função do comprimento adimensional como mostra a equação 4.2, proposta a partir de resultados experimentais:

$$
\Pi=\Lambda^{\gamma} \Rightarrow\left(\frac{p_{i}-p_{s}}{p_{d}-p_{s}}\right)=\left(\frac{i}{N_{B M}+1}\right)^{\gamma}
$$

O parâmetro $\gamma$ será 1,0 para escoamento apenas de líqüido e aumenta com a compressibilidade do fluido devido à presença do gás.

\footnotetext{
${ }^{4} \mathrm{Na}$ equação original, aparece o termo $4 \mathrm{~m}$ no lugar do termo $2 \mathrm{~s}$ no denominador dentro dos parênteses. No entanto, m é definido como metade da altura média da fenda, ou seja, $\mathrm{m}=\mathrm{s} / 2$ e a equação pode ser escrita dessa forma.
} 
O problema deste método é que ele não considera o refluxo provocado pela rotação do eixo. Para escoamentos de líquiido ou de fluidos de baixo FVG, essa parcela realmente é pouco importante. Para fluidos com alto FVG, no entanto, a vazão devido à rotação passa a ser importante pois a diferença de pressão na região de sucção é menor. Além disso, nenhuma correlação para o fator $\gamma$ foi proposta, sendo esse fator ajustado para que a curva se aproximasse da melhor forma aos resultados experimentais. Dessa forma os cálculos teóricos dependem da coleta prévia de dados experimentais.

O método de WINCEK (1992) é bem mais detalhado tanto por considerar o efeito da rotação do eixo, como por desenvolver equações específicas para cada uma das fendas. Para as três fendas, considera-se que a vazão volumétrica total através de cada uma é dividida em duas parcelas: uma provocada pela diferença de pressão entre as câmaras e outra pela rotação do eixo, indicadas, respectivamente, pelos subscritos $d p$ e $r$. WINCEK (1992), no entanto, não considerou as perdas de carga localizadas sendo que, neste trabalho, modificou-se algumas das equações originais de forma a incluir tais perdas. As equações ${ }^{5}$ para cada tipo de fenda são apresentadas a seguir juntamente com as equações modificadas e efetivamente utilizadas no trabalho. Também foram incluídas as equações para escoamento turbulento liso, não consideradas por WINCEK (1992).

\section{a) Fenda Periférica:}

A vazão volumétrica total através da fenda periférica é dada por:

$$
\dot{V}_{P}=\dot{V}_{P, d p}+\dot{V}_{P, r}=(w+u \cdot \operatorname{sen} \alpha) A_{P}
$$

Onde

$$
A_{P}=s_{P} l_{P}, l_{P}=\frac{\pi-\beta}{\pi} \sqrt{s t^{2}+\left(D_{e} \pi\right)^{2}} \text { e } \beta=\operatorname{arcos} a / D_{e}
$$

\footnotetext{
${ }^{5}$ A nomenclatura utilizada foi adaptada para este trabalho, não sendo, necessariamente, igual à de WINCEK (1992).
} 
dependem de parâmetros geométricos do parafuso como mostra a figura 4.15, e $w$ e $u$ são as componentes da velocidade devidas à diferença de pressão e à rotação, respectivamente.
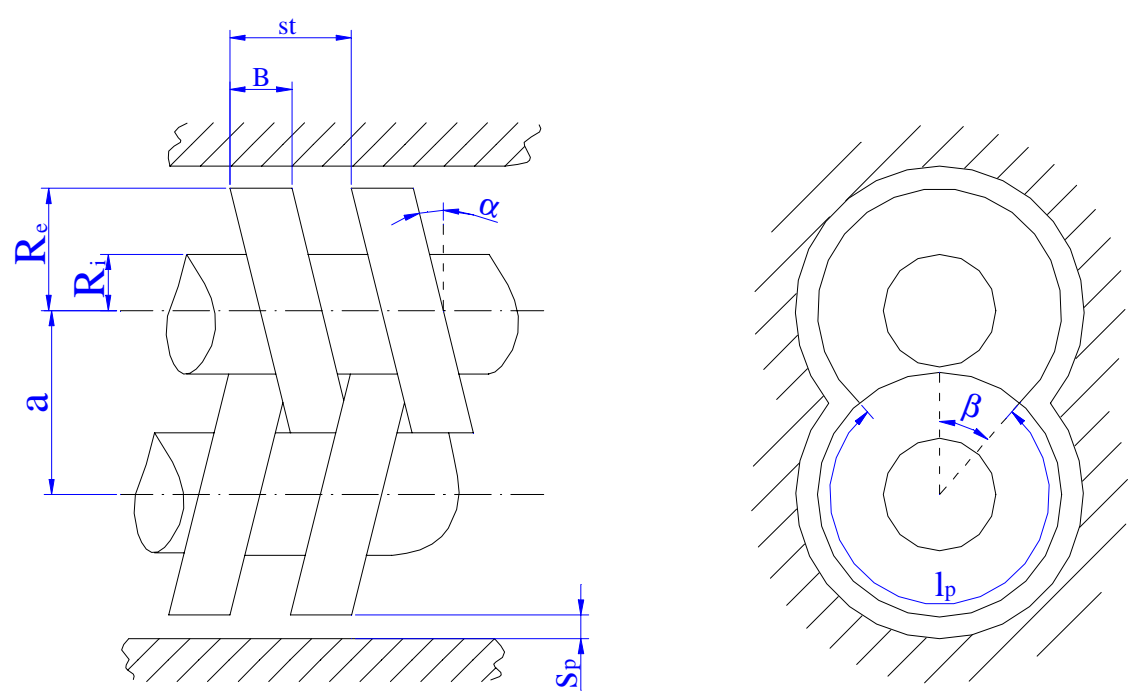

Fig. 4.15: Parâmetros geométricos para o calculo do refluxo através da fenda periférica.

Segundo WINCEK (1992), a componente $w$ é dada por:

$$
w=\sqrt{\frac{4 \Delta p \cdot s_{P}}{B \cdot \rho_{l} \cdot \lambda}}
$$

Onde o coeficiente de atrito é dado por:

$$
\lambda=\frac{96}{R e}
$$

para escoamento laminar ou

$$
\lambda=\frac{0,3322}{\operatorname{Re}^{0.25}}
$$

para escoamento turbulento liso ou

$$
\frac{1}{\sqrt{\lambda}}=2,00 \cdot \log \frac{2 s_{P}}{k}+0,97
$$


para escoamento turbulento rugoso em fendas anulares. Sendo que, para o escoamento turbulento, o autor sugere a utilização da equação para escoamento turbulento rugoso.

Considerando-se as perdas localizadas, a equação 4.7 ficaria:

$$
w=\sqrt{\frac{2 \Delta p}{\rho_{l}\left(\frac{\lambda \cdot B}{2 . s_{P}}+1,5\right)}}
$$

Substituindo-se a equação 4.8 na equação 4.11 , tem-se, para escoamento laminar:

$$
w=\frac{\sqrt{\left(\frac{24 B \cdot \mu_{l}}{s_{P}{ }^{2}}\right)^{2}+12 \rho_{l} \Delta p}-\frac{24 B \cdot \mu_{l}}{s_{P}{ }^{2}}}{3 \rho_{l}}
$$

Para escoamento turbulento liso, tem-se:

$$
0,1396 \cdot B \cdot\left(\frac{\mu_{l}}{\rho_{l} \cdot s_{P}^{5}}\right)^{0.25} w^{1.75}+1,5 w^{2}-\frac{2 \Delta p}{\rho_{l}}=0
$$

E, para escoamento turbulento rugoso:

$$
w=\sqrt{\frac{2}{\left(\frac{\lambda \cdot B}{2 s_{P}}+1,5\right) \frac{\Delta p}{\rho_{l}}}}
$$

Onde $\lambda$ é constante e dado pela equação 4.10.

A componente devida à rotação é dada por:

$$
u=\frac{D_{i}^{2} \varpi}{2\left(D_{e}-D_{i}\right)}\left[\ln \left(\frac{D_{e}}{D_{i}}\right) \cdot\left(1+\frac{D_{e}^{2}}{D_{e}^{2}-D_{i}^{2}}\right)-\frac{1}{2}\right]
$$

b) Fenda radial:

A vazão volumétrica total através da fenda radial é dada por:

$$
\dot{V}_{R}=\dot{V}_{R, d p}+\dot{V}_{R, r}
$$




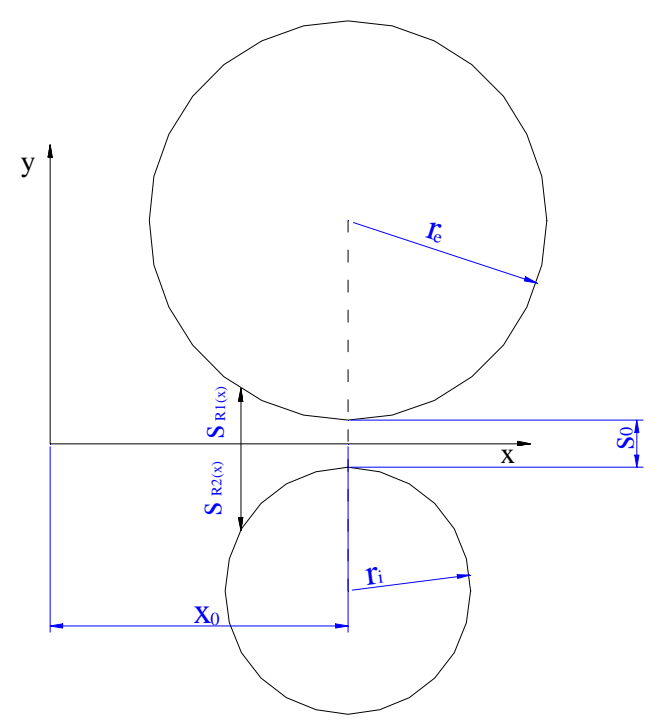

Fig. 4.16: Parâmetros geométricos para o cálculo do refluxo através da fenda radial (WINCEK (1992)).

A componente da diferença de pressão é dada por:

$$
\dot{V}_{R, d p}=\frac{B \cdot \Delta p}{12 \mu_{l} \int_{0}^{2 x_{o}} \frac{1}{s_{R}(x)^{3}} d x}
$$

para escoamento laminar ou

$$
\dot{V}_{R, d p}=4,709 \frac{B}{\left(\int_{0}^{2 x_{o}} \frac{1}{s_{R}(x)^{3}} d x\right)^{4 / 7}}\left(\frac{\Delta p^{4}}{\mu_{l} \rho^{3}}\right)^{1 / 7}
$$

para escoamento turbulento liso ou

$$
\dot{V}_{R, d p}=\frac{2 B \sqrt{\Delta p}}{\sqrt{\rho_{l} \int_{0}^{2 x_{o}} f(x) d x}}, f(x)=\frac{s_{R}(x)^{3}}{\left(2,00 \cdot \log \frac{2 s_{R}(x)}{k}+0,97\right)^{2}}
$$

para escoamento turbulento rugoso.

A espessura da fenda $s_{R}(x)$ é calculada a partir do raios interno e externo do parafuso, como a seguir: 


$$
s_{R}(x)=s_{R 1}(x)+s_{R 2}(x)=R_{e}+R_{i}+s_{o}-\sqrt{R_{e}^{2}-\left(x-x_{o}\right)^{2}}-\sqrt{R_{i}^{2}-\left(x-x_{o}\right)^{2}}
$$

No caso da fenda radial, não faz sentido utilizar os termos para a perda de carga localizada devido à ausência de cantos vivos.

A componente devida à rotação é dada por:

$$
\dot{V}_{R, r}=\frac{\varpi\left(R_{e}-R_{i}\right)}{2} B \cdot s_{o}
$$

c) Fenda de flanco:
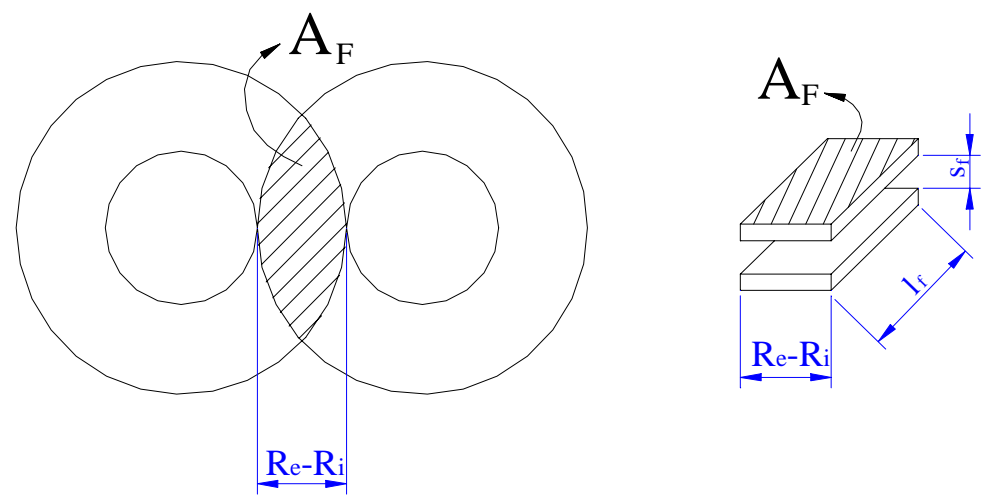

Fig. 4.17: Parâmetros geométricos para o cálculo do refluxo através da fenda de flanco (WINCEK (1992)).

Segundo WINCEK (1992), a vazão volumétrica na fenda de flanco é dada por:

$$
\dot{V}_{F}=\dot{V}_{F, d p}+\dot{V}_{F, r}
$$

A componente da diferença de pressão é dada por:

$$
\dot{V}_{F, d p}=\frac{\left(R_{e}-R_{i}\right)}{2} \sqrt{\frac{4 s_{F}^{3} \Delta p}{\lambda \cdot l_{F} \cdot \rho_{l}}}
$$

Com $\lambda$ dado pelas equações 4.8 e 4.10 para escoamento laminar e turbulento rugoso respectivamente. Para o cálculo dessa componente, utiliza-se um comprimento de fenda fictício como mostra a figura 4.17. Ele é definido como o comprimento de um 
retângulo que teria a mesma largura $\left(R_{e}-R_{i}\right)$ e área $\left(A_{F}\right)$ que a fenda de flanco. É dado por $^{6}$ :

$$
l_{F}=\frac{R_{e}^{2}}{R_{e}-R_{i}}(2 \beta-\operatorname{sen} 2 \beta)
$$

Com a inclusão das perdas localizadas, no entanto, a vazão devida à diferença de pressão será dada por:

$$
\dot{V}_{F, d p}=A_{F} \cdot v=\left(R_{e}-R_{i}\right) \cdot l_{F} \cdot v
$$

Onde $v$, de maneira análoga à fenda periférica, é dada por:

$$
v=\frac{\sqrt{\left(\frac{24 l_{F} \mu_{l}}{s_{F}{ }^{2}}\right)^{2}+12 \rho_{l} \cdot \Delta p}-\frac{24 l_{F} \mu_{l}}{s_{F}{ }^{2}}}{3 \rho_{l}}
$$

para escoamento laminar ou:

$$
0,1328 \cdot l_{F}\left(\frac{\mu_{l}}{\rho_{l} \cdot s_{F}{ }^{5}}\right)^{0.25} v^{1.75}+1,5 v^{2}-\frac{2 \Delta p}{\rho_{l}}=0
$$

para escoamento turbulento liso ou

$$
v=\sqrt{\frac{2}{\left(\frac{\lambda \cdot l_{F}}{2 s_{F}}+1,5\right)} \frac{\Delta p}{\rho_{l}}}
$$

para escoamento turbulento rugoso.

A componente devida à rotação é dada por:

$$
\dot{V}_{F, r}=\frac{\varpi a}{2}\left(R_{e}-R_{i}\right) s_{F}
$$

Somando-se as vazões volumétricas de todas as fendas, chega-se à equação para a vazão de refluxo. Para parafusos duplos e gêmeos, tem-se:

\footnotetext{
${ }^{6}$ A equação do comprimento equivalente é, originalmente, diferente desta. Esta, no entanto, é uma forma mais simples de se escrever a mesma equação.
} 


$$
\dot{V}_{\text {Rec total }}=\dot{4 V}_{P}+2 \dot{V}_{R}+2 \dot{V}_{F}
$$

Inicialmente, parte-se de um perfil de pressão linear. Uma vez que o modelo tenha convergido para este perfil, verifica-se a vazão volumétrica na entrada de cada estágio do modelo. Se essa vazão, que é a soma da vazão de líqüido que recircula mais a vazão (gás + líqüido) proveniente do estágio anterior, for igual à vazão teórica, então mantém-se a pressão do estágio. Caso contrário, se a vazão resultante for maior ou menor que a vazão teórica, corrige-se a pressão do estágio para ajustar a vazão volumétrica do estágio. Um aumento da pressão diminui a vazão volumétrica no estágio pois reduz-se o volume específico do gás e o acúmulo de liqüido devido à diminuição da diferença de pressão com o estágio posterior e o aumento da diferença com o estágio anterior. Já a diminuição da pressão do estágio tem efeito contrário. A pressão corrigida é encontrada resolvendo-se a seguinte equação:

$$
\dot{V}_{g a ́ s, d}+\dot{V}_{R e c, d}=\dot{V}_{g a ́ s, s}
$$

Ou seja, a soma da vazão volumétrica do gás com a vazão de recirculação em um determinado estágio, após a correção de pressão, deve ser igual à vazão de gás na sucção. Dessa forma garante-se que a redução da vazão do gás seja compensada exatamente pela corrente de recirculação analogamente como ocorre na bomba real.

Admitindo-se que não haja variação da temperatura antes e depois da correção da pressão, a equação 4.32 fica:

$$
\dot{V}_{g a ́ s, a} \frac{p_{i, a}}{p_{i, d}}+\dot{V}_{R e c, d}=V_{g a ́ a s, s}
$$

Sendo que a vazão de recirculação, dada pela equação 4.31 varia em função de $\Delta \mathrm{p}\left(\Delta \mathrm{p}=\mathrm{p}_{\mathrm{i}+1}-\mathrm{p}_{\mathrm{i}, \mathrm{d}}\right)$. Considerando-se fixa a pressão do estágio posterior ao que se está 
calculando $\left(\mathrm{p}_{\mathrm{i}+1}\right)$, pode-se variar a pressão $\mathrm{p}_{\mathrm{i}, \mathrm{d}}$, utilizando-se o método da dicotomia, para encontrar a solução da equação 4.33 .

Inicialmente, a hipótese de variação isotérmica antes e depois da correção não é válida. No entanto, conforme a pressão aproxima-se do ponto de convergência, as mudanças, tanto da pressão quanto da temperatura, são de amplitudes cada vez menores e essa hipótese passa a valer. A correção das pressões dos estágios é feita até que a vazão volumétrica ao longo do modelo seja constante e igual à da sucção.

\subsubsection{Eficiência das bombas e compressores}

Como dito anteriormente, a eficiência das bombas e compressores do modelo devem representar as perdas que ocorrem devido ao atrito viscoso. Portanto, deve-se calcular a potência de atrito para se estabelecer a eficiência.

As perdas do lado do gás, devido à sua baixa viscosidade, são mínimas frente às perdas ocorridas do lado do líqüido. Dessa forma, será adotada uma eficiência de $100 \%$ para os compressores. O cálculo da potência de atrito no lado do líqüido será dividido em duas partes: perdas na região periférica, $\dot{E}_{P}$, e no canal do parafuso, $\dot{E}_{c}$, como pode ser visto na figura 4.18. Admite-se que a potência de atrito na região de

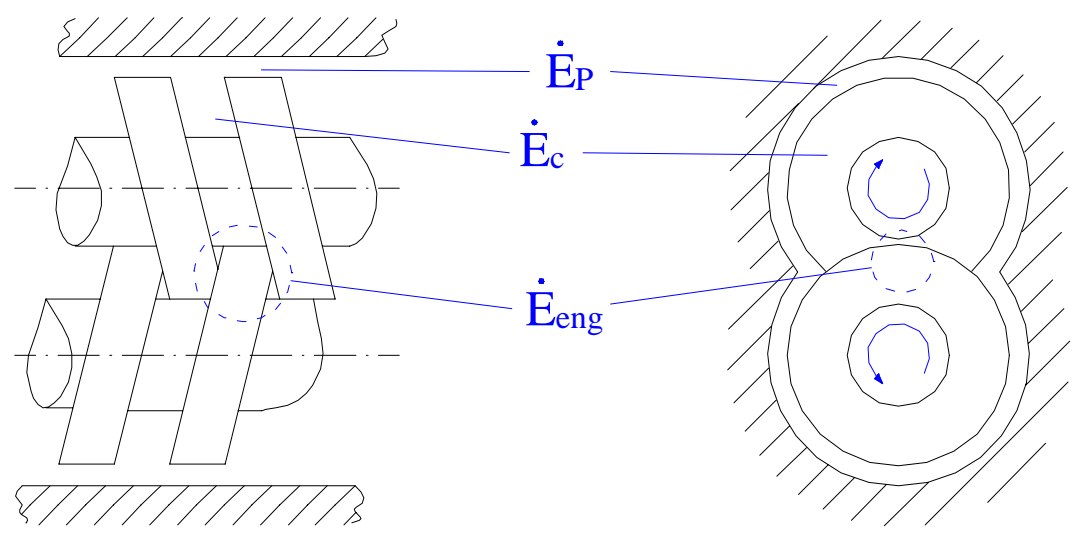

Fig. 4.18: Potência de atrito nas diversas regiões da bomba multifásica. 
engrenamento, $\dot{E}_{\text {eng }}$ é pequena já que, nessa região, a direção e o sentido da velocidade tangencial nos dois parafusos é aproximadamente o mesmo, reduzindo os gradientes de velocidade e a tensão de cisalhamento nas fendas (radial e de flanco) dessa região.

A teoria da lubrificação fornece a potência de atrito na região periférica devido à rotação do fuso, que, para o volume de controle mostrado na figura 4.19, é dado por:

$$
\dot{E}_{P, r}=\frac{8(\pi-\beta) \pi^{2} R_{e}^{3} B \mu_{l} n^{2}}{s_{P}}
$$

A parte devido à translação pode ser calculada a partir da figura 4.19, admitindo fluido newtoniano.

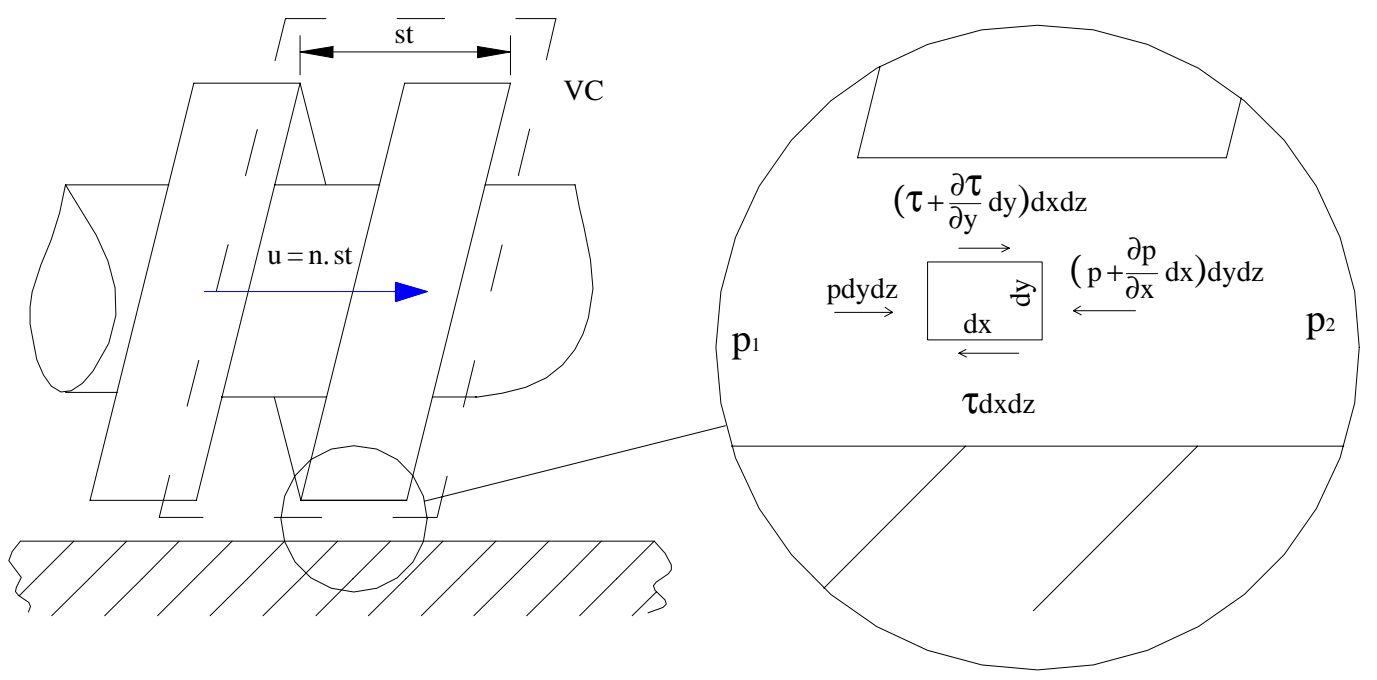

Fig. 4.19: Balanço de forças na região periférica.

Fazendo-se o balanço de forças no elemento infinitesimal mostrado no detalhe da figura 4.19, tem-se:

$$
p d y d z+\left(\tau+\frac{\partial \tau}{\partial y} d y\right) d x d z-\tau d x d z-\left(p+\frac{d p}{d x} d x\right) d y d z=0
$$

Como a tensão de cisalhamento é dada por: 


$$
\tau=\mu_{l} \frac{\partial u}{\partial y}
$$

Pode-se encontrar $\tau$ :

$$
\tau=\frac{d p}{d x} y+\frac{\mu_{l} n \cdot s t}{s_{P}}-\frac{s_{P}}{2} \frac{d p}{d x}
$$

A tensão de cisalhamento no parafuso pode ser encontrada fazendo-se:

$$
y=s_{P} \Rightarrow \tau=\frac{s_{P}}{2} \frac{d p}{d x}+\frac{\mu_{l} n \cdot s t}{s_{P}}=\frac{s_{P} \Delta p}{2 B}+\frac{\mu_{l} n \cdot s t}{s_{P}}
$$

Assim, a potência de atrito devido à translação será dada por:

$$
\dot{E}_{P, t}=A \cdot \tau \cdot n \cdot s t=2(\pi-\beta) R_{e} B \cdot n \cdot s t\left(\frac{s_{P} \Delta p}{2 B}+\frac{\mu_{l} n \cdot s t}{s_{P}}\right)
$$

O cálculo da potência de atrito no canal não é tão simples quanto na região periférica. O cálculo da tensão de cisalhamento só seria possível através da resolução numérica da equação de Navier-Stokes em três dimensões. Tal método inviabilizaria o modelo uma vez que a carga computacional aumentaria demais. Também o modelo ficaria limitado a uma determinada geometria do canal, sendo necessário refazer todos os cálculos para uma geometria diferente. Para ser aplicado ao modelo, o cálculo da potência de atrito no canal deve ser simples de modo que a mudança de parâmetros como condições de operação, geometria do canal e propriedades do líqüido sejam computados rapidamente.

MICHAELI e GREFENSTEIN (1995) estudaram extrusores de parafuso duplo e sugeriram a seguinte expressão para calcular a parte devida ao movimento do fluido dentro do canal:

$$
\dot{E}_{c}=\frac{2 k_{f}-1}{\operatorname{sen} \alpha} \mu_{c} \Delta l \int_{-h(x)}^{0} \int_{x_{\varepsilon}}^{W / 2}\left(\dot{\gamma}^{2}(x, y)\right) d x d y
$$


Sendo que a variável $x_{\varepsilon}$ indica o grau de preenchimento do canal e $\mathrm{h}(\mathrm{x})$ representa a sua geometria, como mostra a figura 4.20a. A razão $\Delta l / \operatorname{sen} \alpha$ representa o comprimento do trecho do canal em se deseja calcular a potência de atrito.

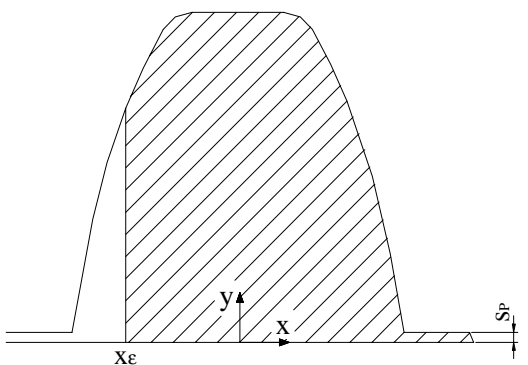

(a)

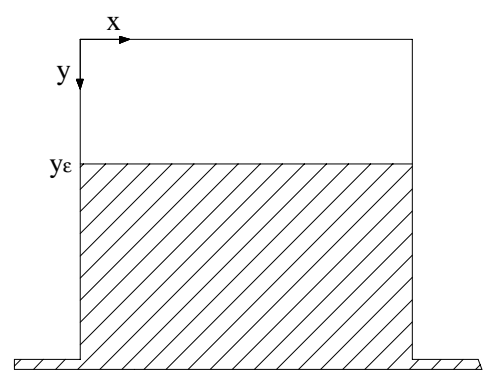

(b)

Fig. 4.20: (a) Seção transversal do canal (MICHAELI e GREFENSTEIN (1995)). (b) Adaptação do grau de preenchimento para a bomba multifásica parafuso.

Segundo MICHAELI e GREFENSTEIN (1995), a taxa de cisalhamento, simplificada para este caso, é dada por:

$$
\dot{\gamma}(x, y)=\sqrt{\left(\frac{\partial u}{\partial y}\right)^{2}+\left(\frac{\partial w}{\partial x}\right)^{2}+\left(\frac{\partial w}{\partial y}\right)^{2}}
$$

No caso da bomba multifásica, a equação 4.39 deve ser modificada uma vez que o preenchimento do canal dá-se de forma diferente e o sistema de eixos ortogonais é deslocado para o fundo do canal como mostra a figura 4.20b. O novo sistema de eixos é usado para que haja compatibilidade com as equações para o perfil de velocidades apresentadas a seguir. Assim a equação para a potência de atrito no canal ficará:

$$
\dot{E}_{c}=\frac{2 k-1}{\operatorname{sen} \alpha} \mu_{l} \Delta l \int_{y_{\varepsilon}}^{H} \int_{0}^{W}\left(\dot{\gamma}^{2}(x, y)\right) d x d y
$$

O fator $y_{\varepsilon}$ representa a região preenchida por gás e é calculado a partir do FVG:

$$
y_{\varepsilon}=R_{e}-\sqrt{R_{i}^{2}+F V G\left(R_{e}^{2}-R_{i}^{2}\right)}
$$


CAMPBELL et al. (1996) calcularam as velocidades $u$ e $w$ para o canal de uma bomba ou extrusor de parafuso simples. Eles aproximaram o canal como sendo um canal retangular, sem curvatura, como mostra a figura 4.21. Admitindo regime permanente, fluxo bi-dimensional na direção $z$, baixo número de Reynolds e que velocidades em função de x e y, chegaram às seguintes equações para as velocidades:

$$
\begin{gathered}
u=u_{o}\left(1+\frac{H}{R_{i}}\right) \frac{y}{H}\left(2-3 \frac{y}{H}\right)+u_{o}\left(1+\frac{y}{R_{i}}\right) \\
w=w_{o}\left(1+\frac{H}{R_{i}}\right) \frac{4}{\pi} \sum_{i=1,3,5}^{\infty} \frac{\operatorname{senh}(i \pi h \xi)}{i \operatorname{senh}(i \pi h)} \operatorname{sen}(i \pi \chi)-u_{o}\left(1+\frac{y}{R_{i}}\right)
\end{gathered}
$$

onde:

$$
\begin{gathered}
H=R_{e}-R_{i}, h=H / W, \xi=y / H, \chi=x / W, \\
u_{o}=-\varpi R_{i} \cos \alpha \text { e } w_{o}=-\varpi R_{i} \operatorname{sen} \alpha
\end{gathered}
$$

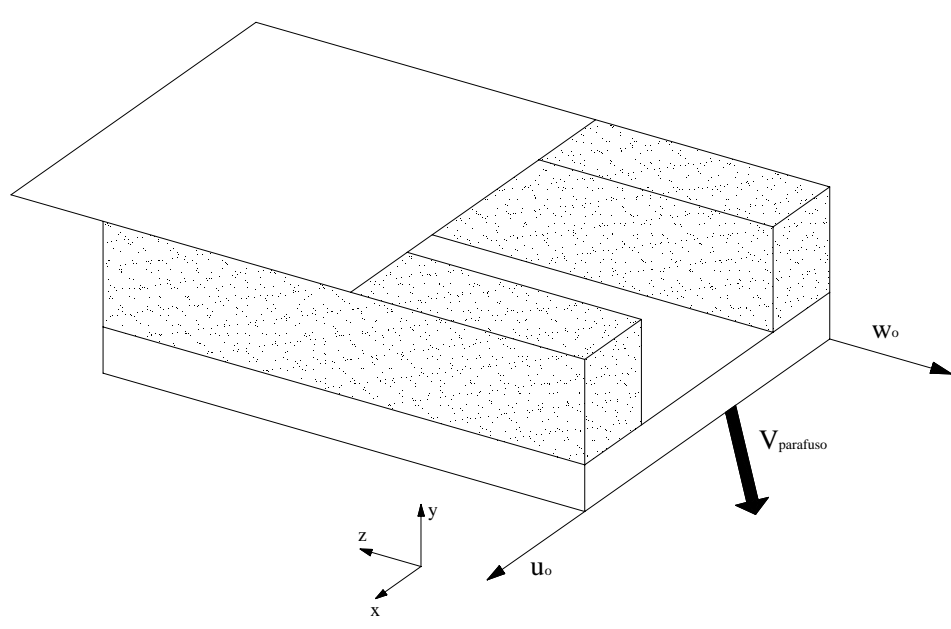

Fig. 4.21: Canal do parafuso (adaptado de CAMPBELL et al. (1998))

As equações acima (4.40 a 4.51) foram desenvolvidas no estudo de extrusores parafusos em que o fluxo pode ser considerado bidimensional na direção z. No caso da bomba de duplo parafuso, devido ao engrenamento que bloqueia completamente o 
canal, isso não é verdade. No entanto, segundo HONG e WHITE (1998), o escoamento no canal pode ser dividido em duas regiões (figura 4.22). A região I, onde as características do escoamento são as mesmas dos equipamentos de parafuso simples, e a região II, de engrenamento, onde isso não é verdade. Assim, pode-se esperar que o cálculo da potência de atrito através desse método (equações 4.41 a 4.45), embora não seja exato, consiste em uma aproximação, subestimando apenas a potência na região II.

Utilizando-se as velocidades 4.44 e 4.45 , pode-se calcular a integral da taxa de cisalhamento da equação 4.42 (conforme a dedução apresentada no apêndice I) e, portanto, a potência de atrito no canal.

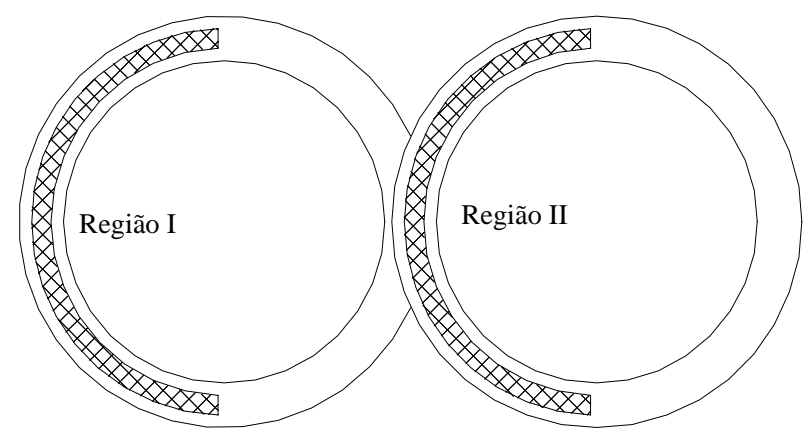

Fig. 4.22: Divisão do parafuso em duas regiões distintas para análise do escoamento (adaptado de HONG e WHITE (1998)).

Uma vez tendo calculado as potências de atrito, a eficiência das bombas do modelo será dada pela razão entre a potência teórica e a potência total:

$$
\eta_{B}=\frac{\dot{V} \Delta p}{\dot{V} \Delta p+\dot{E}_{P}+\dot{E}_{c}}
$$

Atribuindo-se a eficiência às bombas e compressores, o modelo calculará a potência realmente consumida. Se o FVG for elevado, então a maior parte da vazão passará pelos compressores e a potência se aproximará da teórica. Conforme o FVG 
diminui, a potência de atrito aumenta e a eficiência se aproximará da eficiência de uma bomba de duplo parafuso comum.

\subsection{Considerações sobre o número de estágios do modelo}

Como foi visto antes no item 4.2.1, um número maior de estágios no modelo poderia melhorar os resultados calculados pelo modelo uma vez que isto diminuiria os efeitos da divisão do processo. No entanto, àquela altura, o perfil de pressão era fixo e não eram calculados nem a potência de atrito nem as correntes de recirculação que eram simplesmente fixadas de forma a manter-se constante a vazão volumétrica ao longo da bomba, em função do perfil de pressão adotado. Com a introdução das modificações do item 4.3, algumas observações devem ser feitas ao se aumentar o número de estágios.

No cálculo do refluxo através das equações de WINCEK (1992), a vazão volumétrica deve representar o acúmulo de líqüido que ocorre durante a movimentação da câmara entre dois pontos. A figura 4.23 mostra o deslocamento de uma câmara entre dois pontos. Durante o deslocamento de uma câmara entre os pontos 1 e 2 a vazão de recirculação é considerada no modelo como sendo constante. O tempo de deslocamento gasto entre esses dois pontos é dado por:

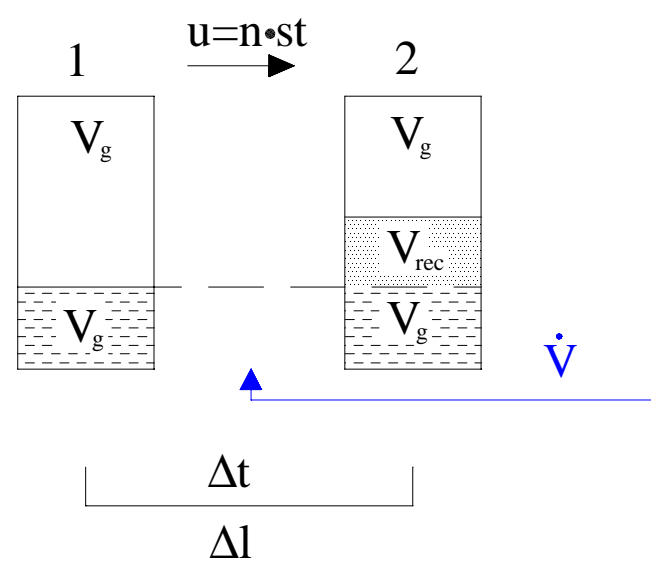

Fig. 4.23: Acúmulo de líqüido devido à recirculação. 


$$
\Delta t=\frac{\Delta l}{u}=\frac{\Delta l}{n \cdot s t}
$$

Com a vazão de recirculação, $\dot{V}$ no desenho, pode-se calcular o volume de líqüido acumulado na câmara:

$$
V_{\text {rec }}=\dot{V} \Delta t=\dot{V} \frac{\Delta l}{n \cdot s t}
$$

Assim, a vazão de líqüido que recircula será dada por:

$$
\dot{V}_{r e c}=n V_{r e c}=n \dot{V} \frac{\Delta l}{n \cdot s t}=\dot{V} \frac{\Delta l}{s t}
$$

O deslocamento $\Delta l$ é dado em função do número de estágios que se escolhe para o modelo:

$$
\Delta l=\frac{L}{N_{m}}
$$

Onde $N_{m}$ é o número de estágios do modelo.

Como o passo pode ser escrito em função do número de câmaras da bomba $\left(N_{b m}\right):$

$$
s t=\frac{L}{N_{B M}}
$$

A vazão de recirculação corrigida fica:

$$
\dot{V}_{r e c}=\dot{V} \frac{N_{B M}}{N_{m}}
$$

Portanto, o valor calculado pela equação de WINCEK (1992) deve ser corrigido como mostra a equação 4.58. Se o número de estágios do modelo e da bomba forem idênticos, o fator de correção será 1 e não se modifica a vazão calculada. Caso o número de estágios seja diferente, então a correção terá efeito. 
Além dessa correção na vazão de recirculação, deve-se observar que, para um número maior de estágios do modelo a conexão das correntes de recirculação e as pressões utilizadas no seu cálculo dão-se de outra forma. No caso, por exemplo, de se utilizar um modelo com o dobro de número de estágios da bomba para representá-la, então cada dois estágios do modelo representam uma câmara ou, melhor, dois instantes de seu movimento como mostra a figura 4.24. Se a corrente de recirculação ligasse dois estágios consecutivos do modelo ( $\mathrm{p}_{\mathrm{A} 2}-\mathrm{p}_{\mathrm{A} 1}$, por exemplo), como foi feito no caso de número igual de estágios da bomba e do modelo, ela estaria representando uma recirculação da primeira para a primeira câmara, o que não é possível. Portanto, como o

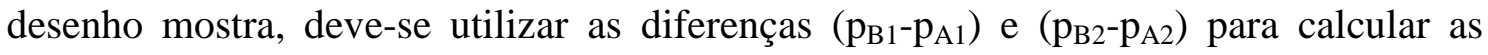
vazões que representarão a recirculação da câmara B para a câmara A em dois instantes diferentes, com as correntes de recirculação conectando dois estágios consecutivos, como na figura 4.2. As conexões devem ser modificadas como mostra a figura 4.24. Na realidade, ao se colocar o dobro de estágios em seqüência, sem levar em conta as modificações citadas, estar-se-ia simplesmente simulando uma bomba com o dobro do
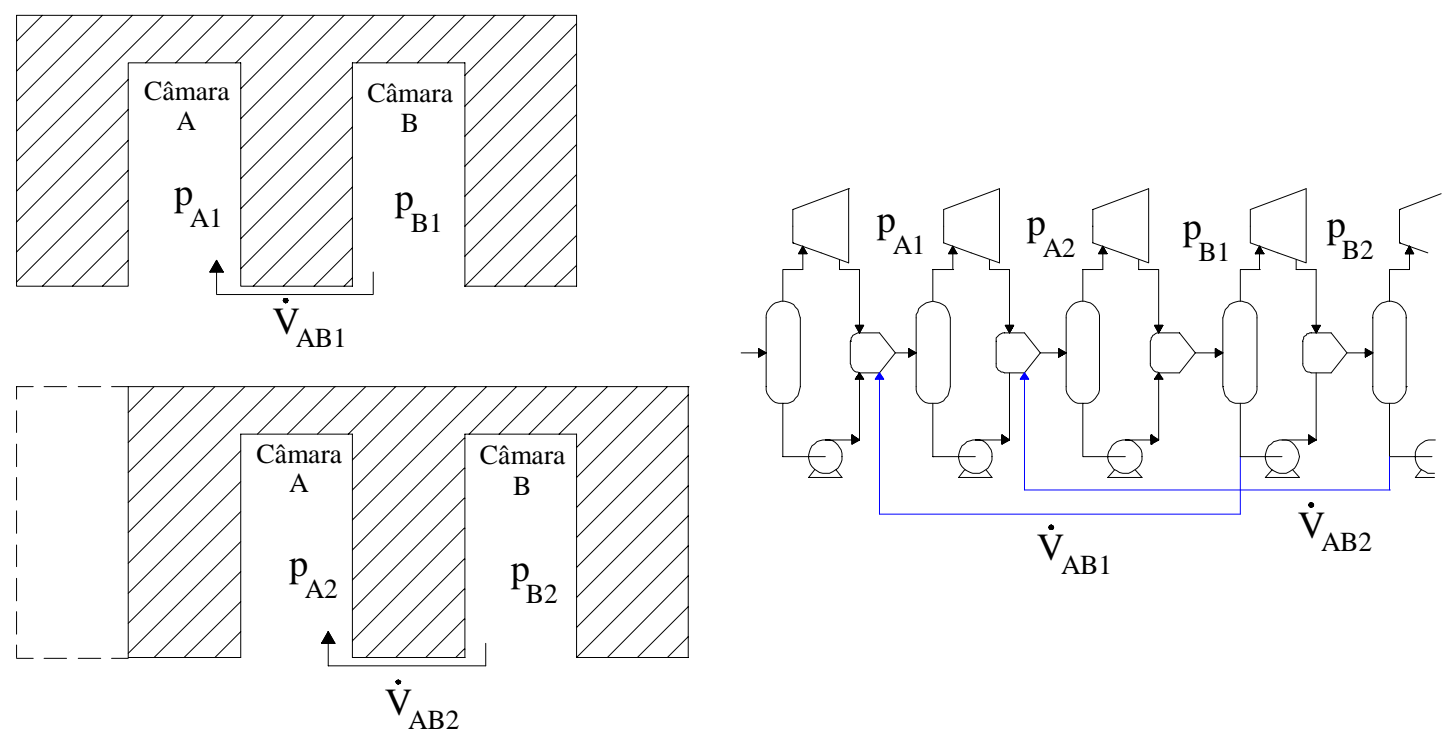

Fig. 4.24: Modelo com número de estágios igual ao dobro do número de câmaras da bomba. 
comprimento da bomba que se desejaria simular. Uma conseqüência direta dessas observações é que o modelo deve sempre ter um número de estágios múltiplo do número de câmaras da bomba.

As equações para a potência de atrito do capítulo 4.3 foram desenvolvidas para apenas um estágio de uma bomba de duplo parafuso, ou seja, para um volume de controle de largura igual a um passo (st) da bomba (ver figura 4.19). Se forem usados um número maior de estágios, as equações para as potências de atrito devem ser corrigidas multiplicando-as pelo fator $N_{B M} / N_{m}$ que corrige a largura do volume de controle já que, nesse caso, um estágio do modelo não corresponde mais a uma câmara da bomba.

Uma última e importante observação a ser feita é que, após as modificações introduzidas no capítulo 4.3, o aumento do número de estágios melhora apenas um pouco os resultados fornecidos pelo modelo. Isso ocorre pois a diferença de pressão entre o último estágio do modelo e a descarga sempre será grande. A última câmara só atinge a pressão de descarga quando se abre para a descarga e o modelo também representa esse aumento instantâneo de pressão no último estágio. Dessa forma a divisão do processo como foi visto na figura 4.11 é, para o último estágio, inviável. Como o aumento de pressão no último estágio é grande, fazendo com que contribua com a maior parcela da diferença entre a potência teórica e a calculada, a utilização de mais estágios revela-se, na realidade, pouco vantajosa principalmente quando o número de câmaras da bomba de duplo parafuso é grande.

Uma forma de contornar esse problema do último estágio seria alterar o método de calcular a potência total consumida pelo modelo. Ao invés de considerar a soma das potências das bombas e compressores para calcular a potência que seria consumida pela bomba multifásica, utiliza-se o modelo para calcular a potência de atrito apenas. A 
potência total seria dada pela soma da potência teórica $(\dot{V} \cdot \Delta p)$ com a potência de atrito. Essa abordagem, que é utilizada no item 4.5, elimina o problema da diferença entre a potência teórica da bomba e do modelo e abre espaço para a inclusão, no futuro, da eficiência politrópica de compressão.

\subsection{Comparação e discussão dos resultados}

Após a inclusão das modificações do item 4.3 no modelo (ver Apêndice II para detalhes do modelo completo) comparou-se os resultados fornecidos pelo modelo com dados experimentais publicados na literatura. As comparações de potência consumida e temperatura de descarga foram feitas utilizando-se os dados da TEXACO (1993). Já os dados de EGASHIRA et al. (1996) foram utilizados para comparar o perfil de pressão e o refluxo da bomba. Os resultados são discutidos nos itens 4.5.1 e 4.5.2.

\subsubsection{Refluxo e perfil de pressão}

EGASHIRA et al. (1996) trabalharam com misturas água-ar para estudar o comportamento de uma bomba multifásica parafuso com três câmaras. A bomba tem a mesma configuração normalmente utilizada nas bombas multifásicas, ou seja, parafusos duplos e gêmeos. Além de medições de vazão e temperatura, também fizeram um levantamento detalhado do perfil de pressão ao longo da bomba para diversas condições de operação, embora não tenham medido a potência consumida. Os estudos foram feitos para rotações variando entre 1200 e $1800 \mathrm{rpm}$, diferenças de pressão de até $2942 \mathrm{kPa}$ (30 kgf/ $\mathrm{cm}^{2}$ ) e FVG's de até 90\%. Os dados geométricos (EGASHIRA (2000) ${ }^{7}$ ) estão na tabela 4.9. O número de câmaras da bomba é de três em um parafuso e duas em outro como mostra o esquema da figura 4.25.

\footnotetext{
${ }^{7}$ Correspondência eletrônica pessoal.
} 
Tabela 4.9: Parâmetros geométricos da bomba multifásica estudada por EGASHIRA (2000) ${ }^{7}$.

\begin{tabular}{lc}
\hline \multicolumn{1}{c}{ Parâmetro } & Valor \\
\hline Diâmetro externo $\left(10^{-3} \mathrm{~m}\right)$ & 179,73 \\
\hline Diâmetro interno $\left(10^{-3} \mathrm{~m}\right)$ & 99,89 \\
\hline Distância entre eixos $\left(10^{-3} \mathrm{~m}\right)$ & 140,02 \\
\hline $\begin{array}{l}\text { Largura axial do filete do } \\
\text { parafuso }\left(10^{-3} \mathrm{~m}\right)\end{array}$ & 17,765 \\
\hline Largura de uma câmara $\left(10^{-3} \mathrm{~m}\right)$ & 18,115 \\
\hline $\begin{array}{l}\text { Altura das fendas }\left(10^{-3} \mathrm{~m}\right): \\
-\quad \text { periférica e radial }\end{array}$ & 0,21 \\
$-\quad$ flanco & 0,18 \\
\hline
\end{tabular}

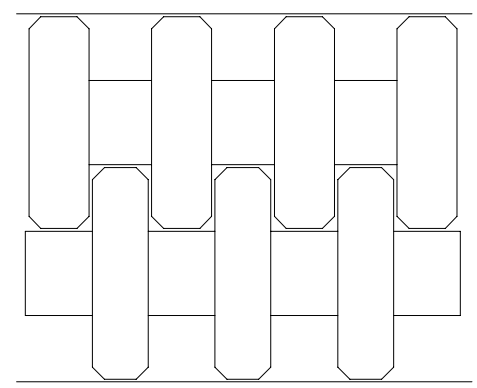

Fig. 4.25: Desenho esquemático da bomba multifásica.

A vazão volumétrica teórica da bomba nesse caso, calculada a partir dos parâmetros geométricos, em $\mathrm{m}^{3} / \mathrm{h}$, é dada por:

$$
\dot{V}_{\text {teor }}=4 \cdot s t \cdot n\left(A_{t r}-A_{F}\right)=6,23 \times 10^{-2} n
$$

Onde $A_{t r}$ é a área da seção transversal do parafuso:

$$
A_{t r}=\pi\left(R_{e}^{2}-R_{i}^{2}\right)
$$

Para a comparação com os valores de vazão de refluxo do modelo, utilizou-se os dados experimentais da tabela 4.10 obtidos por EGASHIRA et al. (1996). Considerouse, para os cálculos do modelo, uma composição molar de $79 \%$ de $\mathrm{N}_{2}$ e $21 \%$ de $\mathrm{O}_{2}$ para o ar. 
Tabela 4.10: Dados experimentais utilizados para a comparação com o modelo (EGASHIRA et al. (1996)).

\begin{tabular}{|c|c|c|c|c|c|c|c|c|c|c|}
\hline Ensaio & & & Teste 1 & Teste 2 & Teste 3 & Teste 4 & Teste 5 & Teste 6 & Teste 7 & Teste 8 \\
\hline \multirow{10}{*}{$\begin{array}{l}\text { Condições de } \\
\text { operação }\end{array}$} & FVG & $\%$ & 61 & 88 & 60 & 90 & 59 & 91 & 64 & 90 \\
\hline & $\Delta \mathrm{p}$ & $\mathrm{kPa}$ & 2932,2 & 2932,2 & 2932,2 & 2922,4 & 2932,2 & 2932,2 & 970,9 & 970,9 \\
\hline & Rotação & $\mathrm{rpm}$ & 1205 & 1205 & 1205 & 1205 & 1805 & 1804 & 1206 & 1205 \\
\hline & $\mathrm{p}_{\mathrm{s}}$ & $\mathrm{kPa}$ & 137,3 & 147,1 & 441,3 & 441,3 & 117,7 & 107,9 & 304,0 & 294,2 \\
\hline & $\dot{\mathrm{V}}_{\mathrm{ar}, \mathrm{S}}$ & $\mathrm{m}^{3} / \mathrm{h}$ & 22,0 & 32,5 & 16,1 & 27,2 & 62,4 & 101,4 & 45,7 & 44,6 \\
\hline & $\dot{\mathrm{V}}_{\text {agua, } \mathrm{S}}$ & $\mathrm{m}^{3} / \mathrm{h}$ & 14,2 & 4,6 & 10,6 & 3,1 & 43,1 & 10,3 & 25,9 & 4,9 \\
\hline & $\dot{\mathrm{V}}_{\mathrm{ar}, \mathrm{D}}$ & $\mathrm{m}^{3} / \mathrm{h}$ & 1,7 & 2,6 & 2,6 & 4,5 & 4,4 & 7,0 & 13,5 & 13,1 \\
\hline & $\dot{\mathrm{V}}_{\text {agua }, \mathrm{D}}$ & $\mathrm{m}^{3} / \mathrm{h}$ & 14,2 & 4,6 & 10,6 & 3,1 & 43,1 & 10,3 & 25,9 & 4,9 \\
\hline & $\mathrm{T}_{\mathrm{S}}$ & ${ }^{\circ} \mathrm{C}$ & 21,3 & 25,7 & 35,2 & 42,0 & 21,0 & 32,7 & 16,5 & 21,0 \\
\hline & $\mathrm{T}_{\mathrm{D}}$ & ${ }^{\circ} \mathrm{C}$ & 24,3 & 36,2 & 39,3 & 55,1 & 22,0 & 40,1 & 16,8 & 24,5 \\
\hline
\end{tabular}


Inicialmente, EGASHIRA et al. (1996) verificaram o refluxo da bomba trabalhando apenas com água. A figura 4.26 a seguir, adaptada de EGASHIRA et al. (1996), mostra a variação da vazão volumétrica de refluxo, para várias velocidades do eixo, em função da diferença de pressão entre sucção e descarga. Como EGASHIRA et al. (1996) e WINCEK (1992) sugerem equações diferentes para o cálculo do fator de atrito na região turbulenta (respectivamente liso e rugoso), e como divergem na utilização ou não dos coeficientes de perda de carga localizadas, decidiu-se comparar os resultados investigando as duas propostas.

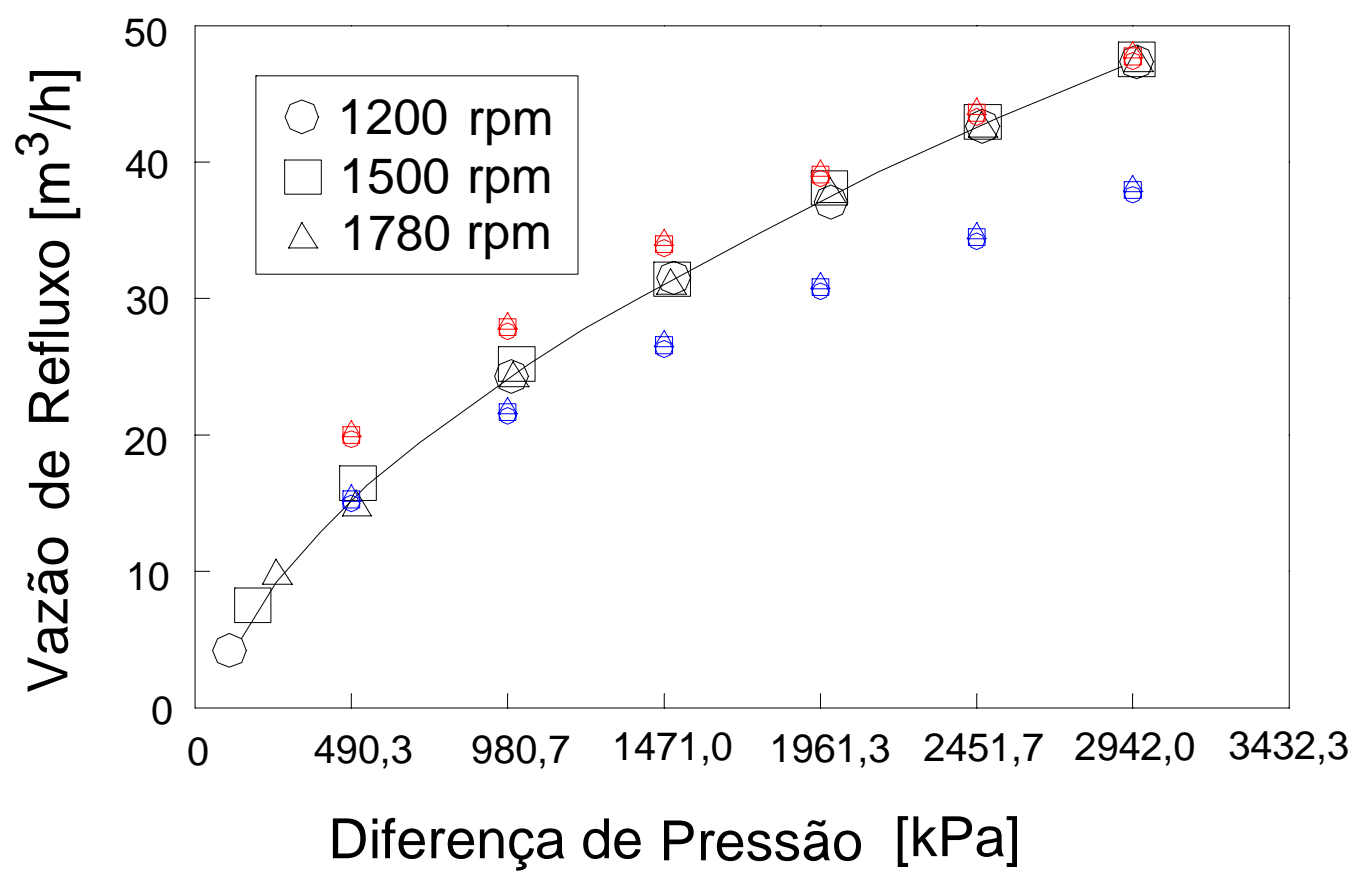

Fig. 4.26: Relação experimental entre refluxo e diferença de pressão (adaptado de EGASHIRA (1996)) para água e resultados da simulação utilizando equações para escoamento turbulento liso (em azul) e turbulento rugoso (em vermelho).

Os pontos em preto, cuja tendência é mostrada pela linha contínua, indicam as medições experimentais feitas. Os dados foram apresentados apenas em gráfico e os valores exatos não estão disponíveis. Sobre o gráfico de EGASHIRA et al. (1996) foram 
colocados os valores obtidos através da simulação do modelo. Os pontos em azul abaixo dos dados experimentais mostram os valores obtidos com as equações $4.13,4.18$ e 4.28 para escoamento turbulento liso com o coeficiente 1,5 de perda de carga localizada. Os pontos em vermelho acima da curva experimental são os valores calculados utilizandose as equações $4.14,4.19$ e 4.29 para escoamento turbulento rugoso sem perdas localizadas. Para esses cálculos, utilizou-se uma rugosidade de $4,0 \times 10^{-6} \mathrm{~m}$ igual à do eixo da bomba ensaiada pela TEXACO (1993). Os valores obtidos, nos dois casos, aproximam-se dos valores experimentais embora em nenhum caso os valores coincidam completamente. Para a faixa de pressões investigada, os valores obtidos com as equações de WINCEK (1992) aproximam-se mais dos valores experimentais. No entanto, observando-se os valores do número de Reynolds envolvidos no escoamento através da fenda periférica, pode-se perceber que a suposição de escoamento turbulento rugoso não é compatível com as curvas que descrevem o comportamento do coeficiente de atrito, como mostra a figura 4.27.

Na figura 4.27, a linha pontilhada inferior indica a curva para escoamento turbulento liso e a superior, o limite a partir do qual tem-se escoamento turbulento rugoso. A região entre as duas linhas tracejadas é a região de transição. Com a bomba trabalhando com água apenas, para as diferenças de pressão variando de 490 a 3432 kPa, o número de Reynolds na fenda periférica variou de 4000 a 11500. Considerandose a rugosidade estimada de $4,0 \times 10^{-6} \mathrm{~m}$, pode-se ver no gráfico 4.27 que a curva do coeficiente de atrito mostrada pela linha vermelha segue, nas condições de operação estudadas, a curva para escoamento turbulento liso havendo apenas um pequeno desvio quando o número de Reynolds aproxima-se de 11500. Apenas para número de Reynolds acima de $10^{5}$ é que a hipótese de escoamento turbulento rugoso seria válida e tal condição seria atingida apenas para diferenças de pressão entre duas câmaras muito 


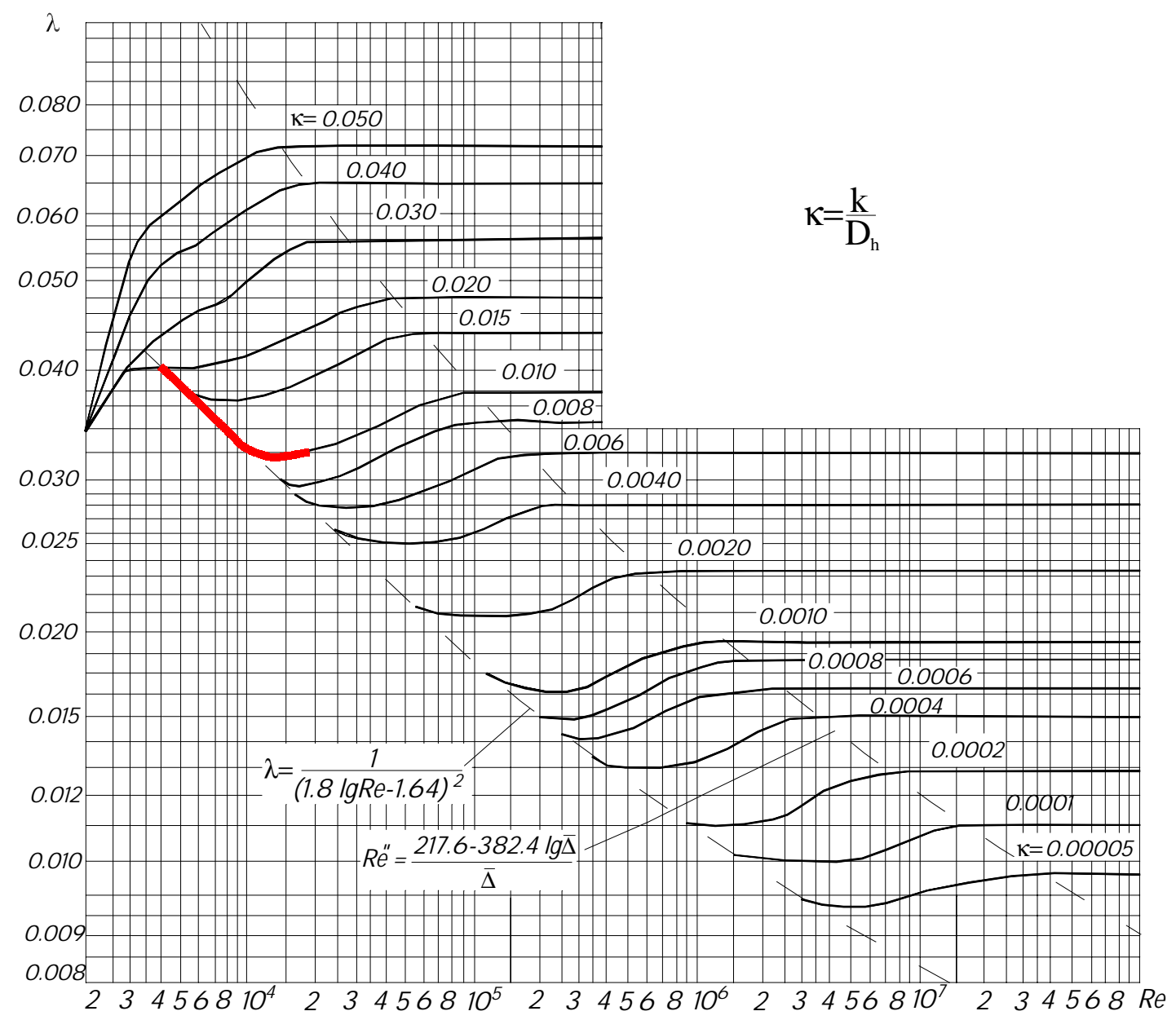

Fig. 4.27: Diagrama de coeficiente de atrito para tubos circulares com rugosidade uniforme (IDELCHIK (1994)).

elevadas, da ordem de $10^{7} \mathrm{~Pa}$. Portanto, segundo os resultados obtidos, a hipótese utilizada por WINCEK (1992) de escoamento turbulento rugoso dificilmente seria válida. As condições do escoamento encontram-se nas regiões turbulenta lisa e de transição. Nesse caso, a hipótese de EGASHIRA et al. (1996) aproxima-se mais da realidade, embora o ideal fosse utilizar também as equações para a região de transição o que asseguraria uma concordância com a realidade inclusive para casos em que a rugosidade fosse grande ou para baixas diferenças de pressão $(\operatorname{Re}<4000)$ entre duas câmaras. 
Segundo EGASHIRA et al. (1996), os dados experimentais indicam que a rotação da bomba não influencia a vazão de refluxo. Isso, no entanto, não é verdade. A rotação contribui para a vazão de refluxo embora, na bomba analisada, tal contribuição seja realmente muito pequena frente à parcela da vazão provocada pela diferença de pressão. Devido às características da bomba (três câmaras apenas) ensaiada por eles, a diferença de pressão entre a primeira câmara e a sucção é grande e, aliada à baixa viscosidade do líqüido, causa uma vazão elevada. Dessa forma a variação da vazão provocada pela mudança na rotação da bomba, que na simulação variou aproximadamente $0,6 \mathrm{~m}^{3} / \mathrm{h}$ quando a rotação passou de 1200 para $1780 \mathrm{rpm}$, fica imperceptível como mostram os dados simulados no gráfico 4.26. Mesmo a vazão total $\left(1,73 \mathrm{~m}^{3} / \mathrm{h}\right.$ para $\left.1780 \mathrm{rpm}\right)$ é pouco expressiva diante dos valores totais da vazão de refluxo. Porém, quando a vazão provocada pela diferença de pressão cai, e diversos motivos podem provocar isso: maior número de câmaras, maior viscosidade do fluido e escoamento de fluido multifásico, a vazão devida à rotação passa a ser importante e as observações feitas por EGASHIRA et al. (1996) não seriam mais válidas.

As figuras 4.28 a 4.35 abaixo mostram a comparação dos perfis de pressão medidos experimentalmente (ensaios da tabela 4.10) por EGASHIRA et al. (1996) e os valores calculados pelo modelo. Os dados experimentais foram apresentados apenas em gráficos mostrando a diferença de pressão adimensional versus comprimento adimensional (definidos na equação 4.2) e sobre eles incluiu-se os valores calculados pelo modelo. Utilizou-se as equações para escoamento turbulento liso com perda de carga localizada para os cálculos. A linha contínua mostra os perfis calculados por EGASHIRA et al. (1996), exceto pelos os testes 4 e 5 (figuras 4.31 e 4.32) onde apenas os valores experimentais foram colocados. Os perfis calculados por EGASHIRA et al. (1996) foram obtidos escolhendo-se o fator $\gamma$ da equação 4.2 para que o valor calculado 
da vazão volumétrica total na sucção se ajustasse, dentro de um erro de $5 \%$, ao valor experimental, ou seja, esse método depende de valores experimentais previamente obtidos.

Os gráficos 4.28 a 4.35 mostram, qualitativamente, uma boa concordância entre os valores medidos e calculados embora uma comparação entre os valores das pressões não seja possível. A diferença entre os valores, principalmente na região de descarga, é maior nos casos de rotação elevada (1800 rpm, figuras 4.32 e 4.33) e de baixa diferença de pressão (980 kPa, figuras 4.34 e 4.35). Esses casos são justamente os que apresentam maiores gradientes na região de descarga (perfil "achatado"). Nessas condições, aumenta-se a probabilidade de haver recirculação de gás e não somente de líqüido visto que a diminuição do volume do gás e, portanto, o aumento do líqüido acumulado, ocorre abruptamente na região de descarga apenas. Nos outros casos (figuras 4.28 a 4.31), o aumento da pressão aproximadamente linear indica um maior acúmulo de líqüido ao longo da bomba e, portanto, uma maior disponibilidade de líquiido para o preenchimento das fendas.

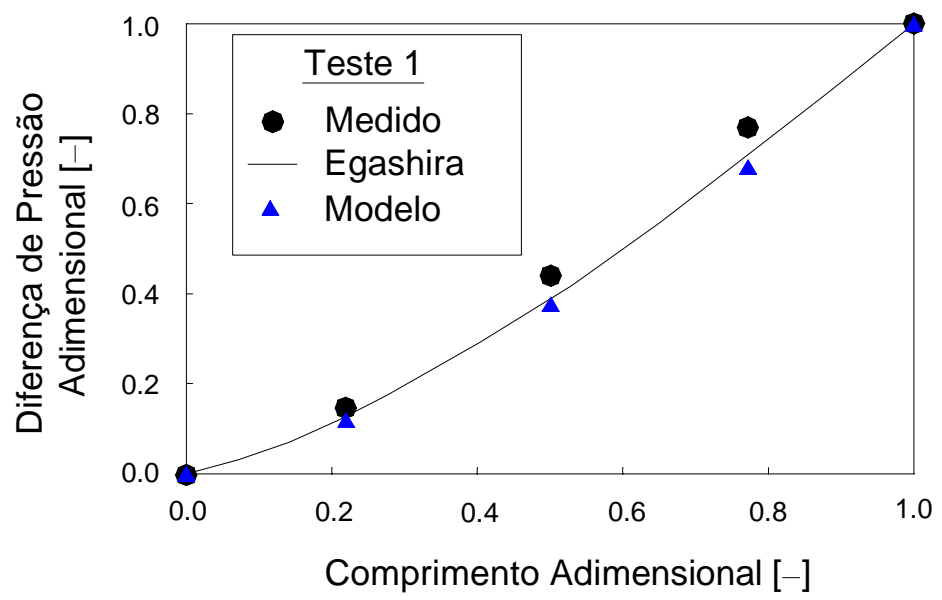

Fig. 4.28: Perfil de pressão - comparação com dados experimentais $\left(1200 \mathrm{rpm}, \mathrm{p}_{\mathrm{S}}=150 \mathrm{kPa}\right.$, FVG $=60 \%, \Delta \mathrm{p}=2940 \mathrm{kPa})$. 


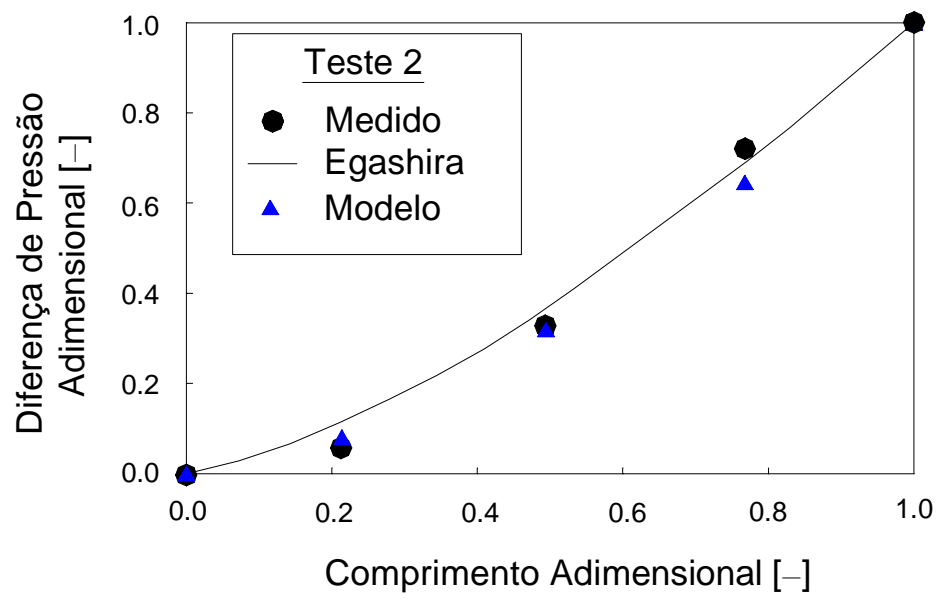

Fig. 4.29: Perfil de pressão - comparação com dados experimentais $\left(1200 \mathrm{rpm}, \mathrm{p}_{\mathrm{S}}=150 \mathrm{kPa}\right.$, FVG $=90 \%, \Delta \mathrm{p}=2940 \mathrm{kPa})$.

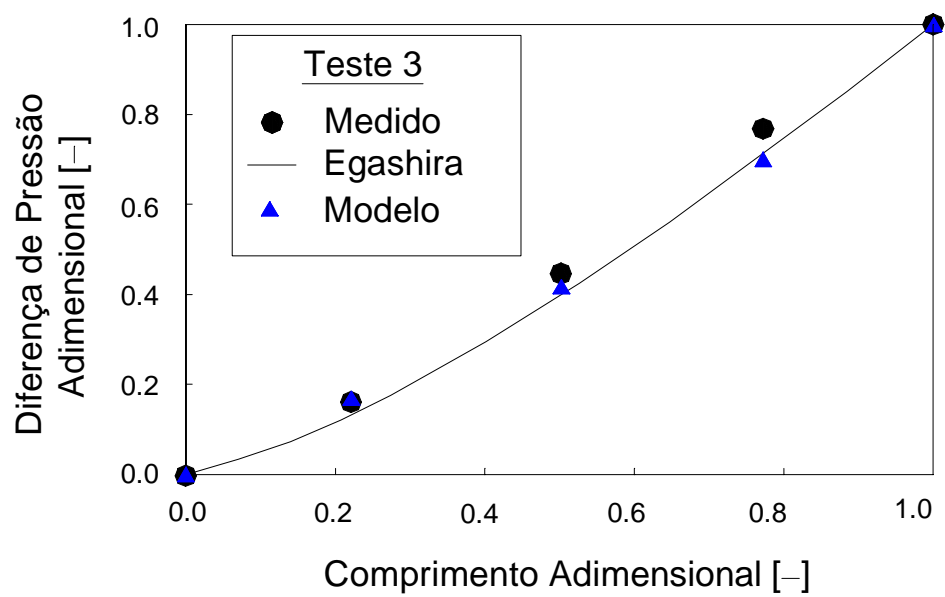

Fig. 4.30: Perfil de pressão - comparação com dados experimentais $\left(1200 \mathrm{rpm}, \mathrm{p}_{\mathrm{S}}=440 \mathrm{kPa}\right.$, FVG $=60 \%, \Delta \mathrm{p}=2940 \mathrm{kPa})$.

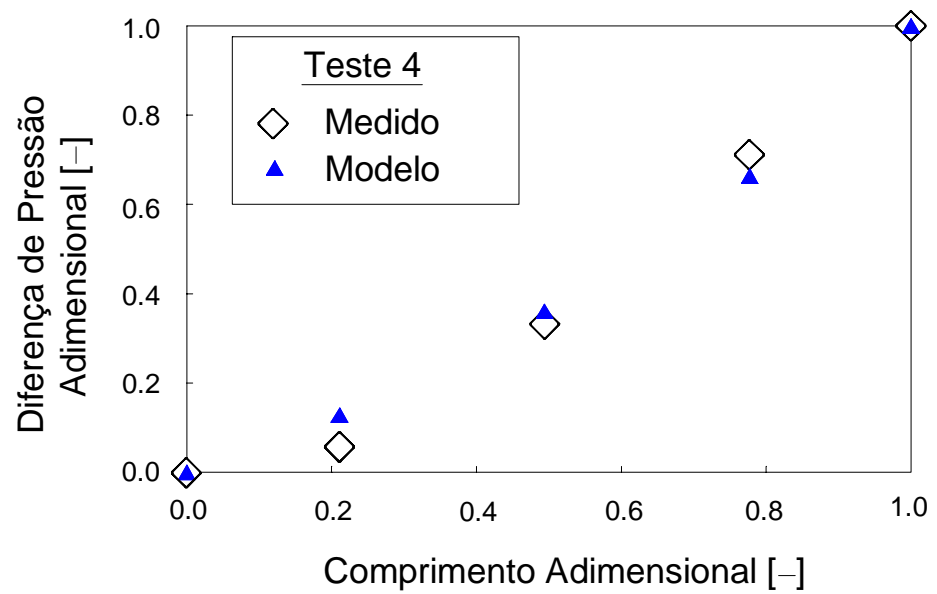

Fig. 4.31: Perfil de pressão - comparação com dados experimentais $\left(1200 \mathrm{rpm}, \mathrm{p}_{\mathrm{S}}=440 \mathrm{kPa}\right.$, FVG $=90 \%, \Delta \mathrm{p}=2940 \mathrm{kPa})$. 


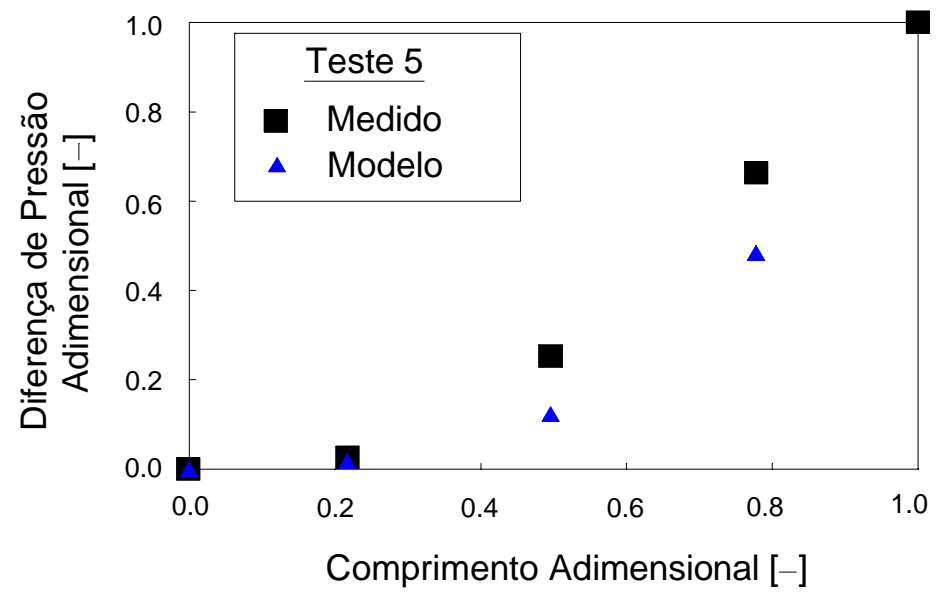

Fig. 4.32: Perfil de pressão - comparação com dados experimentais $\left(1800 \mathrm{rpm}, \mathrm{p}_{\mathrm{S}}=150 \mathrm{kPa}\right.$, FVG $=60 \%, \Delta \mathrm{p}=2940 \mathrm{kPa})$.

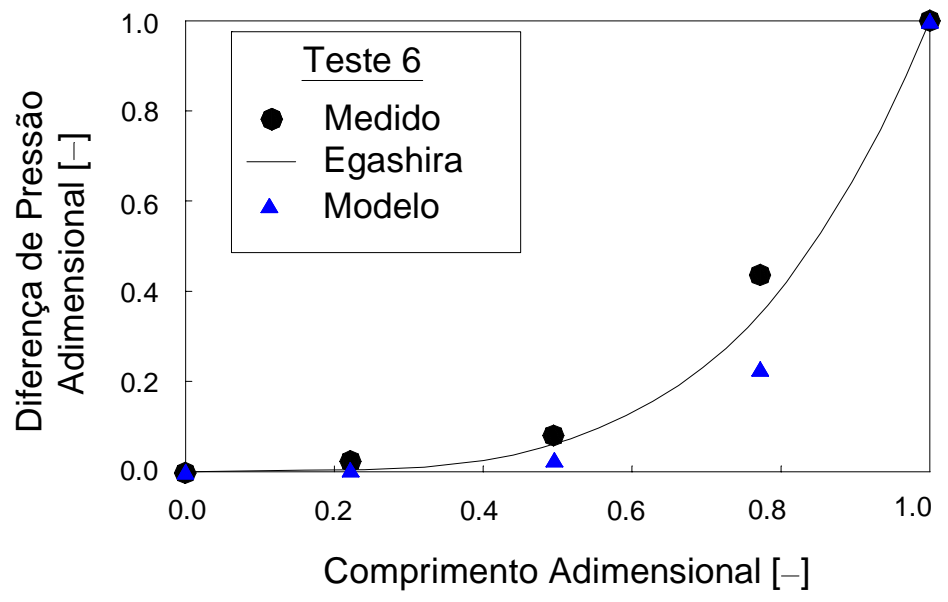

Fig. 4.33: Perfil de pressão - comparação com dados experimentais $\left(1800 \mathrm{rpm}, \mathrm{p}_{\mathrm{S}}=147 \mathrm{kPa}\right.$, FVG $=90 \%, \Delta \mathrm{p}=2940 \mathrm{kPa})$.

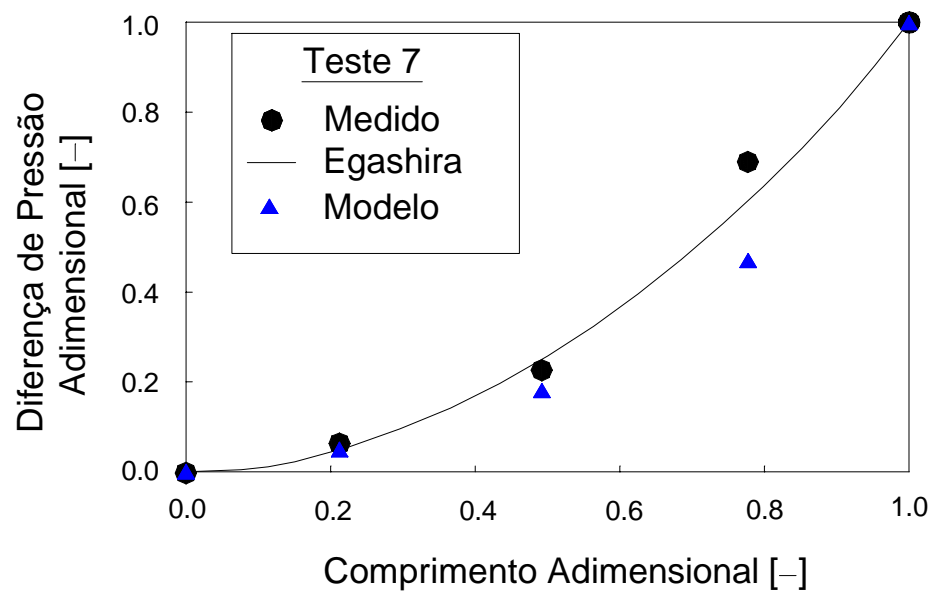

Fig. 4.34: Perfil de pressão - comparação com dados experimentais $\left(1200 \mathrm{rpm}, \mathbf{p}_{S}=290 \mathrm{kPa}\right.$, $\mathrm{FVG}=60 \%, \Delta \mathrm{p}=980 \mathrm{kPa})$. 


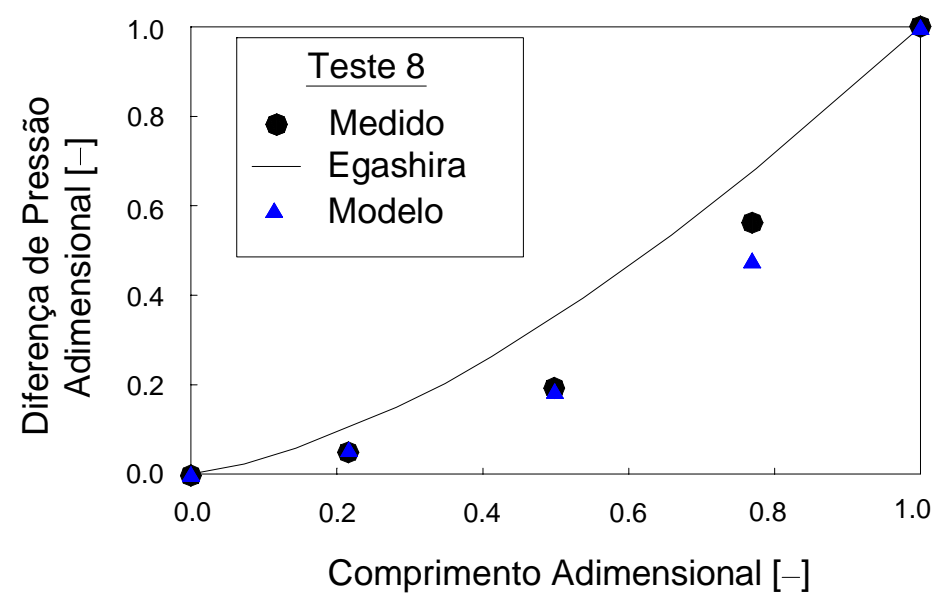

Fig. 4.35: Perfil de pressão - comparação com dados experimentais $\left(1200 \mathrm{rpm}, \mathrm{p}_{\mathrm{S}}=290 \mathrm{kPa}\right.$, FVG $=90 \%, \Delta p=980 \mathrm{kPa})$.

A tabela 4.11 apresenta os valores de vazão volumétrica de refluxo calculados pelo modelo, supondo fendas totalmente preenchidas com líqüido, e os obtidos experimentalmente nos diversos ensaios. Os valores de refluxo experimentais foram calculados subtraindo-se a vazão real na sucção (gás+líqüido) da vazão volumétrica teórica da bomba.

Tabela 4.11: Vazão volumétrica de refluxo: Modelo x Experimental.

\begin{tabular}{ccc}
\hline \multirow{2}{*}{ Ensaio } & \multicolumn{2}{c}{ Vazão de refluxo $\left(\mathbf{m}^{\mathbf{3}} / \mathbf{h}\right)$} \\
\cline { 2 - 3 } & Modelo & Experimental \\
\hline Teste 1 & 32,1 & 39,8 \\
Teste 2 & 27,2 & 38,0 \\
Teste 3 & 40,4 & 48,3 \\
Teste 4 & 35,4 & 44,7 \\
Teste 5 & 13,0 & 7,1 \\
Teste 6 & 6,4 & 0,9 \\
Teste 7 & 16,8 & 3,5 \\
Teste 8 & 12,8 & 25,4 \\
\hline
\end{tabular}

A diferença encontrada nos valores sugere que a adoção da hipótese de fendas completamente preenchidas de líqüido pode afetar o cálculo do refluxo, principalmente nos casos em que o gradiente de pressão é grande apenas na região de descarga (testes 5 
a 8). Uma possível explicação para o comportamento do refluxo observado na tabela 4.11 é que, nos casos onde o acúmulo de líqüido é grande ao longo de toda a bomba, a presença de gás na corrente de refluxo é pequena e apenas contribui para a diminuição da viscosidade e o aumento da vazão de refluxo. Conforme o acúmulo de líqüido diminui, a vazão de gás passa a ser significativa e, apesar da vazão de refluxo total aumentar devido à baixa viscosidade, a vazão de líqüido diminui, sendo a maior parte da corrente de refluxo composta por gás. A única ressalva a ser feita é quanto ao teste 8 que apresenta uma vazão de refluxo calculada menor que a real. Nesse teste, todas as condições do ensaio são praticamente iguais às do teste 7 . No entanto, apesar de terem aproximadamente a mesma pressão e temperatura de sucção, diferença de pressão, rotação e vazão volumétrica de gás, a vazão de líqüido é muito maior no teste 7 do que no teste 8 . Para a bomba operando em condições semelhantes, seria esperado que a vazão de líquiido e, portanto, a de refluxo fossem semelhantes como o modelo calculou.

As figura 4.36 a 4.40 mostram a influência de vários parâmetros: FVG, pressão de sucção, rotação, diferença de pressão e viscosidade do líqüido, no perfil de pressão calculado pelo modelo. Como pode-se observar, baixos FVG, pressão de sucção e diferenças de pressão e altas rotações e viscosidade favorecem um perfil de pressão mais achatado, com grandes gradientes de pressão apenas próximo da descarga. Esse comportamento está de acordo com a teoria e experimentos encontrados na literatura. Além desses fatores, segundo EGASHIRA et al. (1996), outros como: viscosidade do gás e temperatura do fluido também contribuem para alterar o perfil de pressão. Uma forma de classificar esses fatores seria dividi-los em dois grupos: fatores que alteram a compressibilidade do fluido multifásico e fatores que alteram o acúmulo de líqüido nas câmaras do parafuso. No primeiro caso entram parâmetros como a pressão de sucção e o FVG. Aumentos na pressão e baixos FVG's reduzem a compressibilidade do fluido 


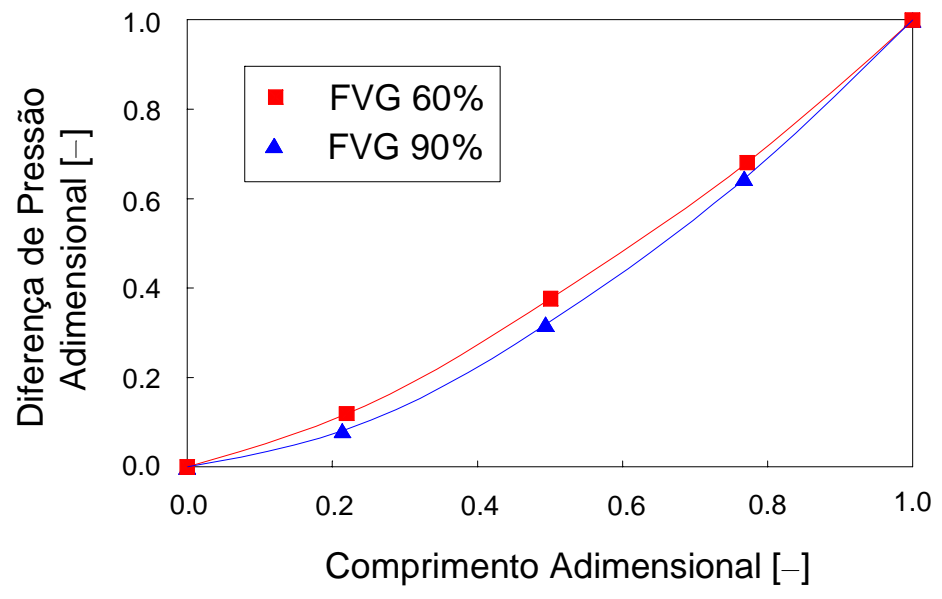

Fig. 4.36: Influência do FVG no perfil de pressão $\left(1200 \mathrm{rpm}, \mathrm{p}_{\mathrm{S}}=150 \mathrm{kPa}, \Delta \mathrm{p}=2940 \mathrm{kPa}\right)$.

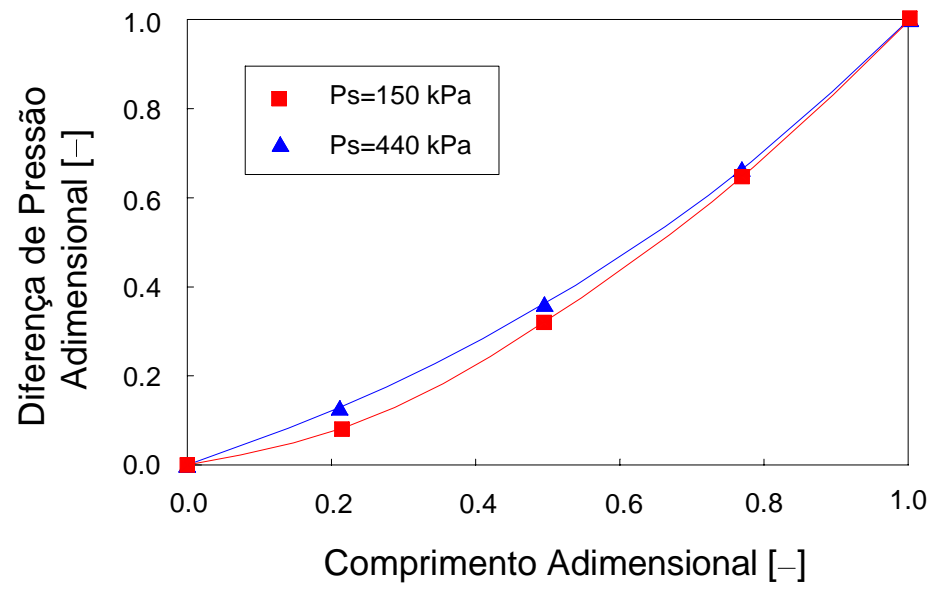

Fig. 4.37: Influência da pressão de sucção no perfil de pressão $(1200 \mathrm{rpm}, \mathrm{FVG}=90 \%, \Delta \mathrm{p}=2940$ $\mathrm{kPa}$ ).

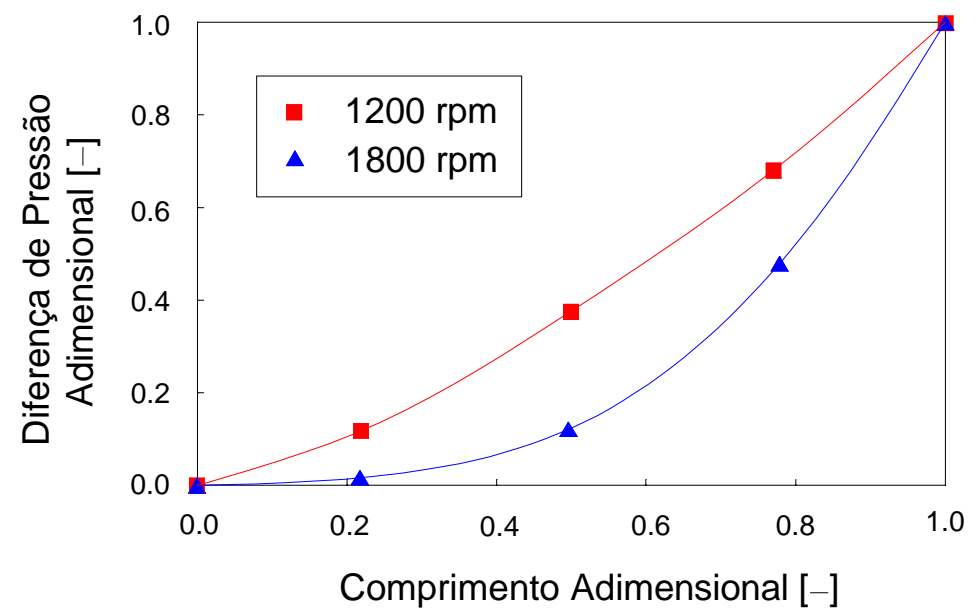

Fig. 4.38: Influência da rotação do parafuso no perfil de pressão $\left(\mathrm{p}_{\mathrm{s}}=150 \mathrm{kPa}, \Delta \mathrm{p}=2940 \mathrm{kPa}\right.$, FVG=60\%). 


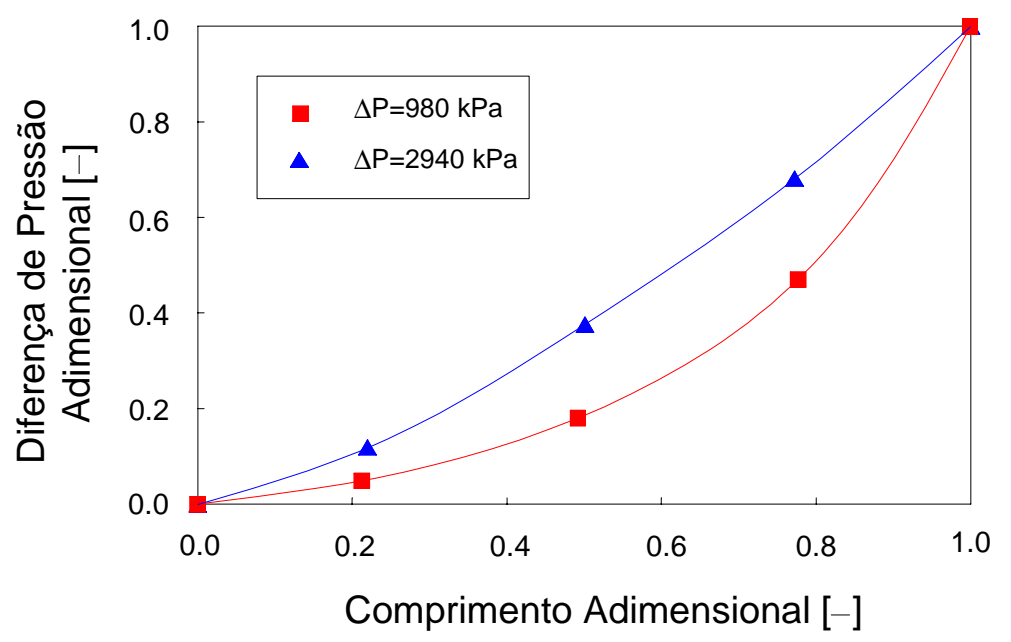

Fig. 4.39: Influência da diferença de pressão no perfil de pressão $\left(1200 \mathrm{rpm}, \mathrm{FVG}=60 \%, \mathrm{p}_{S}=150(\Delta)\right.$ e 290 ( $) \mathbf{k P a})$.

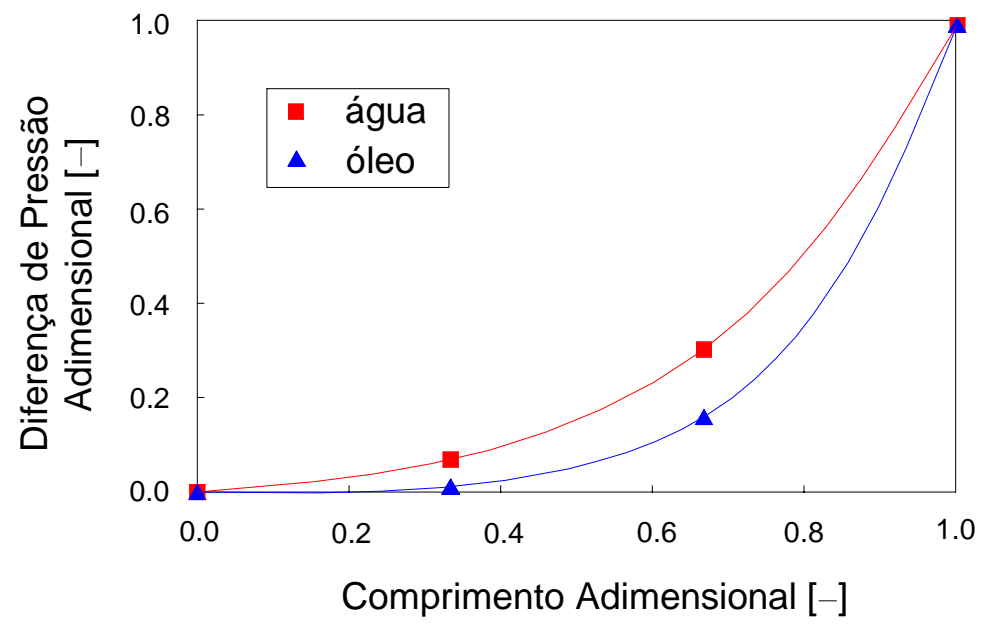

Fig. 4.40: Influência da viscosidade do líqüido no perfil de pressão ( $\mathrm{p}_{\mathrm{S}}=650 \mathrm{kPa}, \Delta \mathrm{p}=2500 \mathrm{kPa}$ ).

fazendo com que seu comportamento aproxime-se do fluido incompressível, ou seja, do perfil de pressão linear. Isso pois a possibilidade de acúmulo de líqüido é reduzida e, nesse caso, as vazões e, portanto, as diferenças de pressão, na entrada e na saída da câmara devem ser semelhantes. Já o segundo caso engloba fatores como diferença de pressão entre sucção e descarga, rotação e viscosidade. Baixas diferenças de pressão e alta viscosidade reduzem a vazão de refluxo, diminuindo a quantidade de líqüido que ingressa nas câmaras e favorecendo um perfil achatado. Já as rotações elevadas 
diminuem o tempo de vida de uma câmara, assim para uma mesma vazão de refluxo a quantidade de líquiido acumulada também será menor. Dentro dos fatores que alteram o acúmulo de líqüido também poderia se incluir parâmetros geométricos da bomba tais como diâmetros interno e externo, largura do filete e espessura das fendas que fazem parte das equações desenvolvidas para o cálculo do refluxo como visto no capítulo 4.3.1.

Apesar de se conhecer como cada fator pode influir individualmente no perfil de pressão, é a combinação dos diversos fatores que definem o aspecto final do perfil já que um fator pode compensar ou potencializar outro. No entanto, observando-se os gráficos, pode-se dizer que o perfil de pressão é mais sensível aos fatores que alteram o acúmulo do liqüido.

\subsubsection{Potência e temperatura de descarga}

Os dados experimentais utilizados neste item são os dos ensaios feitos pela TEXACO (1993) com a bomba L4HK 200-54, de duplo parafuso, do fabricante Leistritz. Esta bomba possui as características geométricas descritas na tabela 4.12.

Tabela 4.12: Parâmetros geométricos da bomba L4HK 200-54 da Leistritz.

\begin{tabular}{lc}
\hline \multicolumn{1}{c}{ Parâmetro } & Valor \\
\hline Diâmetro externo $\left(10^{-3} \mathrm{~m}\right)$ & 200 \\
\hline Diâmetro interno $\left(10^{-3} \mathrm{~m}\right)$ & 140 \\
\hline Passo $\left(10^{-3} \mathrm{~m}\right)$ & 54 \\
\hline Rugosidade $\left(10^{-3} \mathrm{~m}\right)$ & 0,004 \\
\hline Altura das fendas $\left(10^{-3} \mathrm{~m}\right):$ & \\
$-\quad$ periférica & 0,200 \\
$-\quad$ flanco e radial & 0,150 \\
\hline Número de câmaras & 7 \\
\hline
\end{tabular}

O gás utilizado nos ensaios é composto por uma mistura de $90 \%$ de metano e $10 \%$ de etano (em base molar). A composição química do óleo não é fornecida, sendo 
este caracterizado somente através de suas propriedades físicas como mostram as tabelas 4.13 e 4.14. A partir da propriedades do óleo fornecidas, é possível reconstruir o óleo no programa Hysys.Process v2.1. Dessa forma, o óleo é representado no programa por um conjunto de pseudo-componentes que simulam o seu comportamento.

Tabela 4.13: Propriedades características do óleo.

\begin{tabular}{lc}
\hline \multicolumn{1}{c}{ Propriedade } & Valor \\
\hline Densidade a $15,6 / 15,6{ }^{\circ} \mathrm{C}$ & $0,9093 \mathrm{~g} / \mathrm{cc}$ \\
Densidade API & 23,93 \\
Peso Molecular & $264.8 \mathrm{~g} / \mathrm{g}$-mol \\
\hline
\end{tabular}

Tabela 4.14: Viscosidade dinâmica em função da pressão e temperatura.

\begin{tabular}{ccccc}
\hline & \multicolumn{4}{c}{ Temperatura $\left({ }^{\mathbf{0}} \mathbf{C}\right)$} \\
Pressão $(\mathbf{k P a})$ & 26,7 & 37,8 & 48,9 & 60,0 \\
\cline { 2 - 5 } & & \multicolumn{4}{c}{ Viscosidade $\left(\mathbf{1 0}^{\mathbf{- 3}} \mathbf{P a . s}\right)$} \\
\hline 1724 & 32,36 & 20,13 & 13,60 & 9,58 \\
\hline 3447 & 33,62 & 20,89 & 14,07 & 9,90 \\
\hline 5171 & 34,93 & 21,68 & 14,55 & 10,21 \\
\hline 6895 & 36,30 & 22,50 & 15,04 & 10,53 \\
\hline 8619 & 37,72 & 23,35 & 15,54 & 10,86 \\
\hline 10342 & 39,19 & 24,23 & 16,04 & 11,19 \\
\hline 12066 & 40,72 & 25,14 & 16,56 & 11,52 \\
\hline
\end{tabular}

A tabela 4.15 mostra os dados selecionados dos ensaios da bomba L4HK 20054. Para cada velocidade do eixo (1000, 2000 e 3000 rpm), analisou-se ensaios com baixo e alto FVG (respectivamente $50 \%$ e 90/95\%) e, para cada uma destas condições, comparou-se três pontos (diferenças de pressão entre sucção e descarga) distintos uma vez que o consumo de potência varia de forma aproximadamente linear com a diferença de pressão. Fixando-se as condições do fluido na sucção e a pressão na descarga, o modelo calculou os valores de potência e as condições do fluido na descarga. Estes valores simulados foram comparados com os dados da tabela 4.15. 
Tabela 4.15: Dados experimentais utilizados para a comparação com o modelo (TEXACO (1993)).

\begin{tabular}{|c|c|c|c|c|c|c|c|c|c|c|c|}
\hline Ensaio & $\begin{array}{c}\text { Rotação } \\
\text { rpm }\end{array}$ & $\begin{array}{c}\mathrm{FVG} \\
\%\end{array}$ & $\underset{\mathrm{kPa}}{\mathrm{p}_{\mathrm{S}}}$ & $\begin{array}{c}\Delta \mathrm{p} \\
\mathrm{kPa}\end{array}$ & $\begin{array}{l}\mathrm{T}_{\mathrm{S}} \\
{ }^{\circ} \mathrm{C}\end{array}$ & $\begin{array}{l}\mathrm{T}_{\mathrm{D}} \\
{ }^{\circ} \mathrm{C}\end{array}$ & $\begin{array}{c}\dot{V}_{o} \\
\mathrm{~m}^{3} / \mathrm{h}\end{array}$ & $\begin{array}{c}\dot{V}_{g} \\
\mathrm{~m}^{3} / \mathrm{h}\end{array}$ & $\begin{array}{c}\dot{V} \\
\mathrm{~m}^{3} / \mathrm{h}\end{array}$ & $\begin{array}{l}\text { Torque } \\
\text { KN.m }\end{array}$ & $\begin{array}{l}W_{\text {real }} \\
\mathrm{kW}\end{array}$ \\
\hline \multirow{3}{*}{311031} & 1000 & 50 & 636 & 965 & 26,2 & 27,6 & 43,4 & 45,7 & 89,1 & 0,32 & 33,5 \\
\hline & & & 646 & 2706 & 26,2 & 29,3 & 42,4 & 44,0 & 86,4 & 0,76 & 78,9 \\
\hline & & & 653 & 3819 & 26,3 & 30,4 & 42,1 & 44,9 & 87,0 & 1,03 & 107,8 \\
\hline \multirow{3}{*}{311032} & 1000 & 90 & 649 & 379 & 26,0 & 28,7 & 9,0 & 76,3 & 85,3 & 0,16 & 16,6 \\
\hline & & & 642 & 1097 & 26,2 & 32,2 & 8,9 & 75,3 & 84,2 & 0,33 & 34,9 \\
\hline & & & 648 & 1734 & 26,6 & 36,8 & 8,8 & 73,4 & 82,2 & 0,48 & 50,7 \\
\hline \multirow{3}{*}{311030} & 2000 & 47 & 649 & 215 & 23,8 & 24,3 & 91,9 & 85,5 & 177,3 & 0,21 & 44,6 \\
\hline & & & 649 & 2583 & 24,9 & 28,1 & 92,2 & 85,1 & 177,3 & 0,81 & 169,1 \\
\hline & & & 649 & 4664 & 25,5 & 30,1 & 89,7 & 85,8 & 175,5 & 1,32 & 276,9 \\
\hline \multirow{3}{*}{303032} & 2000 & 90 & 654 & 282 & 28,2 & 30,8 & 21,3 & 169,7 & 191,0 & 0,17 & 36,0 \\
\hline & & & 637 & 2845 & 28,1 & 43,1 & 20,9 & 169,7 & 190,6 & 0,78 & 163,1 \\
\hline & & & 637 & 5649 & 28,4 & 55,2 & 21,0 & 163,4 & 184,4 & 1,45 & 302,5 \\
\hline \multirow{3}{*}{304034} & 2000 & 95 & 641 & 312 & 27,4 & 36,3 & 8,9 & 173,3 & 182,2 & 0,17 & 34,9 \\
\hline & & & 636 & 2907 & 28,9 & 59,2 & 9,0 & 165,8 & 174,8 & 0,78 & 163,2 \\
\hline & & & 642 & 4674 & 30,0 & 78,0 & 8,7 & 164,0 & 172,7 & 1,20 & 250,7 \\
\hline \multirow{3}{*}{312030} & 3000 & 50 & 648 & 848 & 20,8 & 22,7 & 124,5 & 135,7 & 260,2 & 0,48 & 151,9 \\
\hline & & & 648 & 2086 & 22,1 & 25,6 & 125,0 & 130,7 & 255,7 & 0,80 & 252,6 \\
\hline & & & 654 & 3783 & 28,0 & 32,9 & 127,1 & 136,4 & 263,5 & 1,24 & 390,2 \\
\hline \multirow{3}{*}{308030} & 3000 & 90 & 654 & 464 & 19,6 & 24,7 & 28,2 & 237,9 & 266,0 & 0,27 & 83,8 \\
\hline & & & 648 & 2063 & 20,1 & 33,5 & 28,9 & 236,5 & 265,4 & 0,69 & 215,4 \\
\hline & & & 653 & 4157 & 21,9 & 47,6 & 28,9 & 241,1 & 270,0 & 1,21 & 381,7 \\
\hline \multirow{3}{*}{309533} & 3000 & 95 & 655 & 660 & 29,7 & 41,8 & 13,6 & 249,1 & 262,7 & 0,24 & 75,6 \\
\hline & & & 642 & 2961 & 29,8 & 62,2 & 13,4 & 246,4 & 259,7 & 0,82 & 255,7 \\
\hline & & & 642 & 5150 & 30,8 & 84,1 & 13,2 & 249,1 & 262,2 & 1,38 & 432,4 \\
\hline
\end{tabular}


A tabela 4.16 mostra os resultados obtidos com as simulações e a comparação com os dados experimentais da TEXACO (1993). A eficiência mecânica utilizada para calcular a potência no eixo, considerando-se, dessa maneira, as perdas nos selos mecânicos e nas engrenagens da bomba multifásica, foi de 95\%. Este valor foi estimado a partir de valores de eficiência mecânica calculados pelo fabricante da bomba e citados em relatório da LEISTRITZ (1995). Considera-se no modelo de simulação que as perdas mecânicas não contribuem para o aumento da temperatura do fluido transportado pois, segundo o mesmo relatório, tal potência é transportada para fora do sistema através de trocadores de calor.

Tabela 4.16: Comparação entre os dados do modelo e dados experimentais.

\begin{tabular}{ccc|ccc|ccc}
\hline \multirow{2}{*}{$\begin{array}{c}\mathrm{N} \\
(\mathrm{rpm})\end{array}$} & \multirow{2}{*}{$\begin{array}{c}\mathrm{FVG} \\
(\%)\end{array}$} & $\begin{array}{c}\Delta \mathrm{p} \\
(\mathrm{kPa})\end{array}$ & \multicolumn{3}{|c|}{$\begin{array}{c}\text { Potência } \\
(\mathrm{kW})\end{array}$} & \multicolumn{3}{c}{$\begin{array}{c}\mathrm{T}_{\mathrm{D}} \\
\left({ }^{\circ} \mathrm{C}\right)\end{array}$} \\
\cline { 4 - 9 } & & & Modelo & Texaco & Erro* $(\%)$ & Modelo & Texaco & Erro* $(\%)$ \\
\hline 1000 & 50 & 965 & 33,2 & 33,5 & $-0,9$ & 27,4 & 27,6 & $-0,6$ \\
& & 2706 & 77,2 & 78,9 & $-2,2$ & 28,9 & 29,3 & $-1,5$ \\
& & 3819 & 106,5 & 107,8 & $-1,3$ & 29,7 & 30,4 & $-2,5$ \\
\hline 1000 & 90 & 379 & 17,0 & 16,6 & 2,3 & 29,6 & 28,7 & 3,3 \\
& & 1097 & 34,7 & 34,9 & $-0,4$ & 32,9 & 32,2 & 2,3 \\
& & 1734 & 49,4 & 50,7 & $-2,5$ & 36,1 & 36,8 & $-2,1$ \\
\hline 2000 & 47 & 215 & 45,4 & 44,6 & 1,8 & 24,8 & 24,3 & 2,1 \\
& & 2583 & 168,4 & 169,1 & $-0,4$ & 27,5 & 28,1 & $-2,1$ \\
& & 4664 & 274,7 & 276,9 & $-0,8$ & 29,2 & 30,1 & $-3,2$ \\
\hline 2000 & 90 & 282 & 42,2 & 36,0 & 17,0 & 32,0 & 30,8 & 3,7 \\
& & 2845 & 147,5 & 163,1 & $-9,6$ & 39,1 & 43,1 & $-9,2$ \\
& & 5649 & 332,6 & 302,5 & 10,0 & 53,4 & 55,2 & $-3,2$ \\
\hline 2000 & 95 & 312 & 42,1 & 34,9 & 20,7 & 35,6 & 36,3 & $-1,8$ \\
& & 2907 & 172,3 & 163,2 & 5,6 & 57,3 & 59,2 & $-3,2$ \\
& & 4674 & 258,0 & 250,7 & 2,9 & 74,0 & 78,0 & $-5,2$ \\
\hline 3000 & 50 & 848 & 153,8 & 151,9 & 1,2 & 23,2 & 22,7 & 2,2 \\
& & 2086 & 241,2 & 252,6 & $-4,5$ & 25,3 & 25,6 & $-1,4$ \\
& & 3783 & 358,3 & 390,2 & $-8,2$ & 31,6 & 32,9 & $-3,9$ \\
\hline 3000 & 90 & 464 & 120,4 & 83,8 & 43,8 & 27,7 & 24,7 & 11,8 \\
& & 2063 & 243,1 & 215,4 & 12,9 & 33,5 & 33,5 & 0,0 \\
& & 4157 & 404,6 & 381,7 & 6,0 & 42,8 & 47,6 & $-10,2$ \\
\hline 3000 & 95 & 660 & 95,6 & 75,6 & 26,4 & 41,4 & 41,8 & $-0,8$ \\
& & 2961 & 274,1 & 255,7 & 7,2 & 59,1 & 62,2 & $-5,1$ \\
& & 5150 & 441,2 & 432,4 & 2,0 & 76,7 & 84,1 & $-8,7$ \\
\hline
\end{tabular}

\footnotetext{
* O erro é definido como: Erro=(Valor do modelo - Valor experimental $) /$ Valor experimental
} 
Quando a velocidade do eixo é menor, 1000 rpm, a potência calculada pelo modelo aproxima-se bastante da potência real, tanto para FVG's baixos como elevados, como mostra a tabela 4.16. O erro, em ambos os casos, fica dentro da faixa de $\pm 4 \%$. Para rotações maiores (2000 e 3000 rpm) e baixos FVG's, a relação entre potência calculada e real mantém-se análoga à obtida para baixas rotações como mostram as figuras 4.41 a 4.44 .

\section{0 rpm, GVF 50\%}

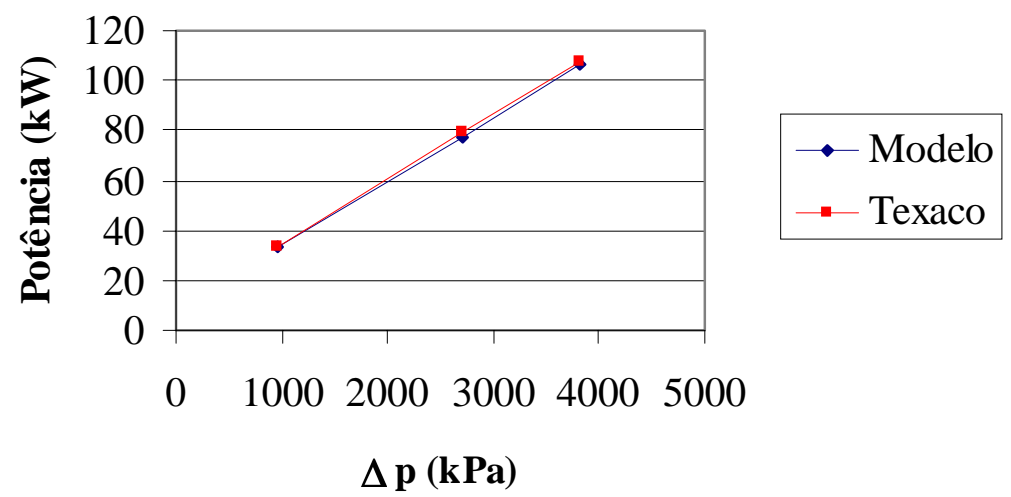

Fig. 4.41: Comparação entre potências calculada e experimental (ensaio 311031).

1000 rpm, GVF $90 \%$

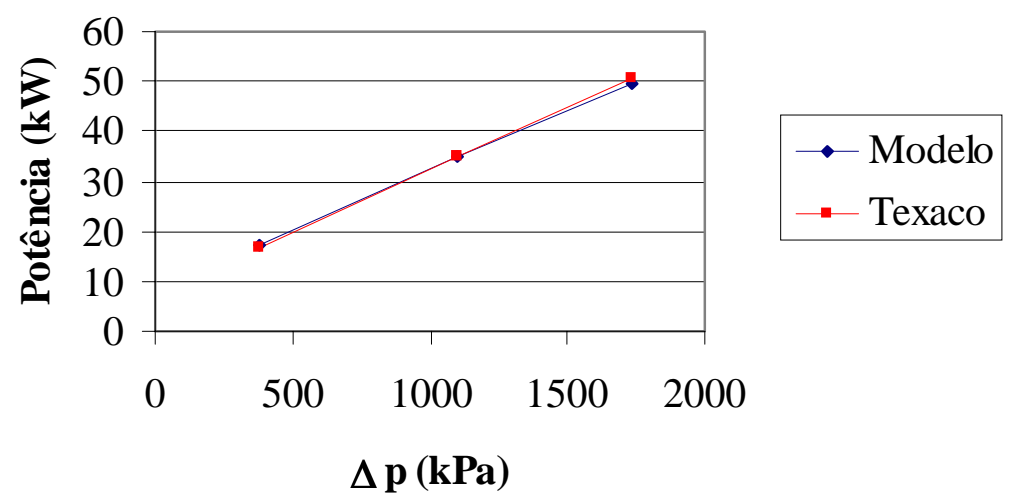

Fig. 4.42: Comparação entre potências calculada e experimental (ensaio 311032). 
2000 rpm, GVF $50 \%$

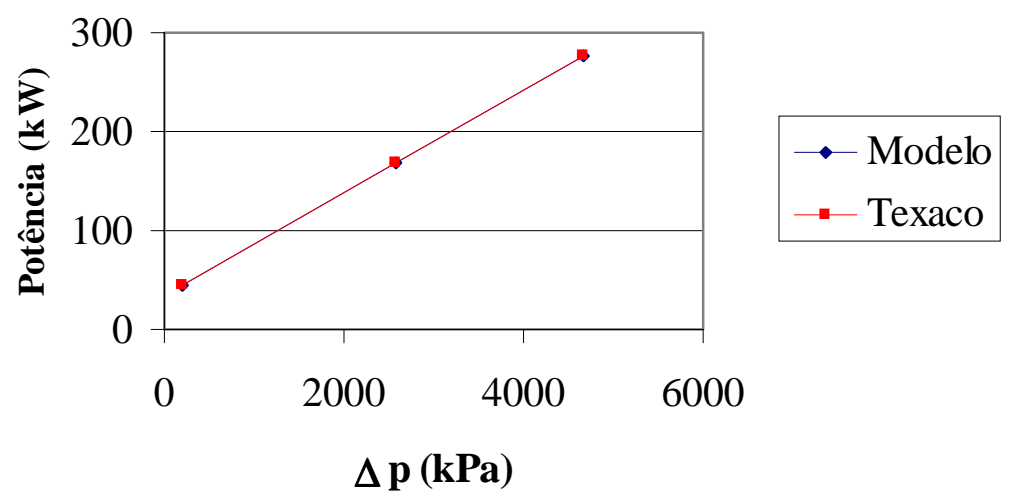

Fig. 4.43: Comparação entre potências calculada e experimental (ensaio 311030).

3000 rpm, GVF $50 \%$

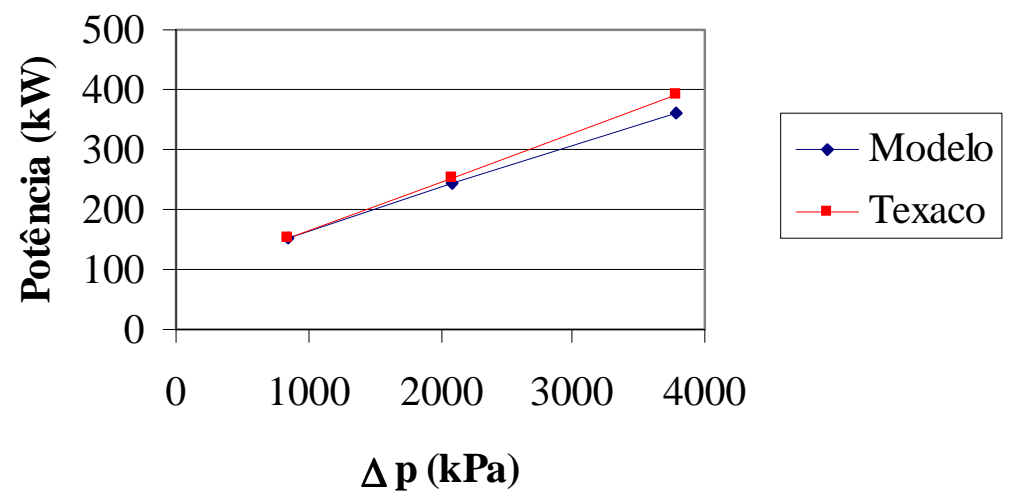

Fig. 4.44: Comparação entre potências calculada e experimental (ensaio 312030).

Quando o FVG e a velocidade do eixo são elevados (90 a 95\% e 2000 a 3000 rpm, respectivamente), o modelo passa a superestimar a potência como mostram as figuras 4.45 e 4.46. Entretanto, conforme a diferença de pressão entre sucção e descarga aumenta, a potência calculada tende a se aproximar da potência medida experimentalmente. Para elevadas diferenças de pressão os valores calculados se aproximam dos dados experimentais. 
3000 rpm, GVF $90 \%$

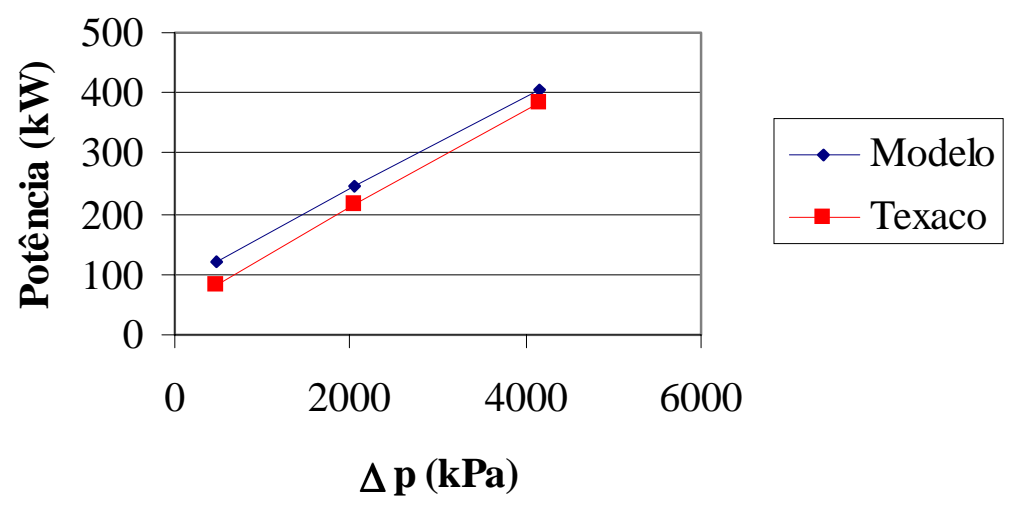

Fig. 4.45: Comparação entre potências calculada e experimental (ensaio 308030).

3000 rpm, GVF $95 \%$

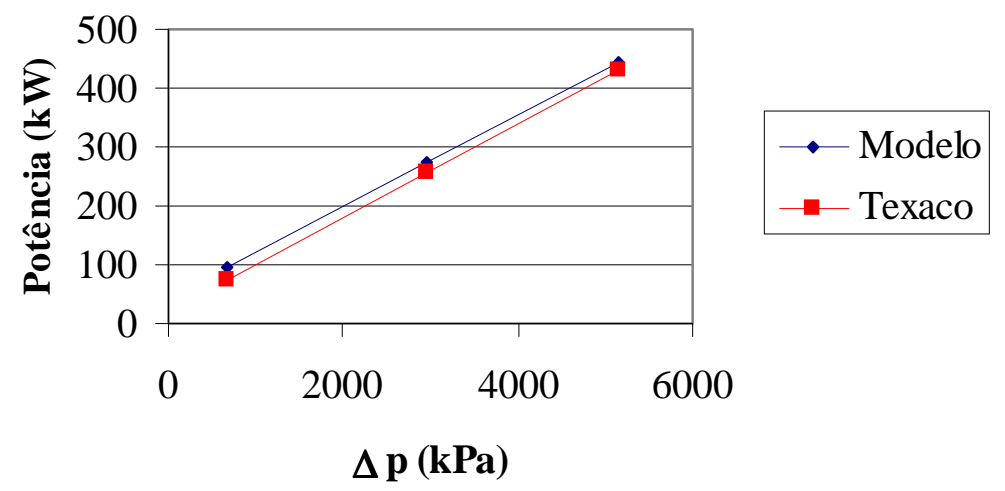

Fig. 4.46: Comparação entre potências calculada e experimental (ensaio 309533).

A explicação para esse comportamento é que, para FVG's altos, a hipótese de fendas totalmente preenchidas com líqüido já não é mais válida e existe, na bomba real, a presença de gás reduzindo a viscosidade e, portanto, a potência de atrito na fenda periférica. Como o modelo calcula a potência de atrito utilizando a viscosidade do líquiido apenas, ele calcula uma potência de atrito maior que a real. Para diferenças de pressão elevadas, a vazão de refluxo aumenta o que causa um maior acúmulo de líqüido 
dentro das câmaras. Quanto maior o acúmulo de líqüido, ou seja, quanto maior a diferença de pressão, maior a possibilidade das fendas estarem preenchidas com líqüido, o que explica a diminuição do erro para altas diferenças de pressão. A velocidade do eixo também influi na quantidade de líqüido acumulado em uma câmara. Uma baixa velocidade implica um maior tempo de vida de uma câmara e, portanto, em um maior acúmulo de líquiido. Assim, quanto maior a velocidade, menores são as chances das fendas estarem preenchidas somente com líqüido. Os dados da tabela 4.15 comprovam esse comportamento. Comparando-se os ensaios com $90 \%$ de FVG, por exemplo, o modelo apresenta, quando a rotação é $1000 \mathrm{rpm}$, o mesmo comportamento observado com baixo FVG. Conforme a rotação aumenta, entretanto, o modelo passa a superestimar os valores de potência.

A figura 4.47 abaixo mostra a variação da potência de atrito calculada pelo modelo com a diferença de pressão entre a sucção e a descarga para vários FVG's. Notase que a potência de atrito diminui com o aumento do FVG e da diferença de pressão. Como o modelo trabalha com a hipótese de fendas completamente preenchidas com líquiido, o que explica a redução é o aumento da temperatura devido à compressão do gás. O aumento da temperatura, e a conseqüente redução na viscosidade e potência de

2000 rpm

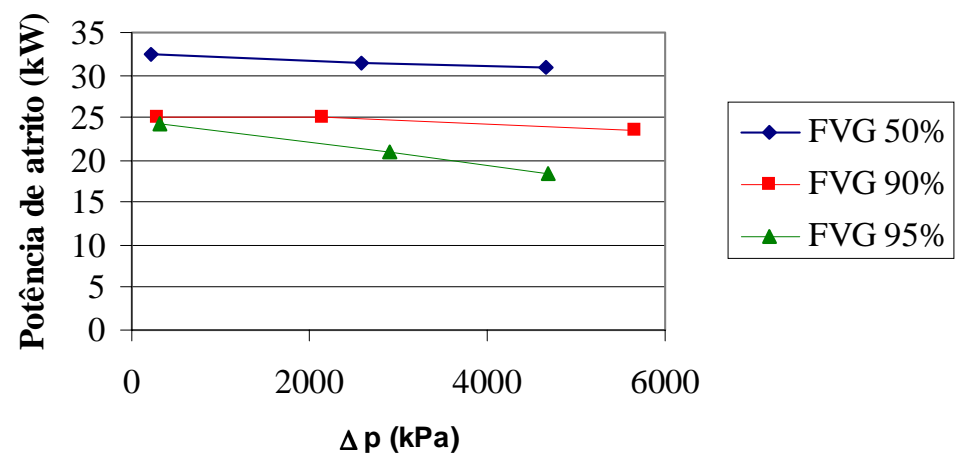

Fig. 4.47: Potência de atrito em função da diferença de pressão e FVG. 
atrito, é maior para maiores volumes de gás e pressões nas câmaras. Esse efeito, no entanto, será perceptível apenas quando a viscosidade do líqüido varia bastante com a temperatura.

A potência de atrito no canal do parafuso pouco contribui para a potência de atrito total. Para a bomba L4HK 200-54, por exemplo, a potência de atrito para um passo do parafuso, considerando-se o canal totalmente preenchido com líqüido $(\mathrm{FVG}=0 \%)$, seria dada aproximadamente por:

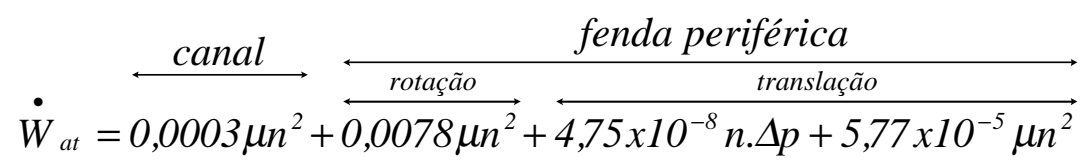

Mesmo que a diferença de pressão entre as câmaras fosse nula, ainda assim a potência de atrito no canal seria responsável por apenas $4 \%$ da potência de atrito total.

\subsection{Eficiência exergética}

\subsubsection{Introdução}

A eficiência exergética pode ser utilizada para se avaliar o desempenho da bomba multifásica. A vantagem da sua utilização é que, ao contrário das eficiências isotérmica e adiabática tradicionalmente propostas, ela não depende de idealizações do processo, sendo calculada a partir das propriedades termodinâmicas do fluido na entrada e na descarga da bomba. Para a bomba multifásica, define-se a seguinte eficiência exergética:

$$
\eta_{e x}=\frac{E x_{D}-E x_{S}}{\dot{W}_{\text {eixo }}}=\frac{E x_{D}-E x_{S}}{\dot{W}_{\text {teor }}+\dot{W}_{a t}}
$$

Definida dessa forma, a eficiência exergética não é influenciada pela exergia química. Isso pois a composição química total do fluxo não se altera. Existe apenas uma mudança desprezível na composição das parcelas do gás e do líqüido devido aos 
processos de evaporação e condensação. Assim a exergia química na entrada e na saída da bomba são praticamente iguais e se anulam quando se calcula a sua diferença.

Existem, como enfatizado no capítulo 3.6, outras definições possíveis para a eficiência exergética e no Apêndice III algumas delas são discutidas. Porém, como parâmetro de comparação de desempenho, a equação 4.62 é a que melhor quantifica a relação entre potência consumida e transmitida ao fluido e somente ela será abordada neste capítulo.

\subsubsection{Resultados}

Com o auxílio do modelo, é possível obter as condições na saída da bomba bem como a potência consumida. Dessa forma pode-se calcular a eficiência exergética da bomba para uma série de condições. Os parâmetros estudados, devido à sua grande influência na potência consumida e/ou aproveitada, são: FVG, rotação, diâmetro externo, comprimento do rotor, refluxo e diferença de pressão.

Uma análise preliminar dos resultados para os ensaios da TEXACO (1993), mostra que a eficiência exergética obtida aproxima-se bastante da eficiência isotérmica. Apenas para $\mathrm{FVG}=95 \%$ e alta diferença de pressão é que houve um desvio maior, como mostra a tabela 4.17. Nesse caso, o aumento de temperatura entre sucção e descarga é grande e a hipótese de escoamento isotérmico se afasta muito da realidade. A semelhança com a eficiência isotérmica auxilia a compreenção do comportamento da curva de eficiência como mostra a figura 4.48. A eficiência isotérmica é composta pela combinação de três fatores:

a) Eficiência mecânica: relação entre a potência teórica e a real

$$
\eta_{\text {mec }}=\frac{\dot{V}_{\text {teor }} \Delta p}{\dot{V}_{\text {teor }} \Delta p+\dot{W}_{a t}}
$$


Tabela 4.17: Comparação entre eficiência exergética e isotérmica.

\begin{tabular}{ccccc}
\hline $\begin{array}{c}\mathrm{N} \\
(\mathrm{rpm})\end{array}$ & $\begin{array}{c}\mathrm{FVG} \\
(\%)\end{array}$ & $\begin{array}{c}\Delta \mathrm{p} \\
(\mathrm{kPa})\end{array}$ & $\eta_{\mathrm{ex}}$ & $\eta_{\text {isot }}$ \\
\hline 2000 & 47 & 215 & 0,24 & 0,23 \\
& & 2583 & 0,55 & 0,58 \\
& & 4664 & 0,56 & 0,59 \\
\hline 2000 & 90 & 282 & 0,33 & 0,32 \\
& & 2845 & 0,41 & 0,42 \\
& & 5649 & 0,33 & 0,32 \\
\hline 2000 & 95 & 312 & 0,33 & 0,33 \\
& & 2907 & 0,39 & 0,36 \\
& & 4674 & 0,38 & 0,31 \\
\hline 3000 & 50 & 848 & 0,34 & 0,35 \\
& & 2086 & 0,45 & 0,47 \\
& & 3783 & 0,52 & 0,54 \\
\hline 3000 & 90 & 464 & 0,24 & 0,24 \\
& & 2063 & 0,35 & 0,35 \\
& & 4157 & 0,33 & 0,33 \\
\hline 3000 & 95 & 660 & 0,37 & 0,35 \\
& & 2961 & 0,38 & 0,35 \\
& & 5150 & 0,34 & 0,29 \\
\hline
\end{tabular}

b) Eficiência volumétrica: relação entre a vazão volumétrica real e a teórica na sucção

$$
\eta_{v}=\frac{\dot{V}_{B M, S}}{\dot{V}_{\text {teor }}}
$$

c) Eficiência isotérmica teórica: relação entre potência transmitida ao fluido e potência teórica gasta

$$
\eta_{\text {isot,teor }}=\frac{F V G \cdot \dot{V}_{\text {teor }} \cdot p_{S} \cdot \ln \left(p_{D} / p_{S}\right)+(1-F V G) \dot{V}_{\text {teor }}\left(p_{D}-p_{S}\right)}{\dot{V}_{\text {teor }}\left(p_{D}-p_{S}\right)}
$$

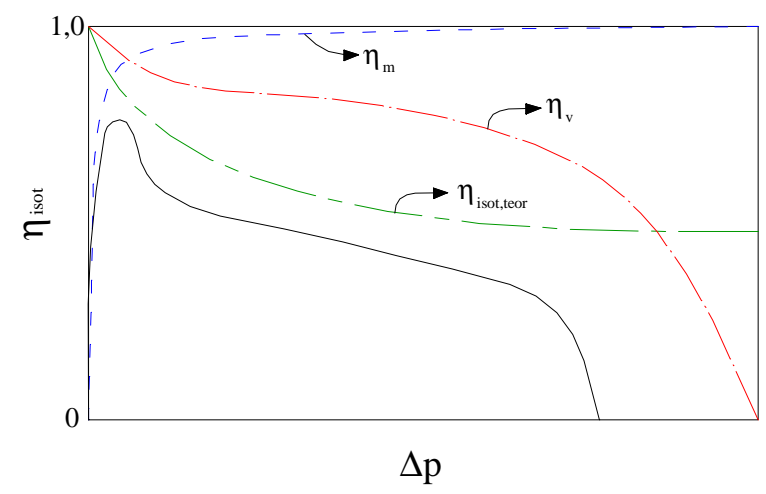

Fig. 4.48: Comportamento da eficiência de uma bomba multifásica de duplo parafuso. 
A multiplicação dos três fatores leva à equação 2.1 da eficiência isotérmica como mostra a figura 4.48. Inicialmente, o que define o comportamento crescente da eficiência total é a eficiência mecânica, representando o fato da potência de atrito ser constante e ficar, proporcionalmente, pouco relevante conforme a potência teórica aumenta. Para diferenças de pressão muito pequenas, praticamente toda a potência do eixo é utilizada para vencer o atrito. A redução na eficiência isotérmica teórica com o aumento da diferença de pressão indica um menor aproveitamento da potência do eixo, refletindo o fato de ter-se cada vez mais potência sendo perdida em vazões de recirculação crescentes. A redução na eficiência isotérmica passa a compensar o aumento na eficiência mecânica para diferenças de pressão maiores. A tendência da eficiência seria atingir um valor constante e igual a $(1-F V G)$ pois, no limite em que a diferença de pressão fosse infinitamente grande, o valor da eficiência mecânica tenderia a 1 e o da eficiência isotérmica a $(1-F V G)$. Isso só não ocorre devido à redução da eficiência volumétrica, que mostra as vazões de refluxos cada vez maiores para diferenças de pressão crescentes. Para a eficiência exergética, a única diferença referese ao processo de compressão, que não é considerado isotérmico e, portanto, acarreta vazões de recirculação um pouco menores (maior eficiência exergética). Das equações 4.63 a 4.65, pode-se concluir que potências de atrito, vazões de recirculação e, principalmente, FVG's elevados provocam uma redução na eficiência.

As figuras 4.49 e 4.50 mostram a eficiência exergética calculada pelo modelo para os ensaios da TEXACO (1993). Pode-se observar que para rotações e FVG's menores a eficiência exergética da bomba é maior. Para os casos analisados, a vazão de refluxo manteve-se constante com a diferença de pressão e praticamente não influencia a eficiência. Rotações maiores aumentam a potência de atrito e diminuem a eficiência, principalmente na região de menores diferenças de pressão. 
$\mathrm{n}=2000 \mathrm{rpm}$

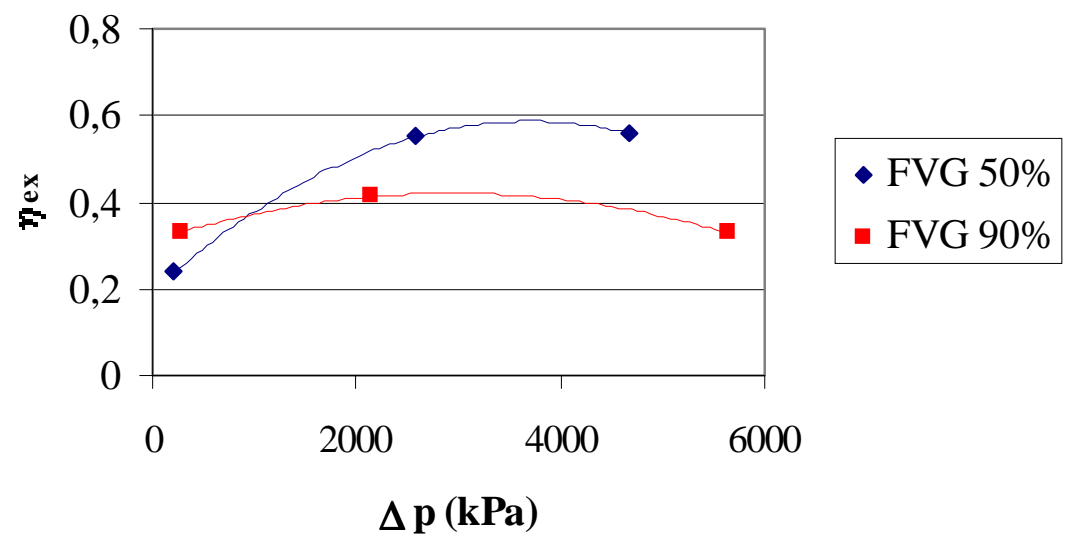

Fig. 4.49: Variação da eficiência exergética com o FVG e $\Delta$ p para 2000 rpm.

$\mathrm{n}=3000 \mathrm{rpm}$

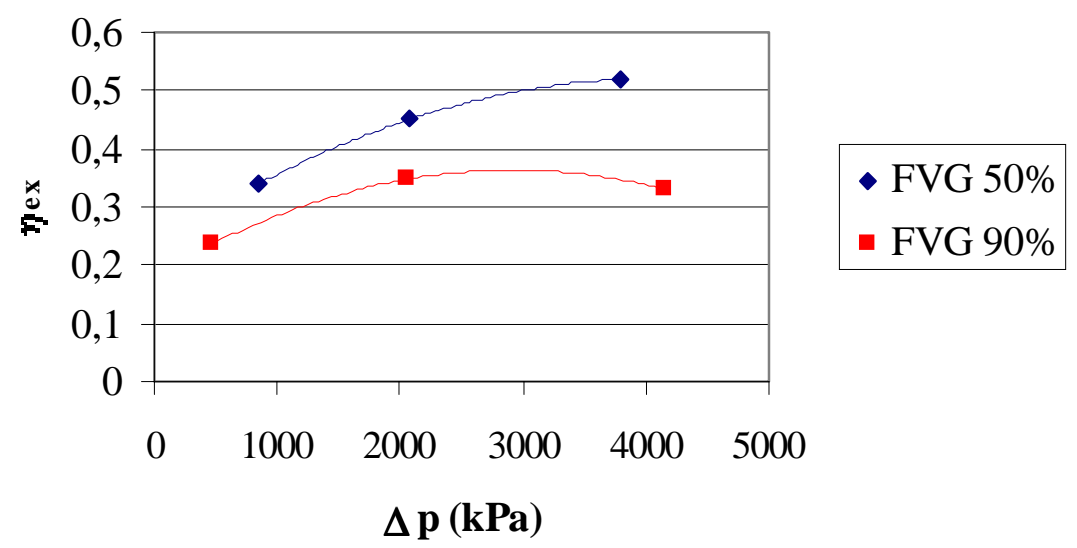

Fig. 4.50: Variação da eficiência exergética com o FVG e $\Delta$ p para $3000 \mathrm{rpm}$.

Os estudos mostrados a seguir mostram a comparação entre duas bombas de diâmetros diferentes. A Bomba 1 possui a mesma geometria da bomba da TEXACO (1993) mostrada na tabela 4.12. A Bomba 2 possui apenas os diâmetros externo e interno menores, mantendo idênticos todos os outros parâmetros geométricos, inclusive a altura do canal como mostra a tabela 4.18. Como critério de comparação, decidiu-se 
fixar a vazão volumétrica e mássica do gás e a vazão volumétrica teórica das bombas, ou seja, a bomba 2, de menor diâmetro, deve operar a uma velocidade maior como mostra a tabela 4.18 .

Tabela 4.18: Parâmetros utilizados na comparação da eficiência exergética entre bombas de geometrias diferentes.

\begin{tabular}{lcc}
\hline \multicolumn{1}{c}{ Parâmetro } & Bomba 1 & Bomba 2 \\
\hline Diâmetro externo $\left(10^{-3} \mathrm{~m}\right)$ & 200 & 160 \\
\hline Diâmetro interno $\left(10^{-3} \mathrm{~m}\right)$ & 140 & 100 \\
\hline Passo $\left(10^{-3} \mathrm{~m}\right)$ & 54 & 54 \\
\hline Rugosidade $\left(10^{-3} \mathrm{~m}\right)$ & 0,004 & 0,004 \\
\hline Altura das fendas $\left(10^{-3} \mathrm{~m}\right):$ & & \\
- periférica & 0,200 & 0,200 \\
- flanco e radial & 0,150 & 0,150 \\
\hline Rotação $(\mathrm{rpm})$ & 1500 & 1986 \\
\hline
\end{tabular}

Para cada uma das bombas, calculou-se a sua eficiência exergética para dois tipos de fase líquiida: água e óleo, e para as bombas operando com 3 ou 7 estágios de compressão a fim de se investigar o efeito da viscosidade e do número de câmaras da bomba. A fase gasosa é composta em todos os casos, como no capítulo 4.5.2, por 90\% de metano e $10 \%$ de etano em base molar. Cada uma dessas configurações foi simulada para três diferenças de pressão: 650, 2500 e $4500 \mathrm{kPa}$. As propriedades físicas do óleo são as mesmas do item 4.5.2. Os resultados obtidos: eficiência exergética, vazão de refluxo e potência de atrito, encontram-se na tabela 4.19 a seguir.

Observando-se apenas o comportamento da eficiência para a Bomba 1, pode-se perceber que, tanto para sete como para três estágios, a eficiência da bomba trabalhando com baixa diferença de pressão $(650 \mathrm{kPa})$ é maior quando a fase líqüida é a água. Para alta diferença de pressão (4500 kPa), o comportamento se inverte e a eficiência é maior com o óleo. Comparando-se a eficiência para uma mesma substância, pode-se ver que a eficiência da bomba operando com água diminui com a diminuição do número de estágios enquanto que quando o fluido é o óleo a eficiência, com um menor número de 
Tabela 4.19: Comparação das eficiências exergéticas de bombas de diâmetros diferentes.

\begin{tabular}{|c|c|c|c|c|c|c|c|c|}
\hline \multirow{2}{*}{$\begin{array}{c}\text { Fase } \\
\text { Líquiiida }\end{array}$} & \multirow{2}{*}{$\begin{array}{c}\text { № } \\
\text { Estágios }\end{array}$} & \multirow{2}{*}{$\begin{array}{c}\Delta \mathbf{p} \\
(\mathbf{k P a})\end{array}$} & \multicolumn{2}{|c|}{$\eta_{\text {ex }}$} & \multicolumn{2}{|c|}{$\dot{\mathbf{V}}_{\text {ref }}\left(\mathrm{m}^{3} / \mathbf{h}\right)$} & \multicolumn{2}{|c|}{$\dot{\mathbf{W}}_{\text {at }}(\mathbf{k W})$} \\
\hline & & & Bomba 1 & Bomba 2 & Bomba 1 & Bomba 2 & Bomba 1 & Bomba 2 \\
\hline \multirow{6}{*}{ óleo } & \multirow{3}{*}{8} & 650 & 0,47 & 0,49 & 1,80 & 1,85 & 17,18 & 15,17 \\
\hline & & 2500 & 0,54 & 0,55 & 1,80 & 1,85 & 17,54 & 15,59 \\
\hline & & 4500 & 0,54 & 0,55 & 1,80 & 1,85 & 17,78 & 16,02 \\
\hline & \multirow{3}{*}{3} & 650 & 0,63 & 0,66 & 1,82 & 1,87 & 6,61 & 5,85 \\
\hline & & 2500 & 0,60 & 0,61 & 2,02 & 1,97 & 6,97 & 6,27 \\
\hline & & 4500 & 0,57 & 0,58 & 2,40 & 2,15 & 7,31 & 6,70 \\
\hline \multirow{6}{*}{ água } & \multirow{3}{*}{8} & 650 & 0,80 & 0,80 & 2,84 & 2,38 & 0,71 & 0,65 \\
\hline & & 2500 & 0,59 & 0,60 & 3,91 & 2,71 & 1,23 & 1,19 \\
\hline & & 4500 & 0,54 & 0,54 & 5,10 & 3,19 & 1,79 & 1,78 \\
\hline & \multirow{3}{*}{3} & 650 & 0,72 & 0,75 & 11,82 & 8,92 & 0,38 & 0,36 \\
\hline & & 2500 & 0,46 & 0,51 & 19,73 & 13,97 & 0,90 & 0,90 \\
\hline & & 4500 & 0,31 & 0,39 & 26,69 & 18,36 & 1,44 & 1,49 \\
\hline
\end{tabular}


estágios, é maior para menores diferenças de pressão e menor para diferenças grandes. As figuras 4.51 e 4.52 a seguir ajudam a visualisar e explicar o comportamento da eficiência.

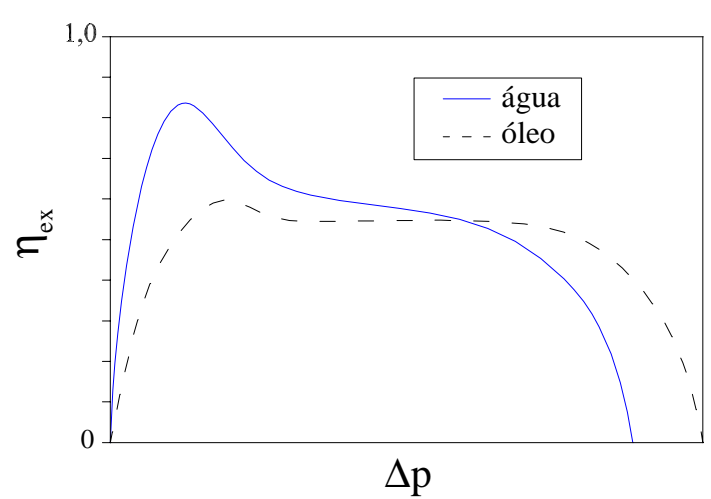

(a)

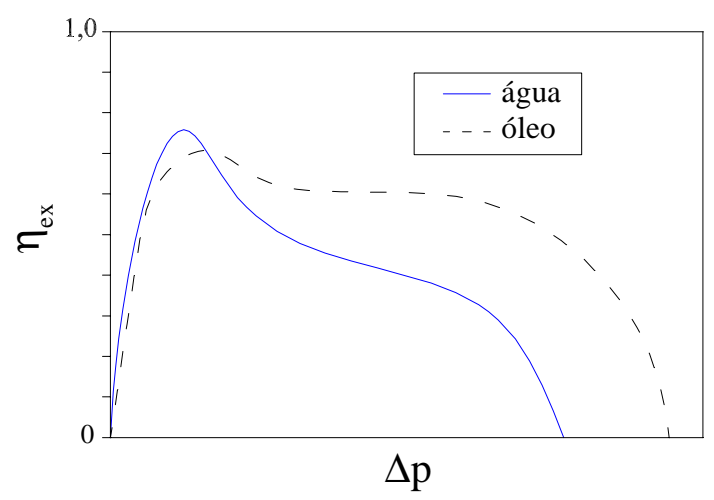

(b)

Fig. 4.51: Eficiência exergética versus $\Delta$ p para água e óleo: a) 8 estágios e b) 3 estágios.

As curvas da figura 4.51 mostram aproximadamente o comportamento da eficiência exergética para as duas substâncias estudadas: água e óleo. Quando o número de estágios é grande (figura 4.51a), a influência da diferença de pressão na vazão de refluxo fica reduzida já que a diferença de pressão entre a primeira câmara e a sucção é pequena nos dois casos, como mostram os dados da tabela 4.19 para 8 estágios. Assim, embora a vazão de refluxo da água seja maior que a do óleo, a contribuição para a exergia destruída é pequena e o que define o comportamento da eficiência é a potência de atrito, muito maior quando a bomba trabalha com óleo e determinando uma eficiência mais baixa nesse caso. Apenas quando a diferença de pressão é alta é que a vazão de refluxo passa a ser importante. Nesse caso, a água, por ter uma viscosidade menor, apresenta uma maior vazão de refluxo, o que explica a menor eficiência quando comparada ao óleo. Quando o número de estágios é reduzido a três (figura 4.51b), o comportamento se mantém semelhante. Apenas o ponto de intersecção, onde ocorre a 
inversão e a bomba operando com água passa a ter eficiências menores, desloca-se para a esquerda (região de baixas diferenças de pressão). Isso ocorre pois há uma redução na potência de atrito devido ao menor número de filetes e um grande aumento na diferença de pressão na região da sucção. Devido à baixa potência de atrito, é necessária uma menor vazão de refluxo para que a sua exergia destruída passe a ser, proporcionalmente, importante. Além disso, as vazões de refluxo, mesmo para baixas diferenças de pressão, são grandes.

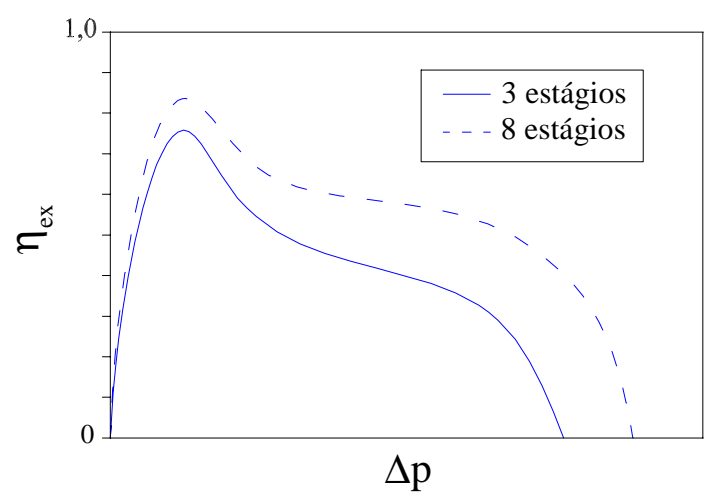

(a)

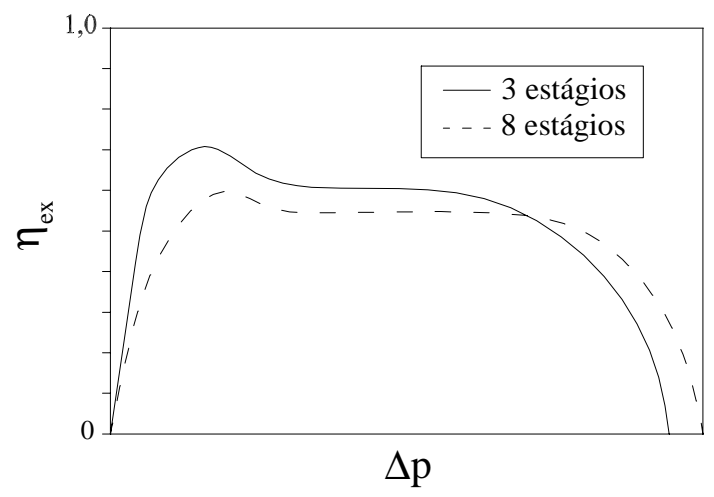

(b)

Fig. 4.52: Eficiência exergética versus $\Delta$ p para 3 e 8 estágios: a) água e b) óleo.

Na figura 4.52a, como a potência de atrito para a água é pequena, uma diminuição no número de estágios pouco contribui para o aumento da eficiência. O que define o comportamento das curvas é a vazão de refluxo, maior para menos estágios. Quando a substância é o óleo (figura 4.52b), o menor número de estágios diminui a potência de atrito o que, inicialmente, contribui para o aumento da eficiência. No entanto, para altas diferenças de pressão, a vazão de refluxo, maior nesse caso, passa a ser importante.

Com a diminuição do diâmetro do parafuso e, conseqüentemente, o aumento da rotação, a eficiência exergética aumenta em todos os casos. A nova combinação 
diâmetro/rotação propicia uma diminuição na potência de atrito e uma redução da vazão de refluxo devido ao perfil de pressão que é mais "achatado" pela alta rotação. Para o óleo, o aumento da eficiência é dado pela diminuição da potência de atrito e os maiores ganhos são para as baixas diferenças de pressão e grande número de estágios. Nesse caso, a potência de atrito é alta e corresponde a uma parcela significativa da potência total. Portanto, uma diminuição da potência de atrito tem um grande impacto. Com a bomba trabalhando com água, o que define o aumento da eficiência é a diminuição da vazão de refluxo e os maiores benefícios ocorrem quando o número de estágios é pequeno e a diferença de pressão, alta. A diminuição da vazão de refluxo devido ao perfil mais "achatado" é significativa e percebida com maior intensidade quando essa vazão é elevada. 


\section{Capítulo 5}

\section{Conclusões}

Neste trabalho foi desenvolvido um modelo de comportamento termodinâmico para simular uma bomba multifásica do tipo duplo parafuso. Para as simulações, é necessário fornecer a composição e as condições do fluido na sucção assim como a pressão de descarga. O modelo calcula, então, a potência consumida, as condições do fluido na descarga, o perfil de pressão e a vazão de refluxo.

O modelo desenvolvido apresenta bons resultados quando se compara dados como potência consumida e temperatura de descarga, principalmente nos casos em que o FVG é baixo. As comparações com dados experimentais indicam que a hipótese de fendas completamente preenchidas com líqüido não é verdadeira para altos FVG's, quando o modelo passa a superestimar a potência.

Para o cálculo do refluxo, as equações de WINCEK (1992), apesar de apresentarem melhores resultados, não encontram correspondência com os diagramas de coeficiente de atrito. Os números de Reynolds envolvidos no escoamento através das fendas não são elevados o suficiente para garantir escoamento turbulento completamente rugoso. As equações de EGASHIRA et al. (1996) para escoamento turbulento liso com perda de carga localizada são mais adequadas para a faixa de Reynolds envolvida. As perdas de carga localizadas, nesse caso, têm uma influência 
muito grande no escoamento e devem ser estudadas com maior cuidado já que fatores como arredondamento das bordas e chanfros podem alterá-las. Quando se compara o perfil de pressão e o refluxo com escoamento bifásico, existem diferenças consideráveis entre os valores experimentais e os calculados, apesar do modelo conseguir, qualitativamente, representar o que ocorre na bomba real.

A vantagem de se utilizar um número maior de estágios no modelo não é tão grande. A utilização de um número de estágios igual ao da bomba multifásica simplifica as conexões no modelo e os cálculos. O maior desvio no cálculo da potência teórica pode ser contornado utilizando-se o modelo para calcular a potência de atrito apenas. Dessa forma elimina-se o desvio e abre-se a possibilidade de incluir a eficiência isentrópica de compressão nos compressores.

De acordo com os resultados do modelo, a principal fonte de perda por atrito na bomba multifásica é a potência de atrito na fenda periférica. Analisando-se as equações 4.34 e 4.39, pode-se verificar que existem diversos parâmetros que afetam essa potência: diâmetro externo do parafuso, rotação da bomba, largura do filete, número de estágios, viscosidade do líqüido, diferença de pressão entre as câmaras e altura da fenda. Dos parâmetros estudados, a rotação, o número de estágios, o diâmetro externo e a viscosidade foram os que mais afetaram a potência de atrito.

A potência de atrito do canal é pouco importante se comparada à potência de atrito na fenda periférica. No caso das simulações com a bomba da TEXACO (1993), por exemplo, a potência de atrito no canal corresponde a apenas $4 \%$ da potência na fenda periférica, mesmo considerando-se o canal completamente cheio de líqüido $(\mathrm{FVG}=0 \%)$. Dessa forma, o impacto de eventuais erros causados pelas simplificações adotadas para o canal será pequeno. Além disso, apesar das equações terem sido desenvolvidas para um canal de seção retangular, é possível utilizar o modelo para 
parafusos com canais que possuem outras geometrias sem que isso implique grandes erros. Para simplificar o modelo, também poderia se excluir o cálculo da potência no canal sem que isso alterasse significativamente o cálculo final.

Com maiores porcentagens de gás, a potência de atrito tende a diminuir quando a diferença de pressão aumenta. Embora a maior quantidade de gás implique uma menor área sujeita à atuação das forças viscosas, a contribuição da potência de atrito no canal é pouco significativa e a redução deve-se, principalmente, ao aumento de temperatura devido à compressão do gás e à provável presença de gás nas fendas. Maiores quantidades de gás provocam aumentos de temperatura maiores e, portanto, viscosidades menores. Também a presença de gás contribui para a redução da viscosidade, explicando a diminuição da potência de atrito. Esse efeito deve ser proporcionalmente maior para rotações menores visto que, para uma mesma diferença de pressão e mesmo FVG na sucção, uma baixa rotação implica um "tempo de vida" maior para as câmaras. Como o tempo de deslocamento da câmara entre a sucção e a descarga aumenta, um volume maior de líqüido penetrará na câmara. As consequiências disso, para um mesmo FVG na sucção, são pressões e temperaturas maiores e viscosidades menores ao longo do fuso.

Ao contrário do que alguns autores citam, a eficiência volumétrica não afeta a potência consumida, mas, sim, a potência aproveitada. A potência total consumida sempre será dada pela soma das potências teórica e de atrito. Quando algum fluido retorna através das fendas, isso significa apenas que parte da potência consumida está sendo desperdiçada. A redução na potência consumida observada para altos FVG's deve-se, como visto no parágrafo anterior, ao maior aumento de temperatura e à presença de gás e não ao aumento da eficiência volumétrica que altos FVG's provocam. 
Deve-se observar que a potência calculada pelo modelo leva em conta apenas as perdas por atrito viscoso, comum a todas as bombas parafuso. A potência calculada, portanto, deve ser corrigida para incluir o atrito mecânico devido aos mancais, selos e engrenagens da bomba, que varia de acordo com o projeto da bomba.

A eficiência exergética definida no capítulo 4.6 aproxima-se bastante da eficiência isotérmica. Apenas para FVG's muito altos é que a diferença entre as duas eficiências começa a aparecer. Nesse caso, a eficiência exergética seria mais adequada para caracterizar o desempenho da bomba visto que não parte da hipótese de escoamento isotérmico. O comportamento da eficiência varia bastante de acordo com a substância que compõe a fase líqüida. Quando a viscosidade é baixa a eficiência é maior utilizando-se um número maior de estágios. Para altas viscosidades, um número menor de estágios é mais vantajoso a menos que a diferença de pressão seja muito elevada. A diminuição do diâmetro, para os casos estudados, proporcionou uma melhora na eficiência da bomba. Um dos fatores que mais afetam a eficiência é o FVG do fluido bombeado que não pode ser controlado. A otimização da bomba para um determinado ponto de operação deve ser feita de forma a se encontrar a geometria que minimize tanto potência de atrito como vazão de refluxo.

Para finalizar o trabalho propõe-se algumas novas linhas de pesquisa que permitiriam uma melhor representação dos processos da bomba pelo modelo:

- Incluir no modelo o cálculo da excentricidade na fenda periférica e seu efeito sobre a vazão de recirculação

- Incluir no modelo a eficiência isentrópica de compressão;

- Verificar a suposição de fendas completamente preenchidas com líquiido e propor formas de calcular a quantidade de gás infiltrada nas fendas; 
- Estudos paramétricos abrangentes para verificar a influência da geometria e condições de operação no comportamento do modelo;

- Utilizar o modelo para desenvolver um método de otimização da geometria da bomba multifásica tipo duplo parafuso. 


\section{Referências Bibliográficas}

BRANDT, J.U. e Wietstock, P. "Screw Pumps for Multiphase Pumping". 4th EC S Berl., p. 38-48, 1992.

CAETANO, E.F. ; SILVA, R.M. ; da SILVA, R.G. ; CAMARGO, R.M.T. e ROHLFING, G. "Petrobras and Bornemmann Pumpen Cooperation on Multiphase Flow Pumping". Proceedings of the 1997 29th Annual Offshore Technology Conference, OTC'97, v.3, Houston, TX, USA, p. 109-118, 1997.

CAMARGO, R.M.T. ; Alves, I.N. e Prado, M.G. "Advances in artificial lift and boosting systems for subsea completion". Proceedings of the 1997 29th Annual Offshore Technology Conference, OTC'97, v.3, Houston, TX, USA, p. 363-373, 1997.

CAMPBELL, G.A. ; SWEENEY, P.A. ; DONTULA, N. e WANG, C.H. "Frame indifference: Fluid flow in single screw pumps and extruders". International Polymer Processing, v11, n 3, p. 199-207, Set. 1996.

COOPER, P. ; SCHIAVELlO, B. ; DE MAROLLES, C. ; DE SALIS, J. ; PRANG, A.J. e BROUSSARD, D.H. "Tutorial on Multiphase Gas-Liquid Pump," Proceedings of the Thirteenth International Pump Users Symposium, Texas A\&M University, p.159-173, Mar. 1996.

COOPER, P. ; PRANG, A.J. ; THAMSEN, P.U. e MAIR, J. “A Versatile Multiphase Two-Screw Pump Package for Subsea Deployment". Offshore Technology Conference Proceedings, paper 8860, Mai. 1998.

CZARNECKI, G.J. ; LIPPINCOTT, J.K. "Screw Pumps", Pump Handbook, ed. Karassic, I.J., Krutzsch, W. C., Fraser, W. H., Messina, J. P.; McGraw-Hill Book Company, 1976.

DAL PORTO, D.F. e LARSON, L.A. "Multiphase Pump Field Trials Demonstrate Practical Applications for the Technology". SPE Production and Facilities, v 12, n 3, p. 159-164, Ago. 1997.

DARRIGAN, P.R. "Multiphase Boosting: Do We Need This Emerging Technology?". 7th International Conference Multiphase 95, França, p. 171-195, Jun. 1995. 
EGASHIRA, K. ; SHODA, S. ; TOCHIKAWA, T. e FURUKAWA, A. "Backflow in Twin-Screw-Type Multiphase Pump". Production Operations and Engineering General Proceedings of the 1996 SPE Annual Technical Conference and Exhibiton, v Pi, Denver, CO, USA, p. 221-230, 1996.

GONZÁLEZ, R. e GUEVARA, E. "Economic Field Development in Venezuela Heavy Oil Fields Using Multiphase Pumping Technology," Proceedings SPE International Heavy Oil Symposium, 1995, Society of Petroleum Engineers (SPE), Richardson, TX, USA. p. 195-201, 1995 (SPE 30262).

HONG, M.H. e WHITE, J.L. "Fluid mechanics of intermeshing counter-rotating twin screw extruders," International Polymer Processing, v 13, n 4, p. 342-346, Dez. 1998.

HYPROTECH, Hysys version 1.1 - Reference vol. 1 e 2. Hyprotech Ltd., 1996.

IDELCHIK, I. E. Handbook of Hydraulic Resistence. $3^{\text {a }}$ edição, Boca Raton, FL : CRC Press, 1994.

INTERNATIONAL PETROLEUM ENCYCLOPEDIA 1996. v 29, ed. West, J., PennWell Pub. Company, 1996.

LEISTRITZ. Information on Multiphase Pump. Leistritz AG, Jun. 1995.

MICHAELI, W. ; GREFENSTEIN, A. e BERGHAUS, U. "Twin-Screw Extruders for Reactive Extrusion". Polymer Engineering and Science, v 35, n 19, p. 1485-1504, Out. 1995.

MEZZEDIMI, V. ; RANIERI, P. ; AGGRADI, G.F. ; GHETTO, G. ; GRANATO, M. ; RADICIONI, A. ; RIGHI, F. e D'ALOISIO, G. "A Solution for Deepwater Multiphase Boosting”. IMechE, 1999 (C556/028).

OLIVEIRA Jr., S. Análise Termodinâmica e Termoeconômica de Processos de Conversão de Energia. São Paulo, EPUSP, 1996. /Notas de Aula. Xerocopiado/

TEXACO. Relatório: Performance evaluation of the Neptunia and L4H Pumps and Multiphase Meters. Texaco Inc., E.\&P. Technology Divison, Cheswick, 1993.

WINCEK, M. Contribuição para o Cálculo do Comportamento de Transporte de Bombas de Fuso Helicoidal no Transporte de Misturas Líqüido-Gás. Trad. de Adriana B. Costa. Erlangen-Nürnberg, 1992. Tese (Doutorado), Universidade de Friedrich-Alexander de Erlangen-Nürnberg. 


\section{Apêndice I}

\section{Cálculo de $\int_{y_{\varepsilon}}^{H} \int_{0}^{W} \gamma^{2}(x, y) d x d y$}

Para calcular a potência de atrito do canal, é necessário resolver a integral $\int_{y_{\varepsilon}}^{H} \int_{0}^{W} \gamma^{2}(x, y) d x d y$, onde a taxa de cisalhamento é dada por:

$$
\gamma^{2}(x, y)=\left(\frac{\partial u}{\partial y}\right)^{2}+\left(\frac{\partial w}{\partial x}\right)^{2}+\left(\frac{\partial w}{\partial y}\right)^{2}
$$

Pode-se separar o cálculo da integral de acordo com as componente da equação A.1, como se segue:

$$
\int_{y_{\varepsilon}}^{H} \int_{0}^{W} \gamma^{2}(x, y) d x d y=\int_{y_{\varepsilon}}^{H} \int_{0}^{W}\left(\frac{\partial u}{\partial y}\right)^{2} d x d y+\int_{y_{\varepsilon}}^{H} \int_{0}^{W}\left(\frac{\partial w}{\partial x}\right)^{2} d x d y+\int_{y_{\varepsilon}}^{H} \int_{0}^{W}\left(\frac{\partial w}{\partial y}\right)^{2} d x d y
$$

Onde as velocidades $u$ e $w$ foram calculadas por CAMPBELL et al. (1996) e são dadas por:

$$
u=u_{o}\left(1+\frac{H}{R_{i}}\right) \frac{y}{H}\left(2-\frac{3 y}{H}\right)+u_{o}\left(1+\frac{y}{R_{i}}\right)
$$

$\mathrm{e}$

$$
w=w_{0}\left(1+\frac{H}{R_{i}}\right) \frac{4}{\pi} \sum_{i=1,3,5 \ldots}^{\infty}\left(\frac{\operatorname{senh}(i \pi h \zeta)}{i \cdot \operatorname{senh}(i \pi h)}\right) \operatorname{sen}(i \pi \chi)-w_{o}\left(1+\frac{y}{R_{i}}\right)
$$

Onde:

$$
\zeta=y / H, \quad \chi=x / W \text { e } h=H / W \quad \text { (A.5), (A.6) e (A.7) }
$$


A primeira parte da integral A.2 pode ser calculada derivando-se $u$ em relação a $y$ e elevando o resultado ao quadrado:

$$
\begin{gathered}
\frac{\partial u}{\partial y}=\frac{u_{0}}{H}\left(1+\frac{H}{R_{i}}\right)\left(2-\frac{6 y}{H}\right)+\frac{u_{0}}{R_{i}}= \\
=u_{0}\left(\frac{2}{H}+\frac{3}{R_{i}}-6 y\left(\frac{1}{H^{2}}+\frac{1}{H \cdot R_{i}}\right)\right)=u_{0}(A-6 y B) \\
\left(\frac{\partial u}{\partial y}\right)^{2}=u_{0}{ }^{2}\left(A^{2}-12 y \cdot A \cdot B+36 y^{2} B^{2}\right)
\end{gathered}
$$

A integral do resultado será dada por:

$$
\begin{gathered}
\int_{y_{\varepsilon}}^{H} \int_{0}^{W}\left(\frac{\partial u}{\partial y}\right)^{2} d x d y=\left.u_{0}{ }^{2} W\left(A^{2} y-6 y^{2} A \cdot B+12 y^{3} B^{2}\right)\right|_{y_{\varepsilon}} ^{H} \\
\int_{y_{\varepsilon}}^{H} \int_{0}^{W}\left(\frac{\partial u}{\partial y}\right)^{2} d x d y=\left.u_{0}{ }^{2} W\left(A^{2}\left(H-y_{\varepsilon}\right)-6 A \cdot B\left(H^{2}-y_{\varepsilon}{ }^{2}\right)+12 B^{2}\left(H^{3}-y_{\varepsilon}{ }^{3}\right)\right)\right|_{y_{\varepsilon}} ^{H}
\end{gathered}
$$

A segunda parte da integral A.2 é obtida derivando-se $w$ em relação a $x$ ou, nesse caso, a $\chi$ devido à mudança de variável utilizada por Campbell:

$$
\begin{aligned}
\frac{\partial w}{\partial \chi} & =w_{0}\left(1+\frac{H}{R_{i}}\right) \frac{4}{\pi} \sum_{i=1,3,5 \ldots}^{\infty} \frac{\operatorname{senh}(i \pi h \zeta)}{i \cdot \operatorname{senh}(i \pi h)} i \pi \cdot \cos (i \pi \chi)= \\
& =4 w_{0}\left(1+\frac{H}{R_{i}}\right) \sum_{i=1,3,5, \ldots}^{\infty} \frac{\operatorname{senh}(i \pi h \zeta)}{\operatorname{senh}(i \pi h)} \cos (i \pi \chi)
\end{aligned}
$$

Elevando-se ao quadrado, tem-se:

$$
\begin{aligned}
& \left(\frac{\partial w}{\partial \chi}\right)^{2}=16 w_{0}{ }^{2}\left(1+\frac{H}{R_{i}}\right)^{2} \sum_{i=1,3, \ldots, \ldots}^{\infty} \sum_{j=I, 3,5, \ldots}^{\infty}\left[\frac{\operatorname{senh}(i \pi h \zeta)}{\operatorname{senh}(i \pi h)} \cos (i \pi \chi) \cdot \frac{\operatorname{senh}(j \pi h \zeta)}{\operatorname{senh}(j \pi h)} \cos (j \pi \chi)\right]= \\
& =D \sum_{i=1,3, \ldots, \ldots}^{\infty} \sum_{j=1,3, \ldots, \ldots}^{\infty}\left[\frac{\operatorname{senh}(i \pi h \zeta) \cdot \operatorname{senh}(j \pi h \zeta)}{\operatorname{senh}(i \pi h) \cdot \operatorname{senh}(j \pi h)} \cos (i \pi \chi) \cdot \cos (j \pi \chi)\right]= \\
& =D \sum_{i=135}^{\infty} \sum_{j=1,35}^{\infty} \frac{[\cosh ((i+j) \pi h \zeta)-\cosh ((i-j) \pi h \zeta)]}{4 \operatorname{senh}(i \pi h) \cdot \operatorname{senh}(j \pi h)}[\cos ((i+j) \pi \chi)+\cos ((i-j) \pi \chi)]
\end{aligned}
$$

Integrando-se em relação a $\chi$, tem-se: 


$$
\int_{0}^{1}\left(\frac{\partial w}{\partial \chi}\right)^{2} d \chi=
$$

$=D \sum_{i=1,3,5, \ldots}^{\infty} \sum_{j=1,3,5, \ldots}^{\infty} \frac{[\cosh ((i+j) \pi h \zeta)-\cosh ((i-j) \pi h \zeta)]}{4 \operatorname{senh}(i \pi h) \cdot \operatorname{senh}(j \pi h)} \int_{0}^{1}[\cos ((i+j) \pi \chi)+\cos ((i-j) \pi \chi)] d \chi$

Na equação A.14, existem duas hipóteses:

$$
\begin{array}{r}
\text { Se } \mathrm{i}=\mathrm{j} \Rightarrow \int_{0}^{l}[\cos ((i+j) \pi \chi)+\cos ((i-j) \pi \chi)]=\left(\frac{\operatorname{sen}(i+j) \pi}{(i+j) \pi}+1\right) \\
\text { Se } \mathrm{i} \neq \mathrm{j} \Rightarrow \int_{0}^{l}[\cos ((i+j) \pi \chi)+\cos ((i-j) \pi \chi)]=\left(\frac{\operatorname{sen}(i+j) \pi}{(i+j) \pi}+\frac{\operatorname{sen}(i-j) \pi}{(i-j) \pi}\right)
\end{array}
$$
logo:

Como i e j são ímpares, então $(i+j)$ e $(i-j)$ são par $\Rightarrow \operatorname{sen}(i+j) \pi=\operatorname{sen}(i-j) \pi=0$,

$$
\int_{0}^{l}\left(\frac{\partial w}{\partial \chi}\right)^{2} d \chi=D \sum_{i=1,3,5}^{\infty} \sum_{j=1,3,5 \ldots}^{\infty} \frac{[\cosh ((i+j) \pi h \zeta)-\cosh ((i-j) \pi h \zeta)]}{4 \operatorname{senh}(i \pi h) \cdot \operatorname{senh}(j \pi h)}, i=j
$$

ou

$$
\int_{0}^{l}\left(\frac{\partial w}{\partial \chi}\right)^{2} d \chi=D \sum_{i=1,3,5 \ldots}^{\infty} \frac{[\cosh (2 i \pi h \zeta)-\cosh (0)]}{4 \operatorname{senh}^{2}(i \pi h)}=D \sum_{i=1,3,5 \ldots}^{\infty} \frac{[\cosh (2 i \pi h \zeta)-1]}{4 \operatorname{senh}^{2}(i \pi h)}
$$

Integrando-se em relação a $\zeta$ :

$$
\begin{aligned}
& \int_{\frac{y_{\varepsilon}}{H}}^{l} \int_{0}^{l}\left(\frac{\partial w}{\partial \chi}\right)^{2} d \chi d \zeta=D \sum_{i=1,3, \ldots}^{\infty} \frac{\left.\left[\frac{\operatorname{senh}(2 i \pi h \zeta)}{2 i \pi h}-\zeta\right]\right|_{y_{\varepsilon} / H} ^{1}}{4 \operatorname{senh}^{2}(i \pi h)}= \\
& =D \sum_{i=l, 3,5}^{\infty} \frac{\left[\frac{\operatorname{senh}(2 i \pi h)-\operatorname{senh}\left(2 i \pi h \frac{y_{\varepsilon}}{H}\right)}{2 i \pi h}-\left(1-\frac{y_{\varepsilon}}{H}\right)\right]}{4 \operatorname{senh}^{2}(i \pi h)}
\end{aligned}
$$

A última parte da integral é obtida de maneira análoga, como se segue: 


$$
\begin{aligned}
& \frac{\partial w}{\partial \zeta}=w_{0}\left(1+\frac{H}{R_{i}}\right) \frac{4}{\pi} \sum_{i=1,3,5}^{\infty}\left(\frac{i \pi h \cdot \cosh (i \pi h \zeta)}{i \cdot \operatorname{senh}(i \pi h)}\right) \operatorname{sen}(i \pi \chi)-w_{0} \frac{H}{R_{i}} \\
& \left(\frac{\partial w}{\partial \zeta}\right)^{2}=\overbrace{16 w_{0}{ }^{2}\left(1+\frac{H}{R_{i}}\right)^{2} h^{2} \sum_{i=1,3,5 \ldots}^{\infty} \sum_{j=1,3,5 \ldots}^{\infty}\left[\frac{\cosh (i \pi h \zeta)}{\operatorname{senh}(i \pi h)} \operatorname{sen}(i \pi \chi) \cdot \frac{\cosh (j \pi h \zeta)}{\operatorname{senh}(j \pi h)} \operatorname{sen}(j \pi \chi]\right.}^{x}+ \\
& -\overbrace{-8 h w_{0}{ }^{2} \frac{H}{R_{i}}\left(1+\frac{H}{R_{i}}\right) \sum_{i=1,3,5 \ldots}^{\infty}\left[\frac{\cosh (i \pi h \zeta)}{\operatorname{senh}(i \pi h)} \operatorname{sen}(i \pi \chi)\right]}^{Y}+\overbrace{\left(w_{0} \frac{H}{R_{i}}\right)^{2}}^{Z}= \\
& =D . h^{2} \sum_{i=1,3,5 \ldots i=1,3,5 \ldots}^{\infty} \frac{[\cosh ((i+j) \pi h \zeta)+\cosh ((i-j) \pi h \zeta)]}{4 \operatorname{senh}(i \pi h) . \operatorname{senh}(j \pi h)}[\cos ((i-j) \pi \chi)-\cos ((i+j) \pi \chi)]+ \\
& -E \sum_{i=1,3,5 \ldots}^{\infty}\left[\frac{\cosh (i \pi h \zeta)}{\operatorname{senh}(i \pi h)} \operatorname{sen}(i \pi \chi)\right]+F
\end{aligned}
$$

A equação A.21 acima, é composta de três partes: X, Y e Z. Integrando-se a parte $\mathrm{X}$ tem-se:

$$
\begin{gathered}
\int_{0}^{1} X d \chi= \\
=D \cdot h^{2} \sum_{i=1,3,5 \ldots}^{\infty} \sum_{j=1,3,5 \ldots}^{\infty} \frac{[\cosh ((i+j) \pi h \zeta)+\cosh ((i-j) \pi h \zeta)]}{4 \operatorname{senh}(i \pi h) \cdot \operatorname{senh}(j \pi h)} \int_{0}^{l}[\cos ((i-j) \pi \chi)-\cos ((i+j) \pi \chi)] d \chi
\end{gathered}
$$

$$
\mathrm{Se} \mathrm{i}=\mathrm{j} \Rightarrow \int_{0}^{l}[\cos ((i-j) \pi \chi)-\cos ((i+j) \pi \chi)]=\left(1-\frac{\operatorname{sen}(i+j) \pi}{(i+j) \pi}\right)=1
$$

$\operatorname{Se} \mathrm{i} \neq \mathrm{j} \Rightarrow \int_{0}^{l}[\cos ((i-j) \pi \chi)-\cos ((i+j) \pi \chi)]=\left(\frac{\operatorname{sen}(i-j) \pi}{(i-j) \pi}-\frac{\operatorname{sen}(i+j) \pi}{(i+j) \pi}\right)=0$

Assim:

$$
\int_{0}^{1} X d \chi=D \cdot h^{2} \sum_{i=1,3,5 \ldots}^{\infty} \frac{[\cosh (2 i \pi h \zeta)+1]}{4 \operatorname{senh}^{2}(i \pi h)}
$$




$$
\int_{\frac{y_{\varepsilon}}{H}}^{1} \int^{1} X d \chi d \zeta=D \cdot h^{2} \sum_{i=1,3,5 \ldots}^{\infty} \frac{\left[\frac{\operatorname{senh}(2 i \pi h)-\operatorname{senh}\left(2 i \pi h \frac{y_{\varepsilon}}{H}\right)}{2 i \pi h}+\left(1-\frac{y_{\varepsilon}}{H}\right)\right]}{4 \operatorname{senh}^{2}(i \pi h)}
$$

Integrando-se a parte Y da equação A.21, tem-se:

$$
\begin{aligned}
& \int_{0}^{l} Y d \chi=-B \sum_{i=1,3,5 \ldots}^{\infty}\left[\frac{\cosh (i \pi h \zeta)}{\operatorname{senh}(i \pi h)} \frac{(-\cos (i \pi \chi))}{i \pi}\right]_{0}^{l}= \\
& \left.=B \sum_{i=1,3,5 \ldots}^{\infty}\left[\frac{\cosh (i \pi h \zeta)}{\operatorname{senh}(i \pi h)} \frac{(\cos (i \pi \chi)-1)}{i \pi}\right)\right]
\end{aligned}
$$

Como i é ímpar $\Rightarrow \cos (i \pi)=-1, \log 0$ :

$$
\begin{aligned}
& \int_{0}^{1} Y d \chi=-2 B \sum_{i=1,3,5 \ldots}^{\infty}\left[\frac{\cosh (i \pi h \zeta)}{i \pi \cdot \operatorname{senh}(i \pi h)}\right] \\
& \int_{\frac{y_{\varepsilon}}{H}}^{1} \int_{0}^{l} Y d \chi d \zeta=-2 E \sum_{i=1,3,5 \ldots}^{\infty}\left[\frac{\operatorname{senh}(i \pi h \zeta)}{(i \pi)^{2} h \cdot \operatorname{senh}(i \pi h)}\right]_{y_{\varepsilon} / H}^{l}= \\
& =-\frac{2 E}{\pi^{2} h} \sum_{i=1,3,5 \ldots}^{\infty}\left[\frac{1}{i^{2}}\left(1-\frac{\operatorname{senh}\left(i \pi h \frac{y_{\varepsilon}}{H}\right)}{\operatorname{senh}(i \pi h)}\right)\right]
\end{aligned}
$$

Integrando-se a parte $\mathrm{Z}$ da equação A.21, tem-se:

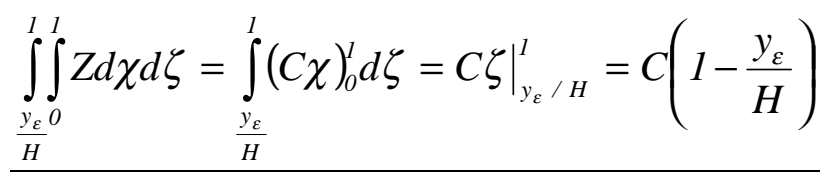

Somando-se as equações A.19, A.26, A.29 e A.30 acima, chega-se a: 


$$
\begin{gathered}
\int_{y_{\varepsilon}}^{H} \int_{0}^{W}\left[\left(\frac{\partial w}{\partial x}\right)^{2}+\left(\frac{\partial w}{\partial y}\right)^{2}\right] d x d y=H \cdot W \int_{\frac{y_{\varepsilon}}{H}}^{1} \int_{0}^{l}\left[\frac{1}{W^{2}}\left(\frac{\partial w}{\partial \chi}\right)^{2}+\frac{1}{H^{2}}\left(\frac{\partial w}{\partial \zeta}\right)^{2}\right] d \chi d \zeta= \\
\left.=\frac{H}{W} D \sum_{i=1,3,5 \ldots}^{\infty} \frac{\operatorname{senh}(2 i \pi h)-\operatorname{senh}\left(2 i \pi h \frac{y_{\varepsilon}}{H}\right)}{2 i \pi h}-\left(1-\frac{y_{\varepsilon}}{H}\right)\right] \\
+
\end{gathered}
$$

Como h=H/W, a equação A.31 reduz-se a:

$$
\begin{gathered}
\int_{y_{\varepsilon}}^{H} \int_{0}^{W}\left[\left(\frac{\partial w}{\partial x}\right)^{2}+\left(\frac{\partial w}{\partial y}\right)^{2}\right] d x d y= \\
=16 w_{0}^{2} \frac{H}{W}\left(1+\frac{H}{R_{i}}\right)^{2} \sum_{i=1,3,5 \ldots}^{\infty}\left[\frac{\operatorname{senh}(2 i \pi h)-\operatorname{senh}\left(2 i \pi h \frac{y_{\varepsilon}}{H}\right)}{4 i \pi h \cdot \operatorname{senh}^{2}(i \pi h)}\right]+ \\
-16\left(\frac{w_{0}}{\pi}\right)^{2} \frac{W}{R_{i}}\left(1+\frac{H}{R_{i}}\right) \sum_{i=1,3,5 . \ldots}^{\infty}\left[\frac{1}{i^{2}}\left[1-\frac{\operatorname{senh}\left(i \pi h \frac{y_{\varepsilon}}{H}\right)}{\operatorname{senh}(i \pi h)}\right]+w_{0}{ }^{2} \frac{H W}{R_{i}^{2}}\left(1-\frac{y_{\varepsilon}}{H}\right)\right.
\end{gathered}
$$

Assim, a integral $\int_{y_{\varepsilon}}^{H W} \gamma^{2}(x, y) d x d y$ será dada pela soma das equações A.11 e A.32. 


\section{Apêndice II}

\section{Explicações sobre o modelo desenvolvido no Hysys.Process v2.1}

O modelo desenvolvido no programa Hysys.Process v2.1 é constituído por uma sequiência de separadores, compressores, bombas, misturadores e correntes materiais como mostra a figura II.1. O fluido multifásico que escoa para a sucção mistura-se com

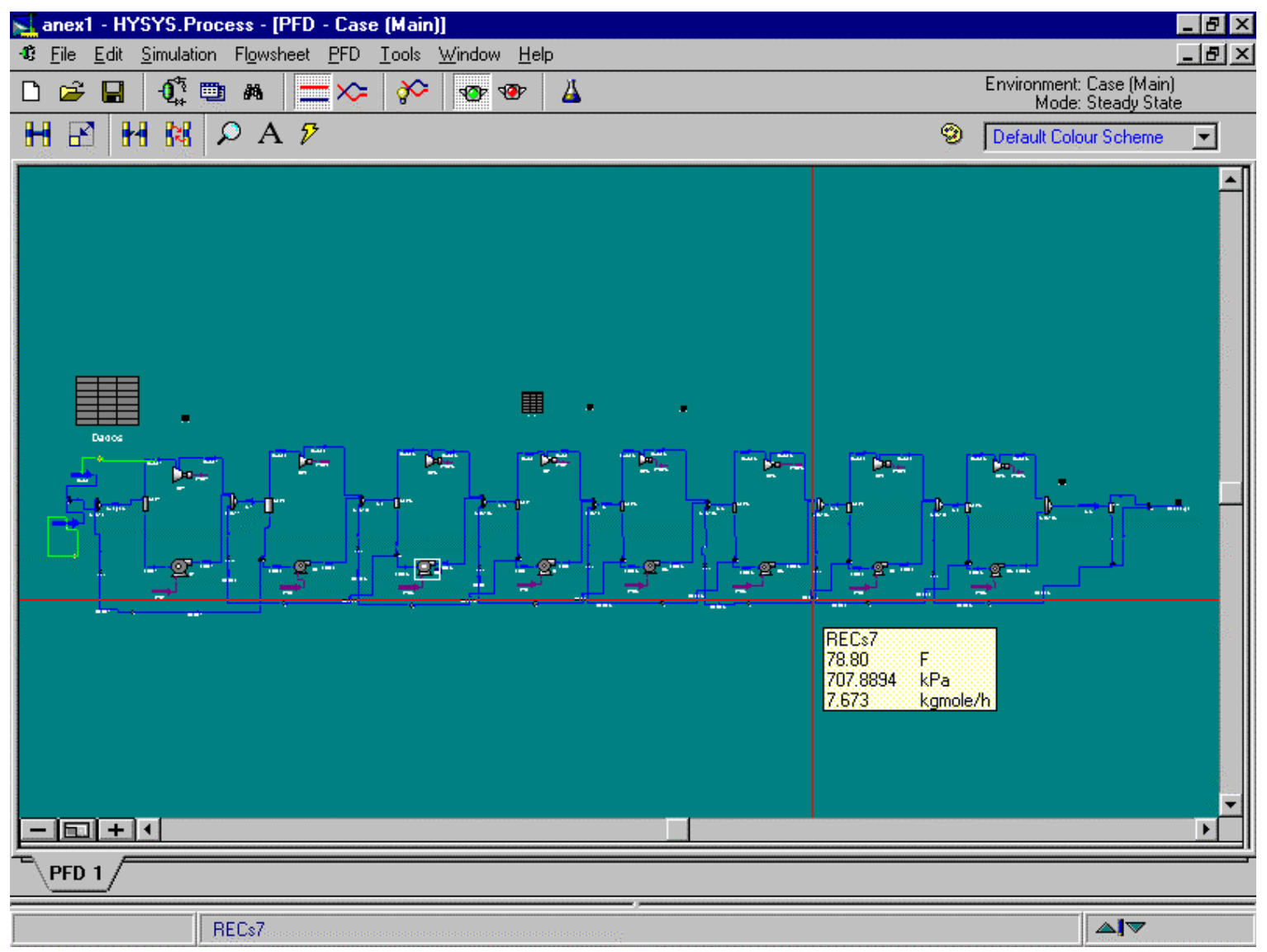

Fig. II.1: Modelo de comportamento termodinâmico - Tela do programa. 
a corrente de refluxo e segue ao primeiro estágio de compressão. O fluido é separado em gás e líqüido, a corrente líquiida segue para a bomba e a gasosa, para o compressor. Após o aumento da pressão, as duas correntes são misturadas para homogeneizar a temperatura. Também neste ponto a corrente de recirculação proveniente do estágio posterior junta-se ao escoamento. Uma vez feita a mistura, o fluido é novamente separado e a corrente líquiida é dividida em duas parcelas: uma que segue ao próximo estágio e outra que reflui ao estágio anterior, representando a vazão de recirculação atrvés das fendas da bomba parafuso.

A caracterização do fluido que escoa para a sucção é feita definindo-se a composição, a vazão, a pressão e a temperatura para as duas correntes iniciais de gás e líqüido, mostradas na figura II.2. A vazão da corrente de líquiido inicial é corrigida conforme haja corrente de refluxo. Se houver refluxo, a vazão de líqüido inicial é corrigida de forma que a soma das vazões volumétricas que segue para a sucção seja compatível com as condições de operação da bomba.

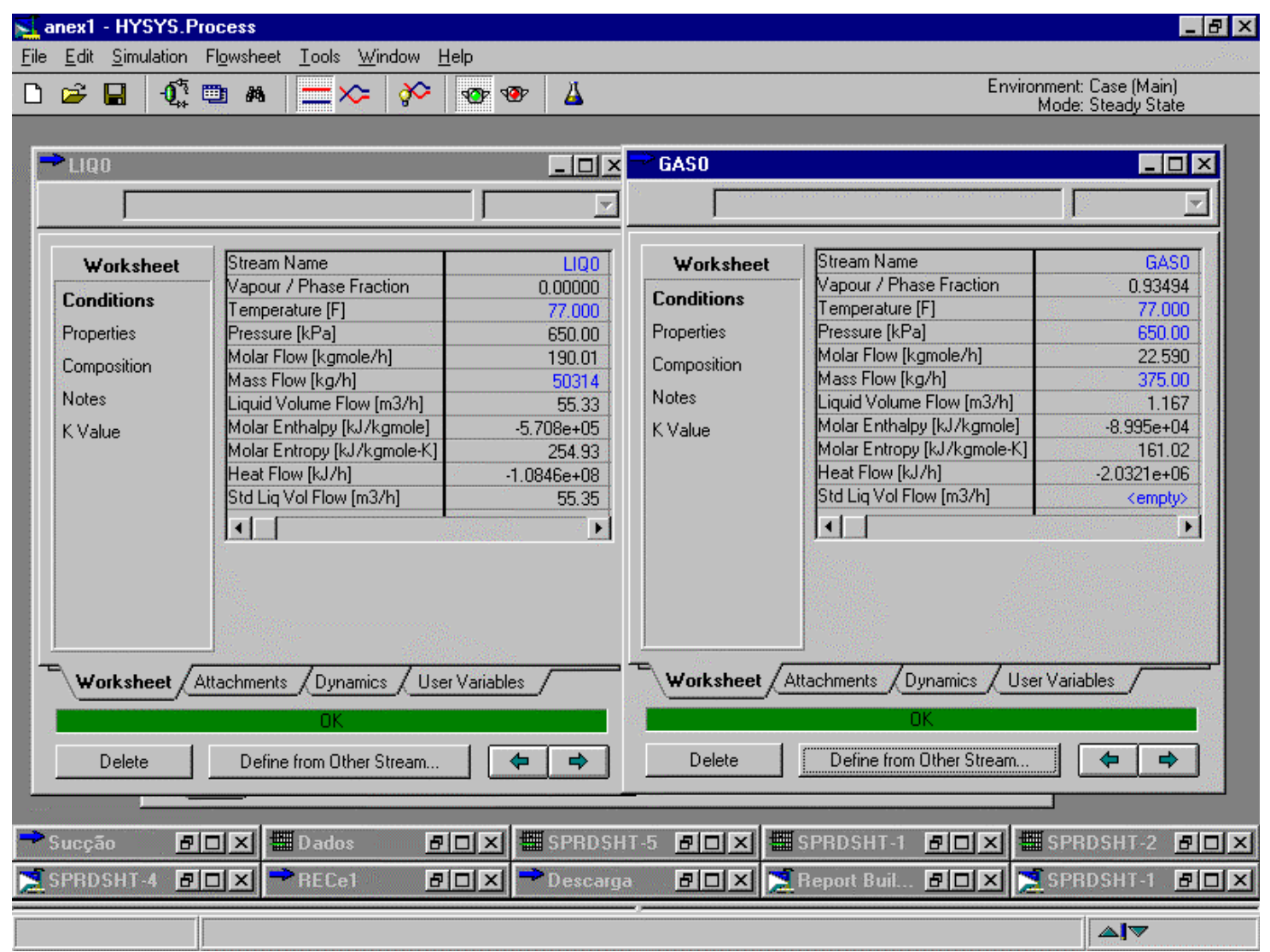

Fig. II.2: Definição da condição do fluido na sucção do modelo.

A recirculação nos diversos estágios de compressão é calculada através do operador RECYCLE do programa. A vazão de recirculação é automaticamente calculada baseada na diferença de pressão e nas propriedades do líqüido que reflui, utilizando-se as equações desenvolvidas no item 4.3.1. O cálculo é feito inserindo-se uma variável de usuário ("user variable") nas correntes de entrada do operador RECYCLE e que calcula a vazão todas as vezes em que a corrente é ativada, como pode ser visto na figura II.3. 


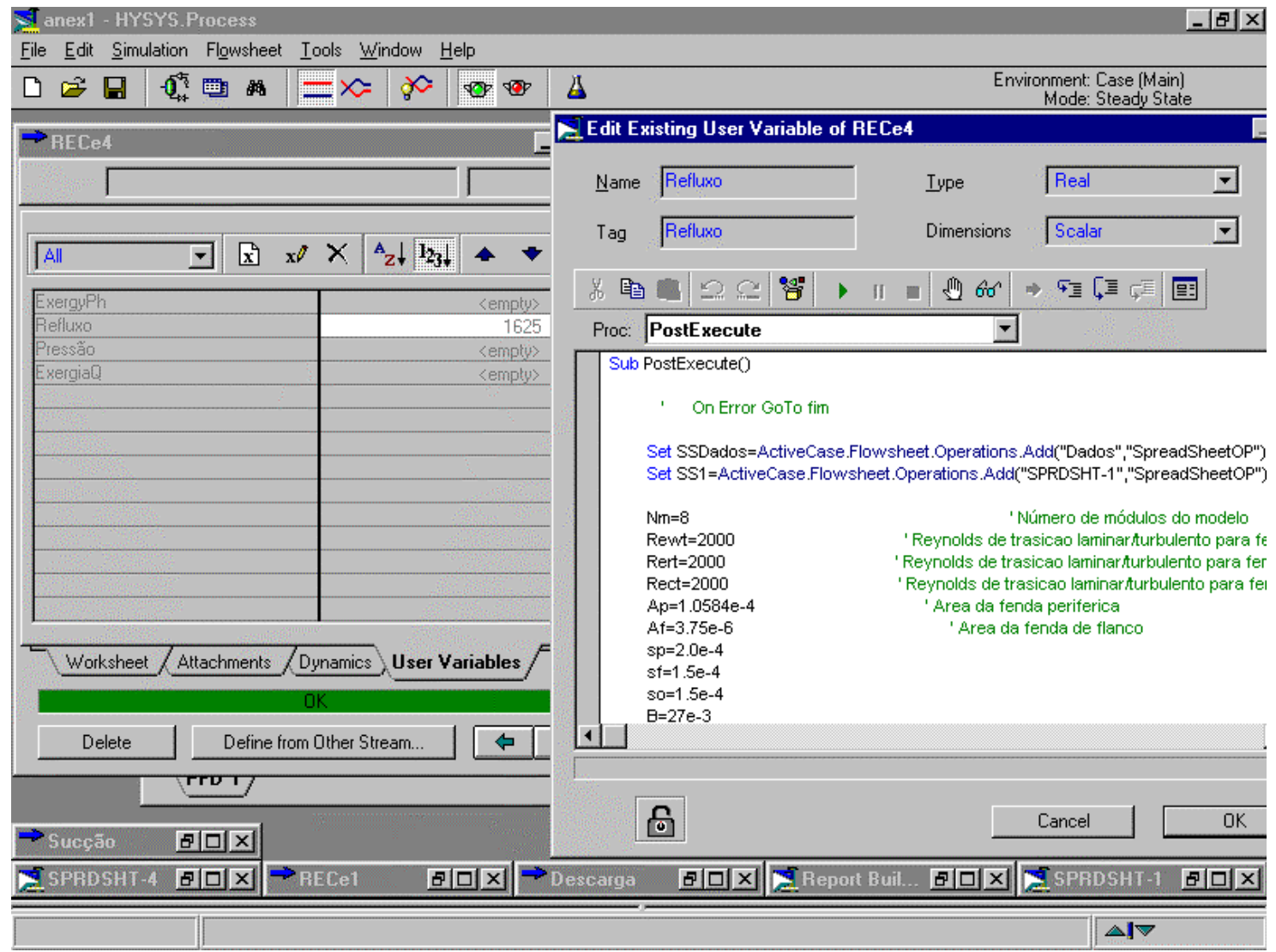

Fig. II.3: Cálculo da vazão de recirculação no modelo.

A eficiência das bombas é calculada baseada na rotação do eixo e na diferença de pressão entre os estágios usando-se as equações deduzidas no capítulo 4.3.2. Também nesse caso o cálculo é feito inserindo-se uma variável cujo código calcula a eficiência da bomba toda a vez em que ela é ativada.

A correção do perfil de pressão é feito como visto no final capítulo 4.3.1, quando o modelo estiver próximo da convergência para o perfil de pressão anteriormente calculado. Se a diferença entre o primeiro estágio e a sucção provocar uma vazão maior que a vazão de líqüido inicial, então o programa calcula uma vazão negativa para a parcela do líqüido que segue ao próximo estágio. Nesse caso, o modelo não irá convergir. Portanto, deve-se calcular a máxima pressão admissível para o primeiro estágio baseando-se na vazão de líqüido inicial e impedir que as pressões calculadas para este estágio sejam maiores que este valor. 


\section{Apêndice III}

\section{Eficiência Exergética de uma Bomba Multifásica de Duplo Parafuso: Definições Alternativas}

A eficiência exergética do capítulo 4.6, embora represente adequadamente a relação entre potência fornecida e aproveitada, apresenta alguns problemas que devem ser discutidos. Os resultados apresentados no capítulo 4.6, por exemplo, mostram que, para o óleo, é mais vantajoso a utilização de uma bomba com um menor número de câmaras pois isso reduz a potência de atrito sem um aumento muito grande da vazão de refluxo. Isso, no entanto, pode ser discutível caso se considere que o óleo é uma substância de alto valor exergético pois possui um alto PCI. Dessa forma, qual seria a vantagem de se reduzir a potência de atrito ao custo do aumento da vazão de refluxo? Se o fluxo volumétrico que se está perdendo é exergeticamente valioso por possuir uma elevada exergia química, pode ser que um aumento na vazão de refluxo, mesmo que não muito grande, implique grandes perdas caso se leve em conta a parcela química da exergia.

Uma forma de se avaliar a perda de exergia química através do refluxo seria utilizar a seguinte definição para a eficiência exergética:

$$
\eta_{e x 2}=\frac{E x_{D}}{E x_{e}+\dot{W}}
$$

Onde $\mathrm{Ex}_{\mathrm{e}}$ é a exergia do fluxo teórico que entra na bomba e não o fluxo na sucção, que é o fluxo que realmente escoa, descontada a vazão de refluxo.

A eficiência definida dessa maneira é influenciada, também, pela exergia química. Considerando que haja uma vazão de refluxo, então o fluxo de exergia química que entra na bomba é maior que o da descarga. Quanto maior a vazão de refluxo, maior será a diferença entre os fluxos de exergia química e menor será a eficiência. Essa eficiência fornece valores diferentes conforme a exergia química associada à vazão de refluxo seja alta ou baixa. Se, para o fluido que reflui a parcela da exergia é próxima de zero, então a vazão de refluxo altera apenas a parcela da exergia física. Praticamente 
não há diferença entre a exergia química dos fluxos de entrada e saída. Caso contrário, o refluxo com uma elevada exergia química provoca uma diminuição no fluxo de exergia química na descarga, provocando uma diminuição na eficiência. A tabela III.1 mostra a comparação dos valores das duas definições de eficiência para a Bomba 1 (ver tabela 4.18) do item 4.6 operando a $1500 \mathrm{rpm}$. A eficiência 1 foi definida no capítulo 4.6 e a eficiência 2 é dada pela equação III.1.

Tabela III.1: Comparação entre as diferentes definições de eficiência exergética.

\begin{tabular}{|c|c|c|c|c|c|c|}
\hline $\begin{array}{l}\text { Fase } \\
\text { Líqüida }\end{array}$ & $\begin{array}{c}\mathrm{N}^{\mathrm{o}} \\
\text { Estágios }\end{array}$ & $\begin{array}{c}\Delta \mathrm{p} \\
(\mathrm{kPa})\end{array}$ & $\eta_{\mathrm{ex} 1}$ & $\eta_{\mathrm{ex} 2}$ & $\begin{array}{c}\dot{\mathrm{V}}_{\text {ref }} \\
\left(\mathrm{m}^{3} / \mathrm{h}\right)\end{array}$ & $\begin{array}{l}\dot{\mathrm{W}}_{\text {at }} \\
(\mathrm{kW})\end{array}$ \\
\hline \multirow{6}{*}{ óleo } & \multirow{3}{*}{8} & 650,0 & 0,47 & 0,97 & 1,80 & 17,18 \\
\hline & & 2500,0 & 0,54 & 0,97 & 1,80 & 17,54 \\
\hline & & 4500,0 & 0,54 & 0,97 & 1,80 & 17,78 \\
\hline & \multirow{3}{*}{3} & 650,0 & 0,63 & 0,97 & 1,82 & 6,61 \\
\hline & & 2500,0 & 0,60 & 0,97 & 2,02 & 6,97 \\
\hline & & 4500,0 & 0,57 & 0,96 & 2,40 & 7,31 \\
\hline \multirow{6}{*}{ água } & \multirow{3}{*}{8} & 650,0 & 0,80 & 1,00 & 2,84 & 0,71 \\
\hline & & 2500,0 & 0,59 & 0,99 & 3,91 & 1,23 \\
\hline & & 4500,0 & 0,54 & 0,99 & 5,10 & 1,79 \\
\hline & \multirow{3}{*}{3} & 650,0 & 0,72 & 1,00 & 11,82 & 0,38 \\
\hline & & 2500,0 & 0,46 & 0,99 & 19,73 & 0,90 \\
\hline & & 4500,0 & 0,31 & 0,98 & 26,69 & 1,44 \\
\hline
\end{tabular}

Os dados da tabela III.1 mostram que, para o óleo, enquanto a eficiência 1 mostra uma vantagem na redução do número de estágios, a utilização da eficiência 2 leva a uma conclusão completamente oposta. Ou seja, a redução da potência de atrito, no caso da eficiência 2, é pouca se comparada à perda de exergia química associada ao óleo extra que reflui.

A eficiência dada pela equação III.1 é bastante elevada pois a exergia química é muito alta devido ao elevado PCI do fluido. Assim, a potência elétrica é pouco significativa e o resultado final passa a ser definido, principalmente, pela diferença entre a exergia que entra na bomba e a que é efetivamente aproveitada descontando-se o refluxo. Como pode-se ver na tabela III.1, quando o líqüido é o óleo a redução na potência de atrito praticamente não influencia a eficiência. Apenas quando a vazão de refluxo aumenta é que há uma redução na eficiência. Quando o líqüido é a água, a eficiência mantém-se próxima de 1,0 pois a exergia química do refluxo de água é próxima a zero e pouco altera a exergia química do fluido multifásico, alta devido à presença de gases combustíveis. Somente quando a vazão de refluxo aumenta muito é que existe uma pequena redução na eficiência.

O problema da eficiência definida pela equação III.1 está justamente nos elevados valores de eficiência. Como não há nenhum tipo de transformação química, a diferença entre as exergias químicas entre sucção e descarga deve-se exclusivamente ao refluxo, tornando praticamente irrelevantes as influências da potência elétrica e da 
variação da exergia física. Sendo assim, pode-se discutir qual a validade de se utilizar a exergia química na definição da eficiência uma vez que a função do equipamento não inclui nenhum tipo de transformação química.

Uma terceira alternativa seria utilizar a definição da equação III.1 porém considerando-se apenas as parcelas físicas da exergia:

$$
\eta_{e x 3}=\frac{E x_{f, D}}{E x_{f, e}+\dot{W}}
$$

Essa definição, no entanto, elimina uma das principais vantagens da primeira definição que é a de apresentar valores próximos de zero quando a diferença de pressão é baixa e a potência de atrito elevada, indicando que a maior parte da potência está sendo destruída para vencer o atrito. Nessa outra definição, ainda que a diferença de pressão seja pequena $\left(\mathrm{Ex}_{\mathrm{S}} \cong \mathrm{Ex}_{\mathrm{D}}\right)$, a eficiência só apresentaria valores próximos a zero se também a exergia na sucção (e, portanto, na descarga) fosse próxima a zero. Caso a exergia na sucção apresentasse valores elevados, mesmo que o aumento de exergia entre sucção e descarga fosse pequeno e a potência de atrito elevada o valor da eficiência não seria pequeno, encobrindo o fato de a maior parte da potência do eixo estar sendo perdida por atrito. Se a exergia na sucção for zero, então o comportamento das eficiências 1 e 3 serão iguais. 
Ficha catalográfica

Nakashima, Celso Yukio

Modelo de Comportamento Termodinâmico de uma Bomba multifásica do Tipo Duplo Parafuso. São Paulo, 2000.

$126 \mathrm{p}$.

Dissertação (Mestrado) - Escola Politécnica da Universidade de São Paulo. Departamento de Engenharia Mecânica.

1. Bomba multifásica 2. Bomba de duplo parafuso 3. Modelo termodinâmico I. Escola Politécnica. Departamento de Engenharia Mecânica II.t 